UNITED STATES DEPARTMENT OF THE INTERIOR

J. A. Krug, Secretary

GEOLOGICAL SURVEY

W. E. Wrather, Director

Bulletin 959-C

\title{
GEOPHYSICAL ABSTRACTS 134
}

\section{JULY-SEPTEMBER 1948}

(NUMBERS 10213-10472)

BY

\author{
V. L. SKITSKY
}

AND

S. T. VESSELOWSKY

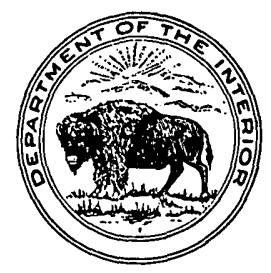

UNITED STATES

GOVERNMENT PRINTING OFFICE

WASHINGTON : 1948

For sale by the Superintendent_of Documents, U. S. Government Printing Office, Washington 25, D. C. Price 20 cents 


\section{CONTENTS}

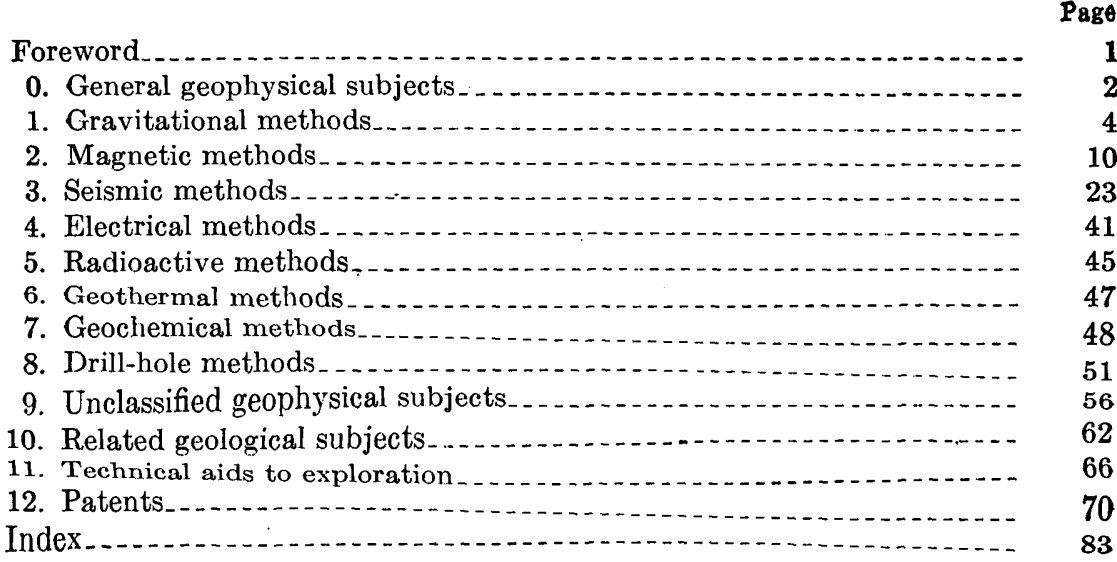

Nоте.-For a greater differentiation of contents section 8 of previous reports is replaced by section 0 and section 9 , and the former section 9 is replaced by section 10 and section 11 . An additional section on drill-hole methods, section 8 , is introduced. 


\title{
GEOPHYSICAL ABSTRACTS 134, JULY-SEPTEMBER 1948
}

\author{
By V. L. Skitsky and S. T. Vesselowsky
}

\section{FOREWORD}

Geophysical Abstracts are issued by the Section of Geophysics of the Geological Survey, United States Department of the Interior, as an aid to those engaged in geophysical research and exploration. The publication covers world literature on geophysics contained in periodicals, books, and patents. It deals with exploration by gravitational, magnetic, seismic, electrical, radioactive, geothermal, and geochemical methods, and with underlying geophysical theory, research, and related subjects.

Inasmuch as geophysicists in the field may have little opportunity to consult libraries, the policy is to provide abstracts sufficiently informative in themselves to keep readers abreast of developments in the United States and abroad.

Distribution.-Geophysical Abstracts 1-86 were issued as Information Circulars by the Bureau of Mines; 87-111 were issued as Bulletins of the Geological Survey; and 112-127 were issued as Information Circulars by the Bureau of Mines. Beginning with 128, Geophysical Abstracts are published as Bulletins of the Geological Survey.

As long as available, Geophysical Abstracts issued as Information Circulars may be obtained free of charge from Publications Distribution Section, Bureau of Mines. Geophysical Abstracts issued as Bulletins of the Geological Survey may be purchased as single copies or by subscription from the Superintendent of Documents, Government Printing Office, Washington 25, D. C. For subscription, the Superintendent of Documents will accept a deposit of $\$ 5$ in payment for subsequent issues. When this fund is near depletion, the subscriber will be notified. The deposit may also be used to cover purchase of any other publication from the Superintendent of Documents.

Author's reprints.-The Geological Survey will appreciate receiving reprints of publications and patent specifications from authors and inventors. These will be filed for reference after being abstracted. 
In reproducing authors' abstracts the Geological Survey reserves the right to make minor changes in accordance with its editorial policy. All reprints and correspondence other than orders for copies of Geophysical Abstracts should be addressed to the Director, Geological Survey, United States Department of the Interior, Washington 25, D. C.

Acknowledgments. - Grateful acknowledgment is made of the advice and assistance received from various sections of the Geological Survey.

\section{GENERAL GEOPHYSICAL SUBJECTS}

10213. Green, C. H. Integration in exploration: Am. Assoc. Petroleum Geologists Bull., vol. 32, no. 7, pp. 1216-1220, Tulsa, Okla., 1948; Geophysics, vol. 13, no. 3, pp. 365-370, Tulsa, Okla., 1948.

During the period 1937-47 the total expenditure for all forms of oil exploration increased more than four times, but the ratio of annual oil production to proved oil reserves remained nearly constant. In the future the maintenance of even such a ratio will require the discovery of new oil provinces and an improvement and integration of existing geophysical methods, radically new methods being improbable. The new provinces now appear to be provided by the continental shelf. An increased effectiveness of exploration on the other hand may be achieved, according to the author, by a fuller integration of activities in the phases of planning, field work, and interpretation.

In the planning phase general direction must come from specialists highly competent in both geophysics and geology and capable of coordinating all available information. In the field work a geologic observer, acting as liaison man between the party chief and the main office, can aid in continuously reorienting operations according to the data that are being obtained. Another desirable form of liaison would be a research and engineering department concerned with the investigations of local problems and adaptation of instruments. In interpretation a review unit charged with consolidating all forms of data should contribute to integrating the activities. There is also need of providing proper incentives and courses of instruction for young people to assure competent personnel in the future. $-r$. S.

10214. Gutenberg, B. Geophysics in war and peace [abstract]: Am. Geophys. Union Trans., vol. 29, no. 2, pp. 155-156, Washington, D. C., 1948.

This address to the International Conference on the Earth Sciences and Civilization held ị Massachusetts in 1947 outlines the general role of geophysics in peace and war and stresses its unifying character in science and international relations. Geophysics is defined as the science dealing with the physical processes of the earth viewed as solid body, water, and atmosphere. Its main divisions, general and applied geophysies, are closely dependent on physics, geology, geochemistry, and astronomy. In many ploblems of general gcophysics cooperation in the use of several of these and other sciences is required, and their respective theories must be harmonized. In applied geophysics the various branches, such as geophysical prospecting, the study of microseisms, the employment of elastic waves, and other practical lines of work, have 
been originally derived from investigations in general geophysics and likewise depend closely on progress and coordination in related fields. This unifying role of geophysics in the sciences is paralleled by its unifying function in international relations, exercised through joint investigations in countries situated in various parts of the earth. $-V$. $S$.

10215. Kunz, Bruno. Die Leistungsfähigkeit der angewandten Geophysik [The potency of applied geophysics] : Bohrtech. Zeitung, vol. 63, no. 4, pp. 1017, Vienna, 1947.

An address delivered to the faculty and students of the Vienna Mining College on the content, methods, and limitations of applied geophysics is presented. The geophysicist investigates the possible presence of useful minerals in the earth by measuring the physical properties of the ground at the surface. Geophysical methods are indirect. The existence of minerals cannot be ascertained by geophysical surveys alone, except that by the magnetic method it is possible sometimes to determine positively that iron ore is present. The geophysicist explores the natural and artificial fields of the earth's crust. Use of geophysical methods is limited by insufficient sensitivity of the instruments used, by the limits of their resolving power, or by such unfavorable circumstances as the screening effect in geoelectric prospecting. A review of the different geophysical methods is given. The first question a geophysicist has to answer in approaching any problem is what the most appropriate method of exploration is in the given case or what combination of methods is the most promising. He must neither expect nor promise too much from a geophysical survey.-S. T. V.

10216. Lee, S. P. Reflections on the last twenty-five years of geophysical work in China: Seismol. Soc. America Bull., vol. 38, no. 2, pp. 81-87, Berkeley, Calif., 1948.

Progress made in theoretical and applied geophysics in China during the last 25 years is outlined. The Chiufeng seismic station near Peking (Pei-p'ing) began its operations in 1930, and by the time of the Japanese invasion in 1937 a total of 2,472 earthquakes had been registered by Wiechert and Galitzin-Wilip seismographs. Seismic observations were also conducted at the Zi-Ka-Wei Observatory in Shanghai, at the PeiChi-Koa seismic station in Nanking (Nan-ching), and at other localities. Magnetic observations were made at the magnetic observatory established in 1935 on Purple Mountain near Nanking (Nan-ching) and at the Lu-Kai-Pang station near Shanghai. Gravity measurements were carried out in southern and eastern China.

As most of the geophysical stations were destroyed during the invasion, a Geophysical Laboratory was established in 1938 near Chunking (Ch'ung-ch'ing). It conducted prospecting with an Askania torsion balance and two Schmidt magnetic field balances in search for galena, hematite, and magnetite deposits. A general magnetic survey was also undertaken in parts of western and southwestern China, and electrical prospecting was conducted in Yunnan and Kweichow. Limited seismological observations, resumed at the Geophysical Laboratory in 1943, were continued until the end of the war in 1945, when the labpratory was moved to Chiufeng. $-V$. S. 
10217. Martin, Rodolfo. Panorama actual de la exploración geofisica en la República Argentina [Present state of geophysical exploration in the Argentine Republic] : Bol. Inform. Petrol., vol. 24, no. 279, pp. 309-330, Buenos Aires, 1947.

Certain geologic features in Argentina, such as vast plains devoid of any rock outcrops, made the use of geophysical methods of exploration necessary because these methods were the only means of obtaining information on subsurface geology. In solving stratigraphic problems the refraction-seismic method has been used with good results. On the other hand, gravimetric and magnetic methods often gave ambiguous results; for example, gravity and magnetic highs instead of lows were obtained over the bottom of depressions. These phenomena are explained by insufficient isostatic compensation over these areas and by a local rising of the heavy sima. In geophysical exploration it was advantageous to employ both gravimetric and magnetic methods in order to avoid ambiguities in the interpretation of the results.

In this manner extensive formations having pronounced magnetic properties were discovered in Mendoza. The retlection seismic method has been used with satisfactory results in many surveys, and through its use the presence of several mineral deposits and oil-bearing formations has been established and later confirmed by drilling. Accompanying the article is a general map of Argentina showing several geologic basins in different parts of the country, the presence of which was established by geophysical surveys. - S. T. V.

\section{GRAVITATIONAL METHODS}

10218. Berroth, Alfred. Numerische Werte der Masse und Dichte der Erde sowie ihrer Hauptträgheitsmomente [Numerical values of the mass and density of the earth and of its principal moments of inertia] : Zeitschr. Geophysik, vol. 17, no. 1 2, pp. 42-50, Braunschweig, 1943.

Theoretically established relations between the basic parameters of the earth's mass, namely its dynamic and static flattening, are derived, and these quantities are calculated on the basis of the latest geodetic and astronomic data. From these computed values, values for the con. stants of Helmert's density law are derived. The mathematical formulation of this law is such that any future corrections of the measured values can be taken into account-Author's abstract, translated by S. T. V.

10219. Berroth, Alfred. Das Schwerefeld des Harzes [The gravitational field of the Harz] : Zeitschr. Geophysik, vol. 18, no. 3-4, pp. 109-123, Braunschweig, 1944.

The Harz constitute an important region for gravimetric studies because of the correlation between their gravitational anomalies and their simple geologic structure. On the basis of numerous astronomic and gravimetric surveys carried out by the Prussian Geodetic Institute, agreement WaS established between the greatest deviations of the plumb line and the contours of the Hercynian, Devonian, and Lower Carboniferous formations. The same agreement was found between the results of gravimetric surveys and the orogenic data of the region. 
Furthermore, the orientation of the terrestrial ellipsoid, which the author determined for this region on the basis of other empirical material, was fully confirmed by these surveys. The orientation of this ellipsoid is of importance for the determination of the horizontal gravitational field and for the discovery of anomalies. A map and table based on the results of the surveys are given, and a new method of description of the horizontal gravitational field by "gravimetric declination" is presented, a conception having its counterpart in magnetic declination. The author expresses the opinion that the horizontal gravitational field is of great importance in geophysical exploration.-Author's abstract, condensed and translated by S. T. V.

10220. Bickel, H. C. A note on terrain corrections: Geophysics, vol. 13, no. 2, pp. 255-258, Tulsa, Okla., 1948.

A means is presented for empirically determining the areal extent within which terrain corrections are appreciable in any given locality. An example is given to show how the same device can be extended to decrease the labor of making terrain corrections in extremely rugged areas.-Author's abstract.

10221. Goguel, Jean. Réflexions sur l'isostasie, la théorie des racines inverses [Reflections regarding isostasy, the theory of antiroots] : Ann. Géophys., vol. 3, no. 3, pp. 229-248, Paris, 1947.

Because isostasy is a condition of equilibrium and does not explain the changes that concern the science of stratigraphy, attention is given to the new theory of antiroots proposed by R. A. Daly, in which changes of surface altitude are viewed as a consequence of variations in the thermal condition of the interior of the earth. The analysis leads to the formulation of a hypothesis regarding the nature of this geothermal condition and furnishes a basis for developing a method of calculating isostatic corrections. It is pointed out that in itself a consideration of gravitational results cannot provide suflicient grounds for choosing between the different geothermal hypotheses advauced at present.-Author's abstract, translated' by $V$. S.

10222. Kazinskii, V. A. Note concerning gravity measurements [in Russian] : Inst. Teor. Geofiz. Trudy, vol. 2, no. 2, pp. 10S-111, Moscow, 1947.

A formula is derived for an approximate determination of gravity differences from the corresponding periods of oscillations of a pendulum. The error caused by the simplifying assumptions made by the author is less than $1 \times 10^{-4} \mathrm{~cm} / \mathrm{sec}^{2}$. This is less than the attainable accuracy of the measurements involved. Auxiliary tables are included to facilitate the use of the formula.-S. T. $\nabla$.

10223. Lagrula, Jean. Contribution à l'etablissement d'un réseau de bases gravimétriques [Contribution to the establishment of a network of gravimetric bases] : Acad. Sci. Comptes Rendus, vol. 224, no. 7, pp. 448450, Paris, 1947.

In 1946 a resolution was adopted by the Section of Gravity, French National Committee for Geodesy and Geophysics, to coordinate the numerous available gravitational data obtaired with Holweck-Lejay 
pendulums. Pursuant to this decision the author presents, as a first contribution to the establishment of a network of bases, gravity values at 19 stations, mainly in France and Algeria. The stations, which include Marseille, Toulon, Barcelona, Ber Rechid, Palma, Breteuil, Lyon, Nice, and others, originally were set up to determine the constant $k$ for deriving the variations of $g$ from variations in the period of the pendulum. Since then further refinements have been made in these measurements by the calibration of the instrument and the determination of corrections for temperature. The precision of the final determinations is believed to be within 2 milligals. $-\nabla$. $S$.

10224. Lejay, Pierre. Déterminations de la pesanteur dans le Nord-Ést et le Centre de la France [Determinations of gravity in northeastern and central France] : Acad. Sci. Comptes Rendus, vol. 224, no. 15, pp. 10861088, Paris, 1947.

A tabulation is given of the values of gravity measured in $1945-46$ with Holweck-Lejay gravimeters in northeastern and central France. The calculations were made by means of the formulas previously employed by the author, with the gravity value $g=980.944$ of the Observatory of Paris as base. During the work several ties were tentatively established with the net of southern France. They suggest that the provisional value $g=980.615$ for Lyon, the base of the surveys of 1941-44, should be increased by 4 milligals. $-\nabla$. $S$.

10225. Lejay, Pierre: Déterminations de la pesanteur dans le Nord et le Centre de la France [Determinations of gravity in northern and central France] : Acad. Sci. Comptes Rendus, vol. 225, no. 1, pp. 10-11, Paris, 1947.

The values of gravity at 95 stations in northern and central France are tabulated. These determinations are a continuation of previous surveys. $-\nabla$. $S$.

10226. Lozano Calvo, Luis. Cálculo del gradiente vertical de la gravedad para las latitudes y altitudes penínsulares [The vertical gradient of gravity computed for altitudes and latitudes of different points on the Iberian Peninsula ] : Rev. Geofís., vol. 7, no. 25, pp. 24-27, Madrid, 1948.

The high precision of modern gravimeters necessitates greater accuracy in the computation of the various corrections and in the reduction of measurements. In the present article an accurate method of computing the free air reduction, the Fayé reduction, is given. It is based on Lambert's formula for the vertical gradient of gravity as a function of the altitude $h$ of a point and its geographic latitude $\phi$. Tables are given for the Fayé correction for different values of $h$ and for $\phi$ ranging from $35^{\circ}$ to $45^{\circ}$ N.CS. T. V.

10227. Martin, Jean, and Bollo, Robert. Liaisons gravimétriques à longue distance [Gravity ties over long distances] : Acad. Sci. Comptes Rendus, vol. 226, No. 7, pp. 563-565, Paris, 1948.

In 1947-48 the gravity net in France, including secondary base stations except Besançon, was resurveyed to test the use of prospecting instruments for the establishment of gravity ties over long distances. The "North American" gravimeters employed contain a beam suspended by 
a system of springs that renders them very nearly astatic and have a double thermostatic circuit assuring constant temperature.

The connection between Paris, Lyon, Geneva, and Chamonix (Mont Blanc) was effected with one instrument over the same itinerary on the initial and return trips, each lasting 15 days, and gave differences of not more than 0.1 milligal between readings at the same station. The connection between Paris, Clermont-Ferrand, 'loulouse, and Pic du Midi was made with three instruments over a different itinerary on the return trip, except for the link from Paris to Toulouse; for this link the difference between readings at terminal stations was 0.19 milligal. The gravity values, corrected for differences between instruments, are tabulated.

In an accompanying note $P$. Lejay points out that the described ties between secondary base stations render the French gravity net homogeneous, but that further measurements with precise pendulum apparatus are necessary to establish uniformly valid absolute values. $-\nabla$. S.

10228. Molodenskii, M. S. The external gravitational fluid and the shape of the earth's physical surface [in Russian]: Akad. Nauk SSSR Izvestiia, Ser. Geog. Geofiz., vol. 12, no. 3 pp. 193-211, Moscow, 1948.

Geodetic determinations, including gravity measurements, are made on the surface of the earth and require subsequent reduction to the geoid, and sometimes further to the ellipsoid. The current methods of effecting such reductions are imperfect, especially for mountainous terrain, because of conflicting theoretical assumptions, which are examined by the author. To obviate the difficulties involved and yet preserve the basic differentiation into the hypsometric and the geoidal surfaces, a method of calculating the external gravitational field and the shape of the earth's physical surface is presented, which makes use of a special near-geoidal surface instead of the conventional geoid of Listing.

This "quasi-geoid," determined on the basis of direct geodetic data and independent of theoretical assumptions, is characterized by values of the gravitational potential on the surface of the earth. Its points can be calculated as ratios of such values to the normal values of gravity on the quasi-geoidal surface. The calculations are analyzed, an integral equation of the quasi-geoid is deduced, the conditions of its solubility and unique solution are determined and examined in the light of their physical connotation, and formulation in terms of the surface-layer density is considered. The equation and its derivatives serve for determining the external gravitational field and the physical surface of the earth. $-V . S$.

10229. Morelli, Carlo. Le anomalie gravimetriche in funzione delle deviazioni della verticale [Gravitational anomalies as functions of plumb-line deviations] : Acad. Naz. Lincei, ser. 8, vol. 7-8, pp. 846-853, Rome, 1946.

It is possible to obtain a theoretical formula which gives the gravity anomaly at a point of the earth's surface as a function of the deviation of the plumb-line from the vertical. The results obtained by this method may be inaccurate, as the author demonstrates by the example of 34 Italian gravimetric stations. He attributes this to the very complicated form of the geoid in mountainous Italy. Consequently, too many terms 813496-48-2 
in the series expansion must be considered, thus rendering the method impractical.-S. T. $\boldsymbol{V}$.

10230. Sans Huelin, Guillermo. Determinaciónes relativas de la intensidad de la gravedad [Relative determinations of the intensity of gravity] : Inst. Geog. y Catastral Mem., vol. 16, no. 1-2, 243 pp., Madrid, 1944.

Relative gravitational measurements were made by the author at about 50 locations in Spain. The Astronomical Observatory of Madrid was the base station, situated at long. $3^{\circ} 41^{\prime} 15^{\prime \prime} \mathrm{W}$. and lat. $40^{\circ} 24^{\prime} 05^{\prime \prime} \mathrm{N}$.; the altitude above sea level was 654 meters. The gravity constant at the base station is $979.981 \mathrm{~cm}$./ $/ \mathrm{sec}^{2}$. A four-pendulum Sterneck apparatus was the chief instrument used; a Strasser astronomical clock, Hipp chronograph, radio receivers, and other auxiliary equipment were also employed. The surveys were carried out with the highest precision attainable; the instruments were repeatedly checked for accuracy; the entire equipment was returned several times to the base station for repetition of the initial determination; and the readings at different stations were adjusted for the most probable values of gravity. Extensive tables and computations are included in the report.-S. T. $\nabla$.

10231. Sans Huelin, Guillermo; and Éspinosa de los Monteros, J. M. Determinación de perfiles con el gravímetro electro-mecánico Askania no. 25 en la soma Linares-Bailen-Jabalquinto [Determination of the gravitational profiles in the Linares-Bailen-Jabalquinto region with the electromechanical gravimeter Askania No. 25] : Inst. Geog. y Catastral Mem., vol. 16, no. 7, pp. 1-15, Madrid, 1944.

A report on gravitational determinations made by the authors in 1943 at some 560 stations along four profiles around the cities of Linares and Bailen is presented. Distances between stations averaged about 200 meters. The instrument used was the Askania electromechanical gravimeter, the characteristics of which were determined by one of the authors (see Geophys. Abstracts 133, no. 9978). Accuracy of the field determinations was as high as 0.1 milligal. A geographic map of the region surveyed and four graphs representing the individual gravitational profiles are appended to the report. Four tables presenting the readings taken, the computed corrections, and the results of the determination are also included. $-S . T$. $\nabla$.

10232. Siñerì, J. G. Sobre él método de lectura del gravímetro Norgaard [About the method of taking readings on the Norgnard gravimeter] : Rev. Geofís., vol. 7, no. 25, pp. 1-10, Madrid, 1948.

The change in gravity, $\Delta g$, between two points of the earth's surface is determined on the Norgaard gravimeter by the angle $a$ which its moving system makes with the horizontal, through the relation $\Delta g=1 / 2 g_{0} \tan ^{2} a$, where $g_{0}$ is the gravity at the initial point. The angle $a$ is measurea with the aid of a special micrometer screw. Possible errors connected with this procedure are discussed, and two changes in the design of the gravimeter which would decrease their effect are suggested. In his tests of the gravimeter and the determination of its constants the author found it convenient to make determinations of gravity on different floors of a building with known differences in level between them.-S. T. $\boldsymbol{\nabla}$. (See also Geophys, Abstracts 133, no. 9980.) 
10233. Sitter, L. U. de. The activity and scientific results of the Geological Service of the Combined Collieries and the Geophysical Survey of the Government Collieries in south Limburg, Netherlands, during the war, 1940-45: Geol. Mijnb., new ser., vol. 8, no. 1-6, pp. 12-19, The Hague, Netherlands, 1946.

A brief account is given of the activities of geological and geophysical organizations established in southern Limburg, Netherlands, during the second world war to investigate collieries. Geophysical work consisted mainly of gravity surveys of the south Limburg coal field and the Peel region and was aimed at delineating the large step faults of the Roerdal fault trough.

A torsion-balance survey gave conclusive results because of specific gravity differences of 0.45 to 0.65 at the contacts of the loose Oligocene and younger sands with the heavy coals. Gradients of as much as 80 Eötvös were registered, allowing an accurate determination of the depth, throw, and dip of the faults. Some additional data were obtained with a Thyssen gravimeter. The findings, embodied in an isogam map, showed a minimum of -25 milligals in the center of the trough and a maximum of +5 milligals on the crests. They gave information on the hitherto little-known structure of the step faults and aided local mining.-V. S. (See also Geophys. Abstracts 128, no. 8976.)

10234. Volet, Charles. L'intensité de la pesanteur déterminée par l'observation de la chute d'un corps [Intensity of gravity determinèd by observation of the fall of a body]: Acad. Sci. Comptes Rendus, vol. 224, no. 26, pp. 1815-1816, Paris, 1947.

The determination of gravity by pendulum instruments presents serious difficulties which affect adversely the precision of measurements. To obviate these difficulties and particularly to avoid systematic errors the author proposes a method of observing the fall of a body at two stations situated at different altitudes. The body is thrown up in the air at each station in turn, and the time periods $t_{1}, t_{2}, t_{3}$, and $t_{4}$ of the upward and downward movements at both locations are measured. Gravity is then calculated by the formula: $4 H=g T\left(t_{2}-t_{3}+t_{1}-t_{4}\right)$, in which $H$ is the difference in altitude between the two stations and $T$ the time of fall through this distance. Suggestions are given on the practical procedures to be used in the application of this "method of two stations."- $\boldsymbol{\nabla}$. S. (For a discussion of difficulties connected with pendulum measurements see Geophysical Abstracts 127, no. 8821.)

10235. Woollard, G. P. Gravity and magnetic investigations in New England: Am. Geophys. Union Trans., vol. 29, no. 3, pp. 306-317, Washington, D. C., 1948.

This paper presents a history of gravity and magnetic work in the New England area, a discussion of the signiticance of this work and of the types of anomalies studied, a discussion of geologic interpretations derived from these studies in general, interpretations made of regional and local anomalies in the New England area, and a discussion of the need for additional work.-Author's abstract. 
10236. Zenor, H. M. A new gravity meter [abstract] : Geophysics, vol. 12, no. 3, p. 498, Tulsa, Okla., 1947.

A land-operated gravity meter has been developed to meet the need for a small, portable instrument. A new spring suspension and reading mechanism are used; the dimensions, weight, and battery requirements have been kept to a minimum, in order that it may be extremely portable. A modification of this instrument, suitable for surveying water-covered areas, is anticipated in the near future.

\section{MAGNETIC METHODS}

10237. Australian Journal of Science. Scientific results of the expedition in the region of the Pole of Inaccessibility : Vol. 10, no. 4, pp. 107-109, Sydney, 1948.

This expedition was conducted by the Arctic Institute of the Northern Sea Route Administration. The results obtained have been summarized in a book by Mikhael Ostrekin. The purpose of the expedition was to explore the less accessible regions of the central Arctic Ocean. Of great value are the data on terrestrial magnetism; they confirm the hypothesis of Soviet scientists concerning the existence of a second magnetic pole in the Northern Hemisphere. This question is of considerable scientific and practical interest because of the development of high-latitude flights with the magnetic compass as the main instrument of navigation.

An indirect confirmation of the existence of a second magnetic pole is to be found in observations in the Sverdrup Islands region made from the air by a British expedition in May 1945.-S. T. $\nabla$.

10238. Bartels, J. Potsdam erdmagnetische Kennziffern, 14 Mitteilung [Potsdam Geomagnetic K numbers, publication no. 14] : Zeitschr. Geophysik, vol. 18, no. 3-4, pp. 180-182, Braunschweig, 1944.

The present publication consists of tables of geomagnetic $\mathrm{K}$ numbers for the period April-August 1943. Since January 1942 the tables have been presented in a new and more comprehensive form.-S. T. $\boldsymbol{V}$.

10239. Bell Telephone Laboratories. Magnetic airborne detector, develonment of a magnetic orienting system: U. S. Office Sci. Res. and Devel. Rept. 1309, 72 pp., New York, January 194:3. (Librery of Congress, OTS PB Rept. 27539.)

This report describes a system for magnetic exploration in.which a detector element is oriented with respect to the earth's magnetic field, Changes in the strength of the field of the order of 10 gammas are registered. The system consists of a gimbal-type mechanism, in which two alternating-current servomotors orient the detecting element around mutually perpendicular axes under the control of two fluxgate valves with suitable electronic-exciting detector and control circuits.

Investigation of various kinds of such circuits with particular attention to their operating stability led to the use of a second harmonic heterodyne method for the orienting system, in which the exciting frequency, the putput erequency. and the motor frequency are respectively 500 cycles, 1,000 cycles, and 166 cycles. The detector Circult is operater on a second harmonic basis but with an exciting frequency of 800 cycles and hence an output frequency of 1,600 cycles, which obviates interaction effects with the orienting circuits. 
Orientation within $1 / 4^{\circ}$ at an angular speed of $20^{\circ}$ per second was obtained in the laboratory and somewhat less in the field. Combined detector noise and parasitic signal assignable to the orienting system amounted to 5 gammas or less. Suggestions for improving the system are given, and plates, graphs, table, and schematic drawings are included.-U. S. Dept. Commerce, Office Tech. Serv., Bibliog. Sci. Ind. Repts., vol. 2, no. 2, p. 108, Washington, D. C., 1946, condensed by $\mathbf{\nabla}$. 8.

Breusee, J. J. Applications de la géophysique aux recherches de mines métalliques ['The application of geophysics to prospecting for metalliferous deposits]. See Geophysical abstract 10341.

10240. Burgaud, R. P. M. Éruptions chromosphériques, crochets et perturbations magnétiques a début brusque [Chromospherical eruptions, hooklike magnetic pulses, and magnetic disturbances with sudden commencements] : Ann. Géophys., vol. 3, no. 3, pp. 264-281, Paris, 1947.

The existence of a relationship between major chromospherical eruptions and intense magnetic storms is generally recognized. A similar relationship is shown by the author to exist also between a magnetic disturbance with a sudden commencement and a solar eruption. A statistical study has revealed that such magnetic disturbance, whatever its intensity, is related to some comparatively strong eruption, that the latter is usually accompanied by a hooklike pulse (crochet) on the magnetogram, and that it is precisely this pulse that is the best index of the intensity of the eruption. The eruptions between $90^{\circ}$ and $60^{\circ}$ E., no matter what their intensity, appear to have only a limited effect on magnetic activity. The statistical analysis was made with the use of data on pulses recorded at the Zi-Ka-Wei Observatory near Shanghai, China, and other information regarding pulses and eruptions that could be obtained.-Author's abstract, condensed and translated by $V$. S.

10241. Burmeister, F. Die Ermagnetischen Observatorien Mūnchen, Maisach, Fürstenfeldbruck in ihrer Entwicklund von 1840 bis 1940 [Geomagnetic Observatories Munich, Maisach, and Fürstenfeldbruck and their development from 1840 to 1940]: Erdphysikal. Warte Sternwarte Veröffentl., no. 7, 24 pp., Munich, 1941.

The Geomagnetic Observatory of Munich began its activity as a temporary addition to the Astronomic Observatory and functioned as such for about 75 years. In 1929 the growing importance of geomagnetic measurements for national economy forced the Bavarian Ministry of National Education to appropriate funds for a small addition. Thesefunds were so meager, however, that they could provide only for the rental of a cellar in a brewery near the village of Maisach, where magnetic instruments were installed. In 1937 it was decided to build a new geomagnetic observatory in Fürstenfeldbruck, about 26 kilometers west of Munich at lat. $48^{\circ} 09^{\prime} 88^{\prime \prime} \mathrm{N}$. and long. $11^{\circ} 16^{\prime} 59^{\prime \prime} \mathrm{E}$., 592 meters above sea level. The new observatory and its instruments are described.-S. T. V.

10242. Burns, W. W. Modern exploratory tools being used in five-company $\mathrm{Ba}$ hama oil search: Oil and Gas Jour., vol. 46, no. 27 , pp. 38-42, 129, Tulsa, Okla., 1947.

This on-the-scene account tells the story of the oil industry's most modern large-scale exploration project, where the airborne' magnetom- 
eter is being, used in conjunction with shoran radar to cover an 80,000 square-mile area, of which only 10 percent is land surface. This is a pioneering project, and the experience gained will probably be valuable in future exploration activities that embrace large areas.-Author's abstract.

10243. Chapman, Sydney. Les orages magnétiques [Magnetic storms]: Rev. Scientifique, vol. 85, no. 7, pp. 387-400, Paris, 1947.

The nature and features of magnetic storms are described, and the geomagnetic field caused by them is analyzed theoretically. Consideration is given to the world-wide extent and regular character of these disturbances, their frequent sudden commencements, and their relation to solar phenomena, as indicated by observatory magnetograms. It is further pointed out that, because magnetic storms are intense and transitory disturbances of the geomagnetic field, they can be expressed vectorially in terms of the other elements of this field. In such representation their intensity is the difference between the total intensity of the geomagnetic field and the intensities of the other components of that field, namely, its principal field and its solar and lunar diurnal variations. The determination of these geomagnetic vectors is described, and a theoretical analysis is made of the expression of the field of disturbance of the type of magnetic storms and of the system of electric currents equivalent to it. $-\nabla$. $S$.

10244. Columbia University, Airborne Instruments Laboratory. AN/ASQ-1 magnetic airborne detection equipment: U. S. Office Sci. Res. and Devel. Rept. 2035, 59 pp., New York, Oct. 1943 . (Library of Congress, OTS PB Rept. 27543.)

The subject of this report is a sensitive stabilized recording magnetometer installed in aircraft and used to locate submerged submarines. The detector element, the stabilizer elements, and the servomotors are all supplied with power at a single frequency which originates in the master oscillator. The output of this oscillator is a remarkably pure sinusoidal voltage at a stabilized frequency of 400 cycles per second. The individual units are described, and the performance characteristics of the detector and stabilizer systems are discussed. Plates, graphs, and a table are included.-U. S. Dept. Commerce, opice Tech. Serv., Bibliog. Sci. Ind. Repts., vol. \&, no. \&, p. 108, Washington, D. C., 1946, condensed by $\nabla . \mathrm{s}$.

10245. Columbia University, Airborne Instruments Laboratory. Handbook of instructions for AM-36/ASQ : U. S. Office Sci. ReS, and Devel. Rept. 4186, 18 pp., New xork. Sept. 1944. (Library of Congress, OTS PB Rept. 27549.)

This device has been developed to overcomo anurious indications in the magnetic airborne detectors traceable to magnetic nesas senerated by eddy currents in the wings. The AM-36 unit is a three-stage bandpass amplifier employing degenerative feedback. The input to the amplifier is the voltage picked up by a coil placed in the airplane in such a position that the radial plane of the coil is parallel to the eddy-current loop. The amplifier output is connected to a compensating coil which, when proper adjustments are made, produces a magnetic field equal in intensity and opposite in phase to the field caused by the eddy currents 
at the detector. The handbook deals with principles of operation, physical data, adjustment, gain test, voltage, resistance, and capacitance measurements. Photographs, circuit diagram, and parts layout are included.-U. S. Dept. Commerce, Office Tech. Serv., Bibliog. Sci. Ind. Repts., vol. 2, no. 2, p. 108, Washington, D. C., 1946, condensed by V. S.

10246. Egedal, J. The magnetic diurnal variation of the horizontal force near the magnetic equator: Terres. Magn. and Atmos. Electr., vol. 52, no. 4, pp. 449-451, Baltimore, Md., 1947.

Data are presented on the diurnal variation of the horizontal geo: magnetic component near the magnetic equator and at other locations in support of A. G. McNish's view that without the Huancayo observations a complete analysis of this variation is not practicable. The range of the diurnal variation of the north component at Huancayo is found to vary from 36 gammas in the analysis of $\mathrm{S}$. Chapman, through 77 gammas in the analysis of McNish, to 105 gammas actually observed. The total range of the diurnal variation of $H$ is represented at magnetic observatories at Alibag, Antipolo, Madras, Kodaikanal, and Batavia by values of 38.5 to 82.5 gammas and at Huancayo by the value of 125 gammas. Such considerable augmentation of the range of $H$ in a narrow area near the magnetic equator appears to indicate that the variation is caused by a varying electric current flowing in a very narrow zone of the atmosphere above the magnetic equator. $-V$. $S$.

10247. Ehrenhaft, Felix. Le mouvement des particules dans les champs magnétiques uniformes et non uniformes [Movement of particles in homogeneous and heterogeneous magnetic fields]: Acad. Sci. Comptes Rendus, vol. 225, no. 20, pp. 926-928, Paris, 1947.

Observations on the movement of magnetized particles in a homogeneous magnetic field, reported in previous papers, are summarized and amplified by new data. It is found that in such a field the particles undergo an inversion of movement with an inversion of the field and carry an excess of either northern or southern magnetic charge.

Experiments have also been made with particles in heterogeneous fields generated by a mutual inclination of two magnets. The results obtained on the pattern of movement in such fields are discussed and illustrated by diagrams. They show that the formula for the force moving the particles, calculated from previous observation, must now include an additional member, the one term expressing the force exerted on the magnetic charge and the other the force of polarization.V. S.

10248. Fanselau, G. Vorläufige Ergebnisse der erdmagnetischen Beobachtungen in Niemegk in den Jahren 1941 and 1942 [Preliminary findings from the magnetic observations made in Niemegk during the years 1941 and 1942] : Zeitschr. Geophysik, vol. 18, no. 1-2, pp. 78-83, Braunschweig, 1943.

This paper is the third from the Niemegk Magnetic Observatory and is similar to the two previous publications in form and content. It contains six tables of magnetic data for the years 1941 and 1942 and a short note on "giant pulsations" of the terrestrial magnetic field.S. T. V. (For the preceding issue of these observations see Geophys. Abstracts 132, no. 9752.) 
10249. Fleming, J. A. The earth's magnetism : Think, vol. 13, no. 10, pp. 17-18, 44, New York, 1947.

A brief account is given of the fundamentals of terrestrial magnetism, which covers the early history of such knowledge, definition of magnetic elements, location of magnetic poles, nature and kinds of magnetic variations, preparation of isomagnetic charts, and the activity of magnetic observatories.- $V$. $S$.

10250. Frowe, Eugene. A total-field magnetometer for mobile operation: Geophysics, vol. 13, no. 2, pp. 209-214, Tulsa, Okla., 1948.

This is the full text of the paper. For abstract published in advance, see Geophys. Abstracts 131, no. 9547.

10251. Gião, Antonio. Sur le magnétisme des masses en rotation [On the magnetism of rotating masses] : Acad. Sci. Comptes Rendus, vol. 224, no. 26, pp. 1813-1815, Paris, 1947.

The relationship between an electromagnetic value, such as the magnetic moment of a nearly spherical rotating mass, and a purely mechanical value, such as the angular momentum of this mass-discovered by P. M. S. Blackett to hold true in the case of the earth, the sun, and the star 78 Virginis-is shown to be deducible from Gião's unitary theory of gravitation and electromagnetism. In terms of this theory it is possible to express space time as a hypersurface of the first class of a certain space and to formulate the external metric shape of such a hypersurface as an invariant quadratic form corresponding to a symmetrical tensor of second rank definable by its covariant components. Then electromagnetic phenomena, treated in the theory essentially as properties of the external metric form of space time, are determinable by means of these covariant components.

The particular relationship between the magnetic moment and the angular momentum of a rotating mass can be further deduced from this system by expressing both values in terms of covariant components of the magnetic field with the use, in part, of equations of relativity applied to a sphere in rotation. $-T . S$.

10252. Gião, Antonio. Sur la relation entre le moment magnétique et le moment de rotation des masses sphériques [On the relation between the magnetic moment and the rotational momentum of spherical masses] : Acad. Sci. Comptes Rendus, vol. 225, n0. 20, pp. 924-926, Paris, 1947.

The derivation of P. M. s. Blackett's formula, expressing the relationship between the magnetic moment and the angular momentum of rotating spherical bodies, from Gião's unitary theory of gravitation and electromagnetism is carried further (see Geophys. abstract 10251). An analysis is made or the equation connecting the internal and external metric coefficients of the covariant components of the ssmmetrical tensor employed for this derivation, and the conditions are deduced under which the relationship must be valid for any metric field produced by rotating masses contained in a space where electromagnetic phenomena can be considered near static. The analysis renders possible a more generalized expression of Blackett's formula in the case of the externat magnetic field of a uniformly magnetized rotating sphere. This generalized expression is valid for any electric charge of the rotating sphere 
and thus holds true even when the charge is zero, so that a mass is found to produce a magnetic field solely by its rotation. $-V$. S.

10253. Gilchrist, Lachlan, and Robinson, B. W. The use of cores to determine the subsurface magnetic dip, magnetic declination, and total force of the earth's magnetic field and to determine the attitude of drill holes [abstracts] : Royal. Soc. Canada Proc., ser. 3, vol. 41, p. 179, Ottawa, Ontario, 1947.

The results obtained by the new method of determining the magnitude of geomagnetic elements with the aid of ccres give information useful in the interpretation both of measurements made on the surface and of the magnetic condition of the earth as a whole. A new method is alşo provided for the determination of the attitude of drill hol.es.

10254. Grindley, E. N. The earth's magnetic field in southern Africa at the epoch, 1 July 1930 : Royal Soc. London Philos. Trans., ser. A, vol. 240, no. 818, pp. 251-294, 4 maps, London, 1947.

This paper gives the results of an attempt to determine the earth's magnetic field in Africa south of the Zambezi and the Kunene at the epoch 1930.5. The data employed are measurements taken at about 700 stations from 1900 to 1925 and observations made by the author at 50 of these stations from 1928 to 1930 to determine the secular variation and deduce therefrom the values of the geomagnetic field for $\mathbf{1 9 3 0 . 5}$ at the other stations.

The magnetic inclination is found to have changed in an almost linear manner, the maximum rate occurring in southwestern Africa. The horizontal intensity has diminished at a gradually increasing rate, the maximum change being near Cape Town. The declination appears to have varied at a high rate until 1928 and much more slowly since then; the greatest total changes are found near Durban. The results are represented by maps plotted according to the method of G. S. Ljungdahl.Author's abstract, condensed by $\nabla$. S.

10255. Instituto Geográfico y Catastral. Carta de declinaciones magnéticas, hoja special del Archipiélago Canario [National map of magnetic declinations, special sheet covering the Canary Islands], 68 pp., Madrid, 1943.

This is one of the general collection of magnetic maps edited by the Instituto Geografico y Catastral of Spain and covers the Canary Islands. The introductory chapter deals with the history of magnetic measurements on these islands, explains the details of the preparation of the map, and gives detailed information on the climate and geology of the archipelago. It is followed by a detailed discussion of the magnetic anomalies and their possible causes. The map is on a scale of $1: 1,000,000$, and the magnetic data are reduced to July 1, 1942.-S. T. $V$.

10256. James, H. L., and Wier, K. L. Magnetic survey and geology of the eastern and southeastern parts of the Iron River district, Iron County, Michigan: U. S. Geol. Survey Circ. 26, 18 pp., 4 pls., 1 fig., Washington, D. C., July 1948. [Processed.]

This report is one of a continuing series in which the results of a restudy of Lake Superior iron-ore deposits are piresented. Iron ore is $813496-48-3$ 
being mined at several places in the eastern and southeastern parts of the Iron River district. It occurs in structurally favorable positions in a complexly folded iron formation of pre-Cambrian age, so that delineation of the iron formation and of the structural features with which it is involved is of prime importance in the search for ore. Most of the area is deeply mantled with glacial deposits, and geologic interpretation must be made largely from drilling, mining, and geophysical data. The interpretation presented is based on detailed magnetic mapping in which vertical magnetometers were used, examination of core from about 125,000 feet of diamond drilling, and mapping of all accessible mine openings. In addition to magnetic and geologic maps, the report contains a detailed description of the rock succession and a discussion of the factors that control the location of ore.

10257. Jensen, Homer. Tool of aerial exploration: World Petroleum, vol. 19, no. 3, pp. 84-87, New York, 1948.

An increasing use of aeromagnetic surveys is noted, and the problems and procedures involved in them are discussed on the basis of the Bahamas survey. This operation was carried out with a Gulf airborne magnetometer towed from a specially adapted Douglas DC-3 plane and required various accessory equipment and about 60 employees. It consisted essentially of preparatory organization, survey flying, and reduction of data, all of which are outlined.

Arrangements for dealing with problems concerned with the weather, positioning, communications, and supplies constituted some of the main organization work. Flying over the area, which is 90 percent under water, had to be done with the aid of mobile shoran stations aboard boats and a permanent station at Nassau ; this method rendered possible the continuous tying of magnetic records with the chart of positions to a tolerance of about \pm 150 feet horizontally and \pm 25 feet vertically. The data of the magnetometer, the pilot deflection indicator, and the radio altimeter, recorded during 1,000 hours of flying, were reduced at the main office in Philadelphia.-V. $\mathbb{S}$.

10258. Joesting. H. R., and Henderson, J. R. Preliminary report on an experimental aeromagnetic survey in northwestern Indiana: U. S. Geol. Survey, Geophysical Investigation, 12 pp., prellminary mav 4, nls. 1, 2. Washington, D. C., 1947. [Ozalid.]

A trial aeromagnetic survey was made in February 1047 over Newton, Jasper, Fuasiki, white. Porter, and Lake Counties in Indiana to determine the advisability of aeromagnetic expowation for oil over the entire state. The 1,500-square-mile area sulveyed is covered by glacial arit, and most subsurface information is derived from deep well logs. $R$. R. Shroces exomic man indicates Devonian bedrock in the northeast and south. Middle Ordoviclan rowe ..... exoosed in quarries east of Kentland.

The survey was made with an AN/Asq-3A magnetometer towed by a irme-engine seechcruft plane carrying a gyro-stabilized sonné continuous-strip camera alld a laum antineter. Traverse lines, spaced 1 mile apart and bound by base lines, were flown at afl drelllgo gievenom of 1,000 feet in 14 hours, with a closing error of 18 gammas for the 160 -mile base-line series. The observed and residual anomalies in total intensity are presented on two isoanomaly maps, deemed accurate within 
12 gammas. It is considered that they give satisfactory indication of variations in the magnetism of and the depth to the underlying crystalline basement, and a fuller aeromagnetic survey of Indiana is recommended. $-\boldsymbol{V}$. $\boldsymbol{S}$.

10259. Kline, M. H., and Ballard, T. J. Cranberry magnetite deposits, Avery County, N. C., and Carter County, Tenn. : U. S. Bur. Mines, Rept. Inv. 4274, 85 pp., 34 figs., Washington, D. C., 1948.

The Cranberry magnetite deposits occur in a belt 26 miles long, extending from 3 miles southeast of Cranberry, North Carolina, to about 6 miles southwest of Magnetic City, Tennessee. The Bureau of Mines investigation was confined to the eastern part of the belt, comprising the area from Fork Mountain, Avery County, North Carolina, to the Heupscup Knob prospects in Carter County, Tennessee. Approximately 10 miles of the eastern part of the belt was surveyed by geophysical methods, a number of magnetic anomalies were diamond-drilled, and a pilot plant was constructed for milling tests.-Authors' abstract.

10260. Knapp, D. G., and Howe, H. H. Magnetic observatory results at Honolulu, Hawaii, for 1937-38: U. S. Coast and Geod. Survey, Serial MO-25, 106 pp., Washington, D. C., 1946.

This publication contains extensive tables of observatory results, reproductions of magnetograms showing the more important magnetic storms, and an explanatory text. The tabulated results include hourly mean values of the magnetic elements $D, H$, and $Z$, summaries of their monthly and annual means, lists of principal magnetic disturbances, amounts of noncyclic change, observed and adopted base-line values of the $D, H$, and $Z$ variometers with their abrupt changes, and other data. The text comprises a description of instruments, discussions of their coefficients and behavior and of the procedures used, and explanations of the various tabies.-Authors' abstract.

10261. Lahaye, E. Les phénoménes solaires at les perturbations de la déclinaison magnétique enregistrées a Ućcle au cours de la période 1939-43 [Solar phenomena and disturbances of magnetic declination recorded at Uccle during 1939-43] : Ciel et Terre, vol. 62, pp. 311-323, Brussels, Belgium, 1946.

Tables are given showing the most important disturbances of magnetic declination during 1939-43, tentatively classified according to their amplitude and general character, and a statistical estimate is made of the time interval separating these disturbances from chromospherical eruptions and from the passing of sun spot groups across the central meridian.-Cent. Nat. Rech. Sci., Bull. Anal.; vol 8, no. 11-12 pt. 1, p. 2628, Paris, 1947, translated by V.S.

10262. Macht, H. G. Das erdmagnetische Feld der Polargebiete [The geomagnetic field of the polar regions] : Zeitschr. Meteorol., vol. 1, no. 10, pp. 289-297, Potsdam, Germany, 1947.

The permanent geomagnetic field of the polar zones, especially the north polar distribution of horizontal force ( $\mathrm{H}$ field), is discussed. The formal computations are based on the "canonical development" of the magnetic potential, $\phi=\Sigma \phi_{\text {n. }}$. The obvious deviation of the north polar 
$\mathrm{H}$ isodynamics from ideal geomagnetic parallels and of the magnetic meridians from great circles, that is, the elliptic and parabolic deformation of these lines, is expressed principally by the two initial terms $\phi_{1}+\phi_{2}$. This "idealized" field is found to be affected by different additional disturbances, further distorting the isomagnetic curves of the north-polar region.

Special attention is given to the physical meaning of the $\phi_{2}$ part of the geomagnetic potential (canonical form). The magnetic coefficient contained in the analytic expression of $\phi_{2}$ is considered to represent the "regular part" of the earth's inhomogeneous magnetization, conceived as "absolute cross magnetization" to the magnetic axis. A new fundamental constituent of the permanent field is thus introduced, which is added to the main part of the earth's homogeneous magnetization.-Author's abstract, Terres. Magn. and Atmos. Electr., vol. 52, no. 4, pp. 503-504, Baltimore, Md., 1947, condensed by V. S.

10263. Madill, R. G. Correlation of daily variation in vertical force between Agincourt Magnetic Observatory and distant field stations [abstract] : Royal Soc. Canada Trans., ser. 3, vol. 41, Proc. 1947, p. 179, Ottawa, Ontario, 1947.

During the summer of 1946 an Askania magnetometer was used to determine the daily variation in vertical force at a number of field stations in certain mining areas of Ontario and Quebec. Stations were distributed within distances of 100 to 350 miles northward from Agincourt. The results of the investigation show that daily-variation corrections measured from Agincourt magnetograms may be used directly to correct field observations in this area. The average disclepancy is of the order of \pm 5 gammas.

10264. Matteson, w. J. Investigation of German magnetometer: U. S. Army Eng. Corps, Eng. Board Reg. 2665, 5 pp., Fort Belvoir, Va., 1945. (Library of: Congress, OTS PB Rept. 15584.)

The German magnetometer here discussed is used to measure the horizontal component of the earth's magnetic field. It is mounted on a trinod and is similar in design to the QHM model developed by the Danish Meteorological omce in 1030. The operation of the QHM magnetometer is described, and plates showing its construction are appended.- $\boldsymbol{V}$. S.

10265. Nagata, Takesi. Measurement of changes in magnetic susceptibility of igneous rocks with temperature in a weak magnetic field: Earthquake Res. Inst.: Bull., vol. 19, no. 35, pp. 579-596, Toky0, 1941.

A method is described for measuring the modification in the magnetic

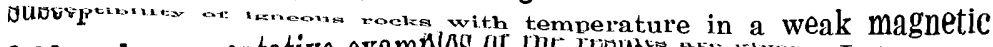

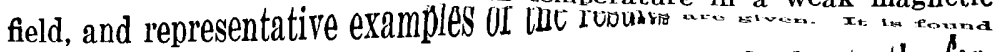
that the magnetization of these rocks, which is chiefly due to the ferromagnetic minerals present in them, changes markedly with their tem-

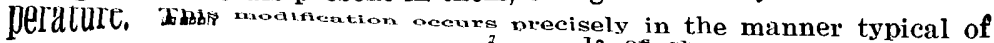
ferromagnetic materials, though the mode of chllilbC in biss usually much more complex. Variations in the magnetization of rocks with temperature would tend to change the magnetization of the earth's crust whenever a temperature change would exist in it. No increase is 
observed in the magnetic susceptibility of rocks in a weak magnetic field, similar to that known as the "Hopkinson effect" in the case of iron.-Author's summary, condensed by $\nabla$.' 'S.

10266. Nagata, Takesi. The mode of development of thermoremanent magnetization in igueous rocks: Earthquake Res. Inst. Bull., vol. 20, no. 14, pp. 192-214, Tokyo, 1942.

The author's observations show that thermoremanent magnetism in igneous rocks can be considered as their irreversible magnetization at a temperature immediately below the Curie point. The intensity of magnetization changes very little with a decrease in temperature, although such a decrease has a marked effect on the magnetic susceptibility of the same specimens. This evidence tends to indicate that thermoremanent magnetization can hardly be caused by modifications in the crystal lattices themselves, produced by physical conditions, if it is assumed that the change in the saturation magnetization of igneous rocks with temperature resembles the change occurring in usual ferromagnetic crystals. The problem is being investigated with a view to estimating the development of thermoremanent magnetism in the rocks of the earth's crust, so as to clarify the effect which rock magnetization has on regional and local anomalies and on secular variations of the earth's magnetic field. - V. $S$.

10267. Newton, H. W. Geomagnetic "crochet" occurrence at Abinger, 1936-46, and allied solar and radio data: Royal. Astron. Soc. Monthly Notices, Geophys. Suppl., vol. 5, no. 6, pp. 200-215, London, 1948.

The rather infrequent occurrence at Abinger of geomagnetic "crochets" (ultraviolet solar radiation effect) has been studied over 11 years, in conjunction with data of solar flares and radio fade-outs. The trace movements in $H, D$ and $V$ of 23 examples are reproduced, in addition to tabulated data for these and for 32 other cases of less certain identification. The general synchronization of flare, fade-out, and crochet (when present) is noteworthy. Comparison is made of the amplitude $\Delta H$ and direction $\Delta D$ of the crochets with the normal diurnal inequality of $H$ and $D$. A striking feature is the change in direction from east to west in $D$ at about $10^{\text {h. }} \boldsymbol{\tau}$ apparent solar time, in conformity with the diurnal inequality in $D$. The correlation with the diurnal inequality in $H$ is less obvious, but $\Delta H$ is of the correct sign (negative) over the range of daylight hours in which crochets occurred. There are indi- cations of other diurnal and seasonal factors (other than a simple dependence upon the sun's zenith distance) in the occurrence of crochets at Abinger. Some crochets in 1946 have synchronized with reported bursts of "solar noise."-Author's abstract.

10268. Nodia, M. Z. The geomagnetic field in the neighborhood of the Dusheti Magnetic Observatory, Georgian S. S. R. [in Russian]: Acad. Sci. Georgian S. S. R. Bull., vol. 7, no. 4, pp. 165-170, Tbilissi, 1946.

Magnetic observations in Georgian S. S. R. in the Caucasus were started in 1844 in the city of Tbilissi, but in 1935 the observatory was transferred to the adjoining town of Dusheti because of disturbances caused by the street railway system and electric transmission lines. Although the geomagnetic properties of the new site were examined prior to the 
transfer of the observatory, a detailed survey of the surrounding region was not made until 1945. Six radial profiles 6 to 8 kilometers long were traversed. Two Schuidt's magnetic field balances were used. The survey disclosed only a few relatively small anomalies. The greatest variations of the horizontal component, referred to the average yearly value, were $-59 \gamma$ and $+98 \gamma$; those of the vertical component were $-90 \gamma$ and $+65 \gamma$. The average value of $H$ for 1944 was $41,114 \gamma$. The report contains computations, tables of readings, and a map of the site. $\rightarrow S . T . V$.

10269. Pawlowski, Stanislaw. Anomalie magnetyczne w Polsce [Magnetic anomalies in Poland] : Poland Instit. Geol. Bull,, no. 2, 44 pp.; Warsaw, 1947.

The most extensive magnetic survey of eastern Poland was made by S. Kalinowski in 1933 . Measurements in the western part, which up to 1945 belonged to Germany, wele made by A. Schmidt in 1900 . The results of these two survevs are analyzed by the author in order to locate the most important anomalies of this area. The region around the city of Kielce is characterized by a very quiet magnetic field without local anomalies of any. importance. The elements of the magnetic field here are : $Z=42,334 \gamma ; H=19,397 \gamma ; D=2^{\circ} 06^{\prime}$. On the basis of available measurements three approximate formulas were derived giving the values of the elements of the normal magnetic field at a point as functions of its geographic coordinates. After analyzing the available material the author concludes that eastern provinces have several important maxima and minima and suggests their further investigation. The book contains extensive tables of measurements and seven magnetic maps.-S. T. $\boldsymbol{V}$.

10270. Pearson, G. L. A magnetic field strength meter employing the Hall effect in germanium: Rev. Sci. Instruments, vol. 19, no. 4, pp. 263-265, Lancaster, Pa., 1948.

The instrument described measures magnetic field strengths as determined from the Hall effect in germanium. The essential parts of this instrument include a small germanium probe and a panel-type microammeter calibrated directly in gauss. Its accuracy is \pm 2 percent at fields betweell 100 and 8,000 gauss. At higher nelas the readings are too low, the error amounting to 9 percent at 20,000 gauss. The chier advantages of this instrument are its small size and portability, con. tinuous reading rather than ballistic as in ordinary field strength meters, and a small nonmagnetic probe with which one can search in very narrow gaps.-Author's abstract.

10271. Ferolcum world. Magnetometer survey in Bahamas: Vol. 45, no. 1, p. 29,

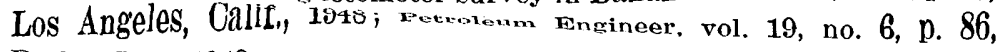
Dallas, Tex., 1948.

The aeromagnetic survey in the Bahama Islands, undertaken by IIV Oll crmparies in May 1947, was completed in November of the same year. It covered apploximlitiby $85, \infty 00$ scuare miles at a cost of $\$ 850,000$. A Gulf airborne magnetometer was flown DV ill aliap Douglas DC-3 plane, and position fixing over the area, which is 90 percent under water, was made by means of Shoran triangulation. The 
orientation stations, set up on boats, were anchored in pairs about 30 miles apart and were moved as the survey advanced. In all, more than 4 miles of magnetic records were obtained, which will take approximately 20,000 man-hours to translate into maps. $-V$. S.

10272. Princep Curto, J. M. Magnetismo fosil [Magnetism of buried rocks]: Rev. Geofís., vol. 7, no. 25, pp. 28-65, Madrid, 1948.

The author predicts that a study of the magnetic state of rocks buried underground will make possible a reconstruction of the past history of terrestrial magnetism. This prediction assumes that the natural magnetism of magmatic masses preserves its intensity and its direction corresponding to the epoch of the cooling of the magma to the temperature of the Curie point. In sedimentary formations the magnetism of their component parts corresponds to the epoch of sedimentation, not to the present state of terrestrial magnetism at the point. This property of volcanic masses will extend our knowledge of secular variation of terrestrial magnetism and will also make it possible to establish the time of formation of certain minerals. $-S . T . V$.

10273. Procopiu, Stéfan. Measures magnétiques en Roumanie, de 1931 à 1940, et cartes magnétiques de la Roumanie, dressées pour le l-er Juillet 1940 [Magnetic measurements in Rumania from 1931 to 1940, and magnetic maps of Rumania plotted for: 1940.5] : Univ. Jassy Ann. Sci., vol. 26 , no. 2, pp. 535-562. Iaşi, Rumania, 1940.

During the period $1931-40,85$ stations were occupied in Rumania for measurements of magnetic declination, inclination, and the horizontal component. The data were reduced to common epoch 1940.5 on the basis of continuous determinations of these elements at Iași during the same period which rendered possible the calculation of secular variations for that locality. The annual values of secular variations found for Iaşi were: $d D=+6.12^{\prime} ; d H=-0.00009$ CGS ; and $d I=+2.4^{\prime}$. With the use of the data for the 85 new stations and of previous data for 54 older stations, likewise reduced to 1940.5 , isoanomaly maps have been drawn of magnetic declination, inclination, and the horizontal component in Rumania. These maps show certain anomalous zones and indicate that the large anomaly of Iaşi-Botoşani extends northwestward and merges with the anomaly at Cernăţi and possibly with anomalies in Poland.- $-V . S$.

10274. Roberts, E. B. The future use of the airborne magnetometer in general magnetic mapping: Photogram. Eng., vol. 13, no. 4, pp. 641-643, Menasha, Wis., 1947.

The limitations of the present airborne magnetometer in magnetic mapping are discussed, and the improvements necessary to adapt it for general three-dimensional magnetic surveys are indicated. Actually the instrument now in use is a magnetic detector of the variometer type, rather than a magnetometer. It serves only certain restricted purposes in mapping by showing the changes of intensity in space but cannot measure the absolute intensity of the magnetic field nor indicate how that field is oriented.

General magnetic mapping, viewed as the portrayal of the magnetic field in all its elements of intensity and orientation on a regional basis, 
requires an independent absolute measure of that field resolved into three vectors furnishing information sufficient for the drawing of properly smoothed, generalized isomagnetic lines. For such mapping, the present airborne magnetometer must be turned into an absolute-intensity indicator provided with suitably gyro-stabilized horizontal and vertical references and other improvements and supplied with equipment for the determination of a true azimuth. Research to that end is in progress. $-\boldsymbol{V}$. S.

10275. Science News Letter. Navy seeks new design for magnetic compass: Vol. 52 , no. 18, p. 275, Washington, D. C., 1947.

A brief note is given regarding research conducted on a remote-reading magnetic compass at the Navy Materials Laboratory of the New York Navy Shipyard. The work is aimed, at perfecting the aircraft compasses which were fastened high on the masts of ships during the war to provide remote readings in the wheel house and which were found to be affected by sea roll. The improvements being developed include an instrument for determining compass vibrations under conditions of rotation and for controlling the earth's magnetic field during such tests.-V. S.

10276. Shwank, O. A. Components of the magnetic field generated by a subterranean layer [in Russian] : Prikladnaia Geofizika, no. 2, pp. 65-66, Moscow, 1945.

A formula is derived by the author for computing the vector components of the magnetic field generated at a point on the earth's surface by a buried magnetized layer of any shape extending to infinity. The derivation is based on Poisson's theorem, and the final formula gives the vertical and horizontal components as functions of the solid angle bounding the layer, and as functions of distances from the point of observation to the upper and lower faces of it. The formula remains valid for a sum of or for a difference of such simple layers.-S. T. V.

10277. Siemens und Halske A. G. Der SRV Messplatz [The SRV measuring equipment], 52 pp., Berlin, 1941-42. (Library of Congress, ots PB Rept. 20438.)

This report contains the description of and operating instructions for an apparatus which measures the strength and direction of the earth's magnetic field by means of three pairs of coils, one pair for each direction, having as a core a rod of highly permeable metal. Because the permeability of this rod changes with the degree or its magnetization, the resulting change in the impedance of the coils can be measured and calibrated by the use of wheatstone bridges and amplifiers as an index of the change of the earth's magnetism. There are eight measuring bands allowing readings from 0.0025 to 0.500 oersted with a 98-percent accuracy. The report contains circuit diagrams and lists of parts for the main pieces of the equipment.-U. S. Dept. Commerce, Office Tech. Serv., Bibliog. Sci. Ind. Repts., vol. 2, no. 1, p. 28, Washington, D. C., 1946 . 
10278. Slaucitajs, L. Anomaly in magnetic horizontal and vertical intensities of Latvian territory and adjacent sea: Baltic Univ. Contr., no. 41, 4 pp., Pinneberg, Germany, 1947.

Isoanomaly maps are drawn of the horizontal and the vertical geomagnetic components in Latvia and the adjacent sea for epoch 1940.5. The map of the horizontal component is based on a DHZ-net with a distance of about 20 kilometers between stations. On this map the central part of the land area appears to be most disturbed, showing deviations of as much as 75 percent from the mean normal value of 16,500 gammas. The map of the vertical component is more detailed, being based on a Z-net with a distance of about 7 kilometers between stations on dry land. Positive values predominate throughout this map, the central part again shows the greatest disturbance, and the most pronounced anomaly also deviates by about 75 percent from the mean normal value of 45,900 gammas.-V. $S$.

Wollard, G. P. Gravity and magnetic investigations in New England: See Geophys. abstract 10235.

\section{SEISMIC METHODS}

10279. Akademiia Nauk SSSR Vestnik. Seismic observations during experimental explosions [in Russian] : Vol. 17, no. 4, pp. 91-92, Moscow, 1947.

Records of seismic observatories constitute valuable material for the study of the earth's crust, but many related questions can be studied better by experimenting with artificial earthquakes. A real earthquake can never be as accurately or as completely observed as an earthquake produced artificially. Many unknown factors which confuse the final conclusions can be completely eliminated in an experimental installation.

An artificial earthquake was produced and studied in detail in January 1947 when 260 tons of dynamite were exploded in the Azerbaydzhan S. S. R. in the Caucasus. Ten high-precision seismographs were installed at distances ranging from 3 to 214 kilometers from the shot point, all equipped with radio receivers and special wiring for timing. The results of these experiments are considered valuable for the elucidation of many questions on local and regional geology. -S. T. $V$.

10280. Berkey, C. P. Engineering implications of the Massena-Cornwall earthquake [abstract] : Geol. Soc. America Bull., vol. 58, no. 12, pt. 2, p. 1167, Baltimore, Md., 1947.

It was found practicable to correlate the destructive effects of the Massena-Cornwall earthquake of September 4-5, 1944, which had an intensity of 7 (Rossi-Forel scale), with the geologic formations of the region. The results showed that such structures as dams, locks, and power houses, that could be established on sound rock foundation, would be in no danger from an earthquake of the same intensity and that installations resting on glacial till would suffer no material damage. However, structures involving loose sands and silts, particularly the marine silt deposits, would require special handling.-Condensed by $\mathbf{\nabla} . \mathbf{S}$. 
10281. Boulware, R. A., and Alcock, E. D. Operating problems of marine seismic surveying: World Petroleum, vol. 19, no. 3, pp. 60-61, New York, 1948.

According to the authors' estimates, the monthly cost of a marine seismic crew is approximately three to four times that of the usual land crew, but its production can be five to seven times that of the land crew if the proper equipment, methods, and personnel are used. Problems of adverse weather, suitable boats, marine position fixing, exploration techniques, and adaptation of instruments are discussed, and suggestions are offered to increase the efficiency of work.

To overcome the principal difficulty, bad weather, it is deemed practical to conduct operations on all calm days, irrespective of holidays, with the aid of increased personnel. The use of large seaworthy boats 60 to 85 feet in length or longer, such as converted naval craft for recording boats and fishing craft for service boats, increases the working time because the crews can proceed in rougher seas. Position fixing by means of radar and shoran requires particular attention to questions of qualified personnel and repairs. Placing and moving of seismometers under water is facilitated by the employment of a single waterproof cable with the instruments and conductors built into it about a strong strain wire. Other suggestions are made. $-\nabla . \mathbf{s}$.

10282. Brekhovskikh, L. M. Reflection of spherical waves from the plane boundary separating two media [in Russian] : Zhur. Tekhn. Fiz., vol. 18, no. 4, pp. 455-472, Moscow, 1948.

This is a mathematical study of the reflection of spherical waves, both acoustic and electromagnetic, from a plane boundary separating two different media. A complete solution of this problem is presented, and formulas are derived for both the Hertzian vector, in the case of electromagnetic waves, and the acoustic potential, in the case of sound phenomena, for any angle of incidence of the incoming wave and for any physical properties of the media. Moreover the author describes a new type of wave, derived from the general equation of wave motion, which extends along the boundary plane and is identical with Mintrop waves in seismic studies. $-S . T . V$.

10283. Bullen, K. E. An introduction to the theory of seismology, $276 \mathrm{pp}$., Cambridge, England, Univ. Press, 1947.

This book presents the essentials of seismological theory for the use of college students, seismologists, and physicists. It is intended primarily for observatory seismologists. The contents cover the mathematical principles of elasticity and of vibrations and waves, their application to problems of wave motion in an elastic body, the recording and treatment of seismic data, the use of the obtained information for the determination of the earth's structure, and the conditions at an earthquake focus. Consideration is also girve to secine subsects dente with in seismology, such as earthquake-resisting structures, microseisms, and seismic prospecting. The thickness of the upper crustal layers in Eurasia is cited as $15 \pm 3$ kilometers for granitic layers and $18 \pm 4$ kilometers for intermediate layers. The total crustal thickness in continental regions is generally estimated to be 30 to 40 kilometers. In some special localities, and particularly in the vicinity of certain mountain ranges, this figure may have to be increased.- V. S. 
10284. Campbell, E. L. Winter seismic operations in the Rocky Mountain region : Mines Mag. vol. 38, no. 1, pp. 10, 44, Denver, Colo., 1948:

An account is given of winter seismic operations in the Rocky Mountains, which are complicated by problems arișing from low temperatures and difficult transportation of equipment. Temperatures at which dynamite freezes are rarely encountered, but coagulation of the binder on the cartridges has been reported. Heavy winds may interfere with recording during much of the winter season. Burying seismometers to reduce effects of wind noise is particularly difficult. Cables and detectors may freeze to the ground, so care must be taken to prevent damage when spreads are changed.

The handling of water for mud pumps presents a serious problem. All pumps, hoses, and tanks that are not in use are in danger of freezing and must be drained.-S. T. V.

10285. Cortright, W. D. Complications in basement reflection correlation [abstract] : Geophysics, vol. 13, no. 2, p. 300, Tulsa, Okla., 1948.

The purpose of this paper is to show by illustration how the top of basement reflection character correlation may be misleading and to suggest some geologic conditions which may have a bearing on the situation. Local vertical migration of the typical basement reflection, although a disturbing factor, does not prevent the extended use of this reflection band as a basis for mapping the basement configuration.

10286. Daly, J. W. An instrument for plotting reflection data on the assumption of linear increase of velocity: Geophysics, vol. 13, no. 2, pp. 153-157, Tulsa, Okla., 1948.

An instrument is described by means of which reflection data may be rapidly and accurately plotted in the case where the velocity is assumed to increase linearly with depths. Lengths corresponding to the radius of the wave-front circle and the depth to its center are obtained directly from observed reflection times by means of suitable scales attached to the device. Reflection data can be plotted either by dip units or by the envelope method.-Author's abstract.

10287. Dix, C. H. Seismograph results in three dimensions [abstract]: Geophysics, vol. 12, no. 3, p. 494, Tulsa, Okla., 1947.

It is assumed that reflection depths, dips, strikes, and horizontal offsets have been determined by a sufficiently accurate process at many places in a three-dimensional region under seismic exploration. It then becomes possible to select on the map of the investigated area a trace, preferably straight, under which a vertical cross section may be made. This cross section can further be plotted by projecting therein the reflectors regarded as plane, with the distance of projection in the plane of the reflector being kept to a minimum. The process may be applied to a whole network of traces on the map by using the same horizontal and vertical scales as the map scale. As the next step the sections can be made on transparent plastic sheets, and can be erected on the map with the aid of half-cut slots (egg-crate fashion) at intersection points. It is then possible to study this transparent cellular network directly as it rests in its correct position on the:map. $\div$ Condensed by $\nabla: S$. 
10288. Dresbach, C. H. Discussion-Multiple reflections: Geophysics, vol. 13, no. 1 , p. 57, Tulsa, Okla., 1948.

In various places along the east side of the San Joaquin Valley in California, roughly 30 miles north of Bakersfield, reflected events have been observed that plotted below the known top of the basement. Sufficient well and velocity data are available to locate them quite closely. From what is known of the character of the basement material, it appears unlikely that the rather smoothly plotting, fairly continuous events could originate from within the basement. The conclusion is therefore forced that they must represent multiple events of some sort.Reprinted in full.

10289. Flores Covarrubias, Luis. Interpretaciones geneticas del volcán Parícutin a la luz de la sismología [A genetic interpretation of the origin of the volcano Parícutin in the light of seismological evidence]: Soc. Geol. Mexicana Bull., no. 7, 28 pp., Mexico City, Mexico, 1945.

Seismologic phenomena preceding the birth of the volcano Paricutin are analyzed on the basis of numerous seismograms and records of Mexican observatories. Seismic phenomena observed in different localities in Mexico and in the submarine region of the adjoining portion of the Pacific Ocean were of a diastrophic character; the shocks observed in the immediate vicinity of Parícutin were of a pronounced volcanic nature. The volcano Parícutin was caused by the existence of a magmatic pocket in this region, and the weakening of the walls of this pocket resulted from telluric movements. The diastrophic movements can be explained as a reestablishment of isostatic equilibrium between the lighter masses of the continent and those of the oceanic bottom which were overloaded by accumulated sediments. The book contains reproductions of several seismograms and detailed tables of seismologic records obtained by the Mexican observatories.-S. $\boldsymbol{T} . \boldsymbol{V}$.

10290. Gaby, P. P., and Solari, A. J. Case history of McDonald Island [abstract] : Geophysics, vol. 13, n0. 2, p. 301, Tulsa, Okla., 1948.

The discovery well at McDonald Island was located on the basis of a reflection seismograph survey made in the fall of 1935. The "lead" was picked up in the course of carrying out a routine reconnaissance seismograph progl'am. The area, situated in the Sacramento River delta, California, has a surface cover of silt, peat, and decayed vegeta. tion. Geophysical problems peculiar to that type of region are discussed, una whe we of buried detectors is also briefly mentioned. The seismograph contour map, as prepared prior to arimes or the aiscovers well. is shown and compared with present contour maps based on well correlation. Probable causes for the differences between these two maps are aiscussed.

10291. Gane, P. G. An electrostatic seismometer: Seismol. Soc. Amelica Bull, vol. 38, no. 2, pp. 95-104, Berkeley, Calif., 1948.

Theoly and description are given of sensitive capacity-type seismometers having small-size, eddy-current damping and an unclampeu period of 0.23 second. The voltage output is taken to the grid of a cathodefollower tube within the instrument and is thereafter amplified. The suspension of the mass is of identical character in both vertical- and 
horizontal-component instruments. Records are given of tremol's observed with a magnification of 7,000.-Author's abstract.

10292. Gogoladze, V. G. Dispersion of the Rayleigh waves in a plane-parallel layer of any elastic characteristics [in Russian] : Seismol. Inst. Trudy, no. 119, pp. 39-45, Moscow, 1945.

A study was made of natural vibrations spreading through a planeparallel layer of a medium with given elastic properties and a constant density. The boundary planes are supposed to be free of stresses. It can be shown that the equation for the frequency of natural vibrations can be replaced by two independent ones. One represents the symmetric vibrations, with the middle plane of the layer remaining undeformed. These vibrations can be kinetically divided into progressing Rayleigh waves and a system of standing waves. The other frequency equation represents asymmetric waves with the middle plane of the layer deforming. These waves also can be kinetically divided. Symmetrical progressing. waves propagate faster than the Rayleigh waves in a semispace of the same elastic properties, whereas the velocity of the asymmetric waves is lower than that of the corresponding Rayleigh waves. -S. TI. V.

10293. Gorshkov, G. P. Seismicity of the eastern portion of the Baltic shield [in Russian]: Seismol. Inst. Trudy, no. 119, pp. 86-96, Moscow, 1947.

Seismic characteristics of the eastern part of the Baltic shield are analyzed. The region under study includes the Kola Peninsula (Kol'skiy Poluostrov) in the north, the Karelo-Finnish S. S. R. in the east, and the southern districts of the Leningrad Oblast in R. S. F. S. R. A list of 25 earthquakes that occurred in this territory is given, covering the period from 1728 to the present time. None of these earthquakes had an intensity of more than the fifth degree. Fourteen earthquakes had a pronounced local character, and the remaining 11 had their epicenter's in the northern part of the territory surveyed. The most intense one was that of October 23, 1904. The author suggests that there is a genetic connection between these earthquakes and the postglacial raising of the Fenno-Scandian plateau.-S. T. V.

10294. Grenet, Gaston. Construction d'un ressort pour séismographe type La Coste par retournement, avantage du procédé [Construction of a spring for a seismograph of the La Coste type by inverse winding, advantages of the procedure] : Ann. Géophys., vol. 3, no. 3, p. 313, Paris, 1947.

Vertical seismographs of the Ia Coste type can be astaticized satisfactorily by the use of springs having a zero initial length. In demonstrating the advantages of such springs, J. B. La Coste suggested for. their construction a method of producing an initial tension in them during the winding. The author had such springs prepared and found that they cause brisk movements of the pendulum of the seismograph. He suggests his own method, which gave satisfactory results in the tests.

The procedure is to reverse the winding of a spring of long curvature, made of joined spiral links, by introducing it inside a cylinder of thin steel, carefully pulling one link after another inside out, placing these links successively on the external surface of the cylinder, and then 
removing the inverted spring from the cylinder. The initial tension thus obtained generally has been found sufficient to provide a good spring of the type suggested by La Coste. Specifications of the elinvar spring prepared by the author are given. $-\nabla$. S.

10295. Gutenberg, B. On the layer of relatively low wave velocity at a depth of about 80 kilometers: Seismol. Soc. America Bull., vol. 38, no. 2, pp. 121-148, Berkeley, Calif., 1948.

To shed light on the boundaries of the layer of low velocity situated at an approximate depth of $80^{\circ}$ kilometers, the seismograms recorded at epicentral distances between $4^{\circ}$ and $26^{\circ}$ are investigated, and the traveltime curves for $P$ and $S$ waves are revised. With the aid of these-data the seismograms obtained at Huancayo, Peru, from nearby earthquakes at intermediate depth are.studied to determine the change of wave amplitude with focal depth at a given distance in and near the shadow zone of wave propagation. In the analysis all observations are interpreted on the assumption that below the Mohorovičic discontinuity the velocity of $P$ and $S$ waves decreases, either gradually or abruptly, to a minimum value at a depth of about 80 to 100 kilometers.

The investigation shows that the layer having a low velocity extends downward to a depth of about 150 to 180 kilometers. Still farther down the velocities increase rather rapidly, but Poisson's ratio remains near 0.30 , contrasting with a value of slightly less than 0.25 in the upper layers. Correspondingly, the rigidity remains relatively small, in comparison with the bulk modulus, apparently down to the surface of the core. Other observations are given.-Author's summary, condensed by $\nabla$. S.

10296. Gzelishvili, I. A. Seismic zoning of the city of Tbilissi [in Russian]: Acad. Sci. Georgian S. S. R. Bull., vol. 7, no. 4, pp. 189-193, Tbilissi, 1946.

Seismic waves arriving at the surface of the earth transform their enelgy in accordance with elastic properties of the upper layer at the point of arrival. Observations carried out in Tbilissi during numerous earthquakes in the last 50 years, particularly during the strong earthquake of 1940, show that earthquake shocks can have a very different intensity at points situated relatively near to one another and that certain districts of the city are characterized by shocks of consistently higher intensity. The ratio of acceleration for shocks felt at different points can be as high as $10 ; 1$, or even more. snocles are more intense at the foot of steep slopes or ravines, where a phenomenon analogous to sea surf takes place.

The height of the water table and the depth of the sedimentary layer are important factors. The possibinty of lnndslides following an earthquake is to be considered also. The author emphasizes the necessity or a similar critical study of every important city or industrial site. The location of the more important structures is to be made on the basis of such studies. 'The article includes a map of the city of Tbilissi, subdivided into four seismic districts, and a table of the "seismologicar coefficients" in these districts.-S. T. $V$.

10297. Haalck, H. Über die Grösse der Elastizitätskonstanten und die Fortpflanzungsgeschwindigkeit der elastischen Raumwellen in Innern des Erdkernes [The values of the elastic constants and the velocity of propa- 
gation of the elastic body waves through the earth's core]: Zeitschr. Geophysik, vol. 17, no. 1-2, pp. 29-32, Braunschweig, 1943.

The question of the possibility of the propagation of transverse seismic waves through the earth's core can be aniswered by an analysis of the relations existing between the elastic constants and the atomic energy equations. Analysis shows that transverse waves can propagate through the earth's core and that their velocity ranges from $4 \mathrm{~km}$./sec. at the core boundary to $5 \mathrm{~km}$./ sec. at the core center. The Poisson ratio in the entire region is equal to 0.38 , and the modulus of shear is $1.4 \times 10^{13}$ cgs at the boundary and about $3.5 \times 10^{12} \mathrm{cgs}$ in the center; the latter figures are about double and fourfold, respectively, those for steel. The core of the earth, as far as its elastic properties are concerned, in no case may be considered as a fluid substance.-4uthor's abstract, translated by S.T. V.

10298. Haggerty, P. E., and Olson, R. W. Preliminary results of a study of seismograph sensitivity requirements: Geophysics, vol. 13, no. 1, pp. 86-91, Tulso, Okla., 1948.

The ambient ground-noise level is one of the most important factors in determining sensitivity requirements for a seismograph system. On the basis of 81 measurements in three areas in Texas, the author concludes that for these areas minimum ambient noise levels (in terms of particle velocity) of the order of 3 to 5 millionths of an inch per second are common. Assuming a seismometer sensitivity of 2 volts per inch per second and an oscillograph sensitivity of 5 inches per volt, an overall gain of 20,000 from the output of the seismometer to the input of the oscillograph would be required to give a half-inch peak-to-peak deflection from a noise signal with a peak-to-peak particle velocity of $21 / 2$ millionths of an inch per second.-Authors' abstract. (See also advance abstract in Geophys. Abstracts 131, no. 9569.)

10299. Handley, E. J. Three dimensional control and calculations in seismic dip wolk [abstract]: Geophysics, vol. 13, no. 2, p. 302, Tulsa, Okla., 1948.

The differences between true dip components and apparent dip components are discussed, and their relationship is studied as a function of the magnitude of true dip and of the angle between the directions of the components and the true dip. For dips that are too large it is shown that dip vectors should be used as dip gradients, with lengths inversely proportional to the tangents of their respective dip angles. In this manner the lengths of the vectors become horizontal contour intervals, which is of considerable value in interpretation:- A universal true dip chart is described for determining from two dip components the magnitude and direction of true dip and the length of the gradient vector.

10300. Hansen, R. F. Aplicaciónes de perfiles de reflexión [Application of seismic reflection profiles]: Bol. Inform. Petról., vol. 24, no. 280, pp. 373-391, Buenos Aires, 1947.

A method of multiple seismic reflection profiles especially suited to the geologic conditions of Argentina has been worked out by the author (see Geophys. Abstracts 131, no. 9590), and the application of this method in seismic exploration is described. The computations and field 
measurements in four different regions along the Rio Colorado, Argentina, showed very good agreement. A complicating phenomenon during these tests was the appearance on seismograms of additional waves of very low velocity. The author concludes that this impulse is a transverse wave generated after the reflection of the initial impulse by the common reflecting horizon. The suggestion that this slow wave is a surface wave spreading from the shot point was rejected by the author because of the absence of these impulses in the stations between the shot point and the point of observation. $-S . T . V$.

10301. Hardtwig, Erwin. Über die Wellenausbreitung in einem visco-elastischen Medium [Propagation of waves in a visco-elastic medium]: Zeitschr. Geophysik, vol. 17, no. 1-2, pp. 1-20, Braunschweig, 1943.

Formulas are derived for the velocity of propagation and damping of longitudinal, transverse, and Rayleigh waves spreading through a visco-elastic medium. From these relations it can be inferred that higher frequencies correspond to greater damping and lower velocities of propagation. The damping coefficient of the Rayleigh waves and the velocity of the elastic waves are determined by the same equation. Therefore, in a given medium the elastic displacements are combined with proportional viscous deformations.

Particular solutions corresponding to Rayleigh waves have damping coefficients which are functions of the frequencies, but these frequencies do not vary with the time. Finally the ratio of the vertical component of the Rayleigh wave to the horizontal one was found to be the same as that of the elastic medium. The motion of an element of the medium is no longer an elliptic one.-Author's abstract, translated by S. T: V.

10302. Harris, Sidon. Modern seismic refraction techniques: World Petroleum, vol. 19, no. 3, pp. 72-76, New York, 1948.

Generally the seismic refraction method of exploration is not as effective for delineation of geologic features as the reflection method. However, it succeeds better in areas having hard surface layers, such as the limestone of the Edwards Plateau in western Texas, where the reception of reflections near the shot point is interfered with by a disturbance spreading horizontally. At present refraction techniques have been improved by the utilization of not only the first arrivals of refracted waves, exclusively employed in earlier days, but also of second, third, and later arrivals, and by the development of different patterns of shooting layouts for various problems and phases of exploration. The use of reconnaissance fan shooting, "broadside" continuous-line shooting, and "in-line" continuous shooting is described, and consideration is given to the calculation of the arrival times adjusted to a reference plane and to the determination of the distance to a refracting horizon corrected for ans and for varistions of depth by the plotting of midpoint maps. In

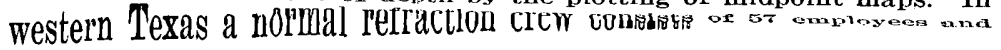
costs about $\$ 40,000$ per month. $-V$. $S$.

10303. Itther, Frank. Discussion on double reflections : Geophysics, vol. 13, no. 1 , pp. 36-40, Tulsa, Okla., 1948.

Double seismic reflections are considered to occur when the energy from a shot is reflected from a flat-lying bed with a high coefficient of reflection and then travels toward the surface where it is reflected down 
again with a change of phase at the base of the low-velocity layer, or at the surface of the ground, or at both. A new wave is thus generated which is similar to the original one initiated by the shot. Such double reflections were found to exist in an oil well in Butte County, California, where there is a relatively flat basalt layer 1,380 to 1,513 feet below the surface. The records made in this well with a seismometer at depths ranging from 3,500 to 7,878 feet and with a geophone at the top of the basalt layer are discussed.- $\boldsymbol{\nabla}$. $\mathrm{S}$.

10304. Jeffreys, Harold. Seismic waves in western and central Europe: Royal Astron. Soc. Monthly Notices, Geophys. Suppl., vol. 5, no. 5, pp. 105-126, London, 1947.

An examination of data on six near earthquakes in western and central Europe indicates that the velocity of $\boldsymbol{P}$ in this region is somewhat higher than in southern Europe and Japan, the difference in $\frac{d t}{d \Delta}$ being about $0^{8} .5 / 1^{\circ}$. The agreement found in a previous comparison is attributed to a possibility that $\boldsymbol{P}$ in the Tauern earthquake was read late owing to its weakness. Apart from the Tauern earthquake, the data on earthquakes considered in previous discussions are consistent with the existence of the difference in velocity. The results are consistent with the observations of the Burton-on-Trent explosion, provided that the foci were shallow, probably within the sedimentary layer. The direct examination of $P g$ and $S g$ at short distances leads to a suggestion of differences of focal depth, but this is contradicted by the comparison of $P$ with $P g$ and of $S$ with $S g$. The outstanding anomaly is that the comparison of $P$ with $P g$ suggests an increase in the allowance for the upper layers for a surface focus, that of $S$ with $S g$ a decrease; the residuals of $S$ and $S g$ show discrepancies at several points from the hypothesis that the errors are purely. random, but their distribution does not suggest any explanation.-Author's abstract.

10305. Kats, A. Z., and Puchkov, S. B. Method of statically equivalent forces applied to the problem of soil vibrations [in Russian]: Seismol. Inst. Trudy, no. 119, pp. 74-82, Moscow, 1947.

Displacements and stresses in an elastic semispace are determined when these are generated by an impulse of short duration or by a disturbing harmonic force. The distribution of the strains and stresses in the semispace is assumed to be the same as that in static loading. Comparison of the computed amplitudes of vibrations at different points with the experimental data obtained by $\mathbf{L}$. Mintrop shows, in the opinion of the authors, an accuracy sufficient for practical purposes.-S. T.V.

10306. Lampson, C. W. Effects of underground explosions, final report: U. S. Nat. Defense Res. Comm. Rept. A-479, 84 pp., March 1946. (Library of Congress, OTS PB Rept. 50860.)

Empirical formulas are given for the peak pressure, impulse, particle velocity, acceleration, and displacement of the medium as functions of the distance, the size of charge, the depth of burial of charge and gauge, and the type of soil. These experimentally derived relationships are correlated with theoretical values obtained with the aid of a dynamic stress-strain curve for soil which is plotted in turn from experimental 
data. Evidence is presented to show that the shape of this curve is typical of a wide variety of soils.

The constants of the equations thus investigated are further correlated with the propagation velocities of seismic waves. The results allow a fairly good prediction of the magnitudes of the various seismic phenomena produced by shallow refraction shooting about a given area. Table, graphs, and sketches are included, and some of the problems are treated in detail in appendixes.-U.S. Dept. Commerce, Office Tech. Serv., Bibliog. Sci. Ind. Repts., vol. 4, no. 4, p. \$09, Washington, D. C., 1947 , condensed by $V . S$.

10307. Leet, L. D. Microseisms in New England-Case history II: Seismol. Soc. America Bull., vol. 38, no. 3, pp. 173-178, Berkeley, Calif., 1948.

Rayleigh waves recorded on the three components of the Harvard station are used to determine the direction of approach of microseisms. In case history $I$ it was observed that microseisms did not radiate exclusively from the center of a well-developed low-pressure storm area and that they remained strong and continued for many hour's after the storm center moved inland over Nova Scotia, northeast of the Harvard station, coming at that time from east, southeast, and south. In case history II a short but distinct microseismic storm ran its course as a cold front advanced to the coast and out over the ocean, but there was no atmospheric storm system within the region covered by the United States Weather Map. It is supposed that microseisms are generated when a pressure gradient of magnitude as yet undefined moves over the crust and, in effect, kneads the surface layer in such a way as to set up vibrations.-A uthor's abstract. (For the first case history see Geophys. Abstracts 131, no. 9575.)

10308. Lester, o. C., Jr. Discussion of multiple reflections: Geophysics, vol. 13, no. 1, pp. 51-54, Tulsa, Okla., 1948.

A field experiment designed for the purpose of recording and identifying sound reflections from the surface of the earth is aescribed: Shot and recording points at varying depths in adjacent deep holes were used. The experiment was performed at several locations in the midcontinent anc gulf coast areas. No evidence of reflections from the ground-air contact was observed.-Author's custract.

10309. Linden, N. A. A catalog of deep-focus earthquakes recorded by the seismic network of the USSR during the years 1909-44 [in Russian] : Seismol. Inst. Trudy, no. 124, 17 pp., Moseow, 1947.

The first seismographs were installed in Russia in 1908. They were the Galitzin instruments, with which regular recording of earthquakes was bosum and eontinued by an increasing number of observatories. Up to 1939 the depth of locus was no xecomad, but since then the coordinates of the hypocenters have been determined and the recordoa correnquakes classified in accordance with the depth of focus. The present çataics contains data on 450 earthquakes the hypocenters of which were deeper than 50 killomelels, The arpek or the byocenter was determined from the difference $p P-P$, using Gutenberg and Richlel'S [ilD]coj so relation $S-P$ determined the epicentral coordinates. The recorded earthquakes are divided into three groups according to the depth of the focus 
and are distributed over eight geographic regions. By far the greatest number falls into the circumpacific belt.-S. T. $\nabla$.

10310. Martinez Barrio,'Domingo. Consideraciónes sobre la historia sísmica de la República Domincana [Deliberations on the seismic history of the Dominican Republic]: Santo Domingo Univ., Inst. Geog. y Geol. Pub. no. 3, 18 pp., Trujillo, Santo Domingo, 1946.

Following the recommendations for inter-American cooperation on seismologic studies proposed by the United States Coast and Geodetic Survey (see Geophys. Abstracts 122, no. 8108), a short history of the seismic activity in the Dominican Republic was compiled. It contains a description of 59 earthquakes which have occurred on the island since 1551. The author estimates that some of these earthquakes reached an intensity of 11th degree. Among the more recent earthquakes, that of January 1897 reached an intensity of 9 th degree. $-S . T . V$.

10311. Martner, S. T. The Dominguez Hills, California, earthquake of June 18, 1944: Seismol. Soc. America Bull., vol. 38, no. 2, pp. 105-119, Berkeley, Calif., 1948.

Two small earthquakes on June 18, 1944, were felt generally in the Los Angeles metropolitan area and did slight damage in the region of Compton and Gardena, Calif., which included collapse of 16 wells in the Rosecrans oil field. Epicenters of these shocks have been determined to be near $33^{\circ} 51^{\prime} \mathrm{N}$. lat. and $118^{\circ} 15^{\prime} \mathrm{W}$. long., with origin times at 4:03:34 p. m. and $7: 06: 06 \mathrm{p}$. m., P. S. T. This occurrence is compared with a previous one in 1941 , and the parallel is so striking that it is strongly suggested that the mechanism was similar in both. Author's summary.

10312. Meisser, Otto. Geophysikalische Untertagemessungen für Nahaufschlüsse und zur Gesteinsüberwachung [Subsurface geophysical measurements for close-range prospecting and observation of rocks], 2 pp., Sept. 1944. (Library of Congress, OTS PB Rept. 19447.)

A study is reported by the Institute of Applied Geophysics at Freiberg, Saxony (Sachsen), on the effects of ground shocks from explosions upon coal mines, quarries, buildings, and especially the sulidity of rocks. These effects were measured by means of a newly constructed electromagnetic instrument, and calculations of the greatest vibration amplitude were made by the author's method described in his textbook: of: geophysics, page 272 (see Geophys. Abstracts 119, no. 7754). No results are reported. $-V$. $S$.

10313: Mintrop, Ludger. Über die Ausbreitung an der Erdoberfläche erzeugter periodischer Bodenschwingungen (Maschinenschwingungen) in die Tiefe [Spreading in the ground of periodic vibrations generated on the earth's surface by machines] : Zeitschr. Geophysik, vol. 18, no. 3-4, pp. 140-149, Braunschweig, 1944.

With the aid of sensitive seismographs, records were made of ground vibrations caused by machines. Seismographs were installed either on the earth's surface or in mines at depths reaching 530 meters. The horizontal distance between the machine and the seismograph: ranged from about 200 meters to several kilometers. The seismograms show 
that the spreading vibrations are neither pure plane nor body vibrations. They propagate chiefly through the upper layer of the ground but are also noticeable at great depths. It is important to note that vibrations caused by a gas motor were discovered on the seismograms of the Wiechert 17-ton pendulum seismograph installed at the Bochum Seismologic Observatory 2 kilometers away. Beating phenomena were discovered on the seismograms also. These facts deserve special attention in the study of microseisms. $-S . T . V$.

10314. Moore, H. C. Seismic comments, Illinois Basin [abstract] : Am. Assoc. Petroleum Geologists Bull., vol. 32, no. 2, p. 304, Tulsa, Okla., 1948.

This is a short generalized discussion of some improvements in seismograph instruments and their use in shooting in the Illinois basin. Mention is made of the importance of interpreting weathering, the need of sufficient control in localizing small structures, and the necessity for cooperation between geologists and geophysicists.

Nagata, Takesi. Measurement of earth-current in the vicinity of Sikano fault. See Geophys. abstract 10346.

10315. Naimark, M. A. Vibrations generated in a thin elastic layer, spread over an elastic semispace, and acted upon by a vertical harmonic concentrated impulse, applied at the free surface of the layer [in Russian] : Seismol. Inst. Trudy, no. 119, pp. 46-62, Moscow, 1947.

The layer is assumed to be thin as compared with the length of the longitudinal or transverse waves spreading through it. The author analyzes the equation which determines the frequency of Rayleigh waves generated on the free surface of a layer supported by an elastic semispace. It can be proved that for a thickness of layer not exceeding a certain value $K$, this frequency equation has one positive and one negative root.

The limiting value of $K$ is determined by the frequency of the disturbing impulse and by the elastic properties of the layer and of the semispace. The amplitudes of the vibrations can be split into two components, one having a velocity identical with that of the longitudinal waves in the semispace and having amplitudes independent of the distance from the disturbing force and another having amplitudes decreasing with the distance. The limiting values of these two vibra. tions on the free surface of the layer are computed.-S. T. $Y$,

10316. Nile, s. W. Seismology in Montana [abstract] : Geol. soc. america sun., vol. 58, no. 12, pt. 2, p. 1268, Baltimore, Md. 1947.

Geologists find ample evidence of the occurrence of earthquakes throughout the mountainous portions or Montana in the geologic past. The first definite report of a quake in the State SCems to pave been in 1869. It is likely that most quakes have occurred in the southwest, between Helena and Virginia City, but a new epicentral region appears to be developing around vasispei in the northwest. The destructive quakes in Helena in 1935 have been followed by many other nonucstructive quakes numbering in the thousands. Strong-motion instruments are in operation in Butte, Bozeman, Helena, and Great Falls. A WoodAnderson sensitive-type instrument also is in operation in Butte. The advisability of installing an instrument at Kalispell is being studied.Condensed by $\boldsymbol{\nabla}$. S. 
10317. Oil. Exploration in the Gulf of Mexico: Vol. 7, no. 7, p. 15, New Orleans, La., 1948.

The organization of seismic reflection prospecting for oil in the Gulf of Mexico is illustrated by the work of the American Exploration Co., which discovered an important oil-bearing structure 12 miles south of Point au Fer, Louisiana, in November 1947. A total personnel of 160 'constitutes the departments of navigation, seismic shooting, and interpretation, the accessory units, and the administrative staff. In operations a navigation crew of 25 men on 5 boats conducts marine position fixing by means of radar, shoran, or other triangulation methods. A similarly constituted shooting crew is charged with the seismic work of detonation and recording. The equipment is serviced by aircraft which can land within a few feet of the objective. Each operation requires about 10 days, with the crews living on boats. The company's total fleet consists of 30 Diesel-powered boats, mostly converted rescue craft. Interpretation of seismic records is made in a special laboratory at the Lafayette headquarters. $-\nabla$. S.

10318. Park, L. B., and McKay, A. E. Geophysical history of Block 31 fleld, Crane County, Texas [abstract] : Oil and Gas Jour., vol. 45, no. 47, p. 126, Tulsa, Okla., 1947.

The Block 31 field, located on University of Texas lands in Crane County, Tex., was a selsmograph discovery resulting from both refraction and reflection surveys over the period from 1937 to 1944 . These surveys are discussed, and maps are presented. The discovery well, The Atlantic Refining Co. 1-A University, Section 33, Block 31 UTL, Crane County, Texas, was completed November 19, 1945. The fleld produces oil from beds of Devonian and Ordovician (Ellenburger)age.

10319. Prata, Emidio. Teoria generale dei sismografi [General theory of the seismograph], 160 pp., 44 figs., 8 tables, Milan, U. Hoepli, 1947.

This book is written to aid seismograph-station operators in the determination of the constants of their instruments. There is also presented some fundamental theory of seismology and some theory and practice relating to the interpretation of seismograms.-Dominion $O b$ servatory, Bibliog. Seismology, no. 2, July-Dec. 1947, p. 41, Ottawa, Ontario, 1948.

10320. Press, Frank, and Ewing, Maurice. A theory of microseisms with geologic applications: Am. Geophys. Union Trans., vol. 29, no. 2, pp. 163-174, Washington, D. C., 1948.

A theory for the origin of microseisms, based on the normal mode of propagation of sound in two layers, is given. It explains the mechanism of transmission of seismic energy from a storm at sea and predicts that periods of 3 to 9 seconds will predominate, depending on the depth of the water and the elastic properties of the bottom: It is shown that this theory can be used to infer elastic properties of the ocean bottom to a depth of the order of several times the depth of the water by a study of the periods of microseisms originating from storms whose positions are known.-Authors' abstract. 
10321. Ramspeck, A. Reine Longitudinal und Transversalwellen in elastischhomogenen Halbraum [Pure longitudinal and transverse waves spreading in an elastic homogeneous semispace]:- Zeitschr. Geophysik, vol. 17, no. 1-2, pp. 21-27, Braunschweig, 1943.

Proof is presented that the equation of purely longitudinal waves, spreading through a homogeneous elastic semispace, has no roots when the source of elastic disturbances is assumed to lie on the boundary of the medium; pure transverse waves can be generated only under very restricted conditions. For such a case only the general wave equation gives solutions. In other words, if the source of impulses lies on the boundary of the semispace, simultaneous generation of longitudinal as well as transverse and surface waves will result.-Author's abstract, translated by S. T. $D$.

10322. Rey Pastor, Alfonso. La comarca sísmica del bajo Segura [The seismic region of the lower Segura River]: Inst. Geog. y Catastral Mem., vol. 16, no. 6, pp. 1-42, Madrid, 1944.

The author defines the seismic region studied as the area affected by the seismic disturbances emanating from foci situated in the valley of the lower Segura River. He analyzes the seismic activity of this region beginning with the earthquake of March 21, 1829, with intensity $10 \frac{1}{2}$, which caused the death of over 1,000 persons. The earthquakes more recent than 1900 were studied on the basis of available seismograms. From the results of this seismologic study the author derives conclusions concerning the geologic structure of the region. They are summarized in the seismotectonic map of the region drawn on a scale of 1: 200,000. Four maps of isoseismic lines of different earthquakes and several graphs and sketches are appended to the study.S. T. V.

10323. Rieber, Frank. It is earlier than you think-A challenge to geophysics [abstract]: Geophysics, vol. 12, no. 3, p. 486, Tulsa, Olela.. 1947.

It is shown that the art of seismic exploration has now reached a critical point, similar to the stage in X-ray development which brought forth the Coolidge tube, or the stage in radio communications which produced the three-electrode vacuum tube and made possible the almost incalculable series of advances that began with the wireless telephone and have culminated with radar. Predictions are made as to the nature and scone of the ndvances which we may shortly expect in the seismic method. It is suggested that the impact of these new techriques on exploration problems should create an "internal frontier," comparable to the external frontier now offered by the continental shelf. Sugcestions are made for cooperation between company management, geolOgISTS, geophyslcists, ana instriwent enesnoera. to expodite the availability of the new techniques.

10324. Rothe, J. P., editor. Comptes rendus des séances de la conférence réunie à Strasbourg du 4 au 8 julllet 1047, Associntion de seismolosie. Union Géodésique et Géophysique Internationale [Transactions of the conference held by the Seismological Association, International Geodetic and Geophysical Union, at Strasbourg on July 4-8, 1947], 89 pp., Strasbourg, France, 1948. 
This conference was held in connection with preparations for the general assembly of the International Geodetic and Geophysical Union proposed for August 1948. The transactions include minutes of the seven sessions and texts of resolutions and reports. $R$. Stonley addressed the conference on international cooperation in seismology ; J. Rothé, on the administration of the International Bureau of Seismology ; H. Labrouste, on seismology at the Institute of the Physics of the Globe in Paris; I. Lehmann, on seismic recording in Europe; and E. Peterschmitt, on the magnitude of seismic disturbances. Other reports were presented. H. Jeffreys read the current "International Seismological summary."-V.S.

10325. Sagoci, H. F. Mail tabakalarda vasatî sismik süratlerin tâyini [Determination of average seismic velocities in sloping beds], with English translation: Tïrkiye Jeoloji Kurumi Bülteni, vol. 1, no. 1, pp. 150-157, Ankara, Turkey, 1947.

A brief summary is given of methods for determining average velocities in seismic prospecting. When reflection records are employed to calculate average velocities in unexplored territory where no well-shot data are available, it is desirable to take into account the step-outs due to the effect of the dip. The author presents theoretical considerations to show that this purpose can be achieved by setting up an asymmetrical split spread and by applying the equation of Gutenberg for dip calculation to two sets of two detectors on each side of the shot point. More reflections can be recorded on a seismogram by means of such an arrangement than is generally done, and it becomes theoretically possible to determine an average velocity-depth function in areas where reflecting beds have appreciable dips.-Author's abstract, amplified by V. S.

10326. Seismological Society of America, Eastern Section. Earthquake Notes, vol. 18, no. 3-4, 16 pp., Washịngton,D. C., 1947.

This issue of the Earthquake Notes, a periodical of the Eastern Section of the Seismological Society of America, contains minutes of the Annual Meeting of June 13-14, 1947, and abstracts of the following papers of general interest: J. V. Atanasoff and others, A new horizontal component seismograph used for project Helgoland; D. L. Bobroff and others, Preliminary seismic results on project Helgoland; V. F. Jennemann, Some measurements of seismic wave velocities from blasts; $D$. Carder, A compound pendulum as a strong motion seismometer; D. Carder and B. Perkins, Structure of the Snake River lava plains near Arco, Idaho, from seismic investigations of large explosions; W. A. Lynch, The envelope method of analysis applied to surface waves; J. T. Wilson, Increase in the period of earthquake surface waves with distance; and of other papers. A list of seismograph manufacturers is given.- $\boldsymbol{V}$. S.

10327. Shoemaker, R. W. Geophysical history of Canal oil field, Kern County, California [abstract]: Oil and Gas. Jour., vol. 45, no. 47, p. 123, Tulsa, Okla., 1947.

The discovery well of the Canal oil field was located with the help of dip reflection seismograph work. Three separate surveys were made before the discovery of the field in 1937. Only the last of these 
surveys indicated structural closure. After the discovery of the fleld an additional survey was made to obtain information on which to base a field-development program.

10328. Shvedchikov, L. K. The twelve-channel seismic station SS-12-46 [in Russian] : Razvedka Nedr, vol. 13, no. 2, pp. 38-44, Moscow, 1947.

A portable twelve-channel seismic station SS-12-46 is in production at the factory "Geophysics" in Moscow beginning with 1947. The apparatus consists of 12 electromagnetic seismographs, 12 amplifiers, an oscillograph with a generator, a mixer, a recorder of the time of explosion, and related equipment. The parts are described and illustrated by diagrams and plates.

Amplification of registration is regulated by a lever from an average value of 30,000 ; all the elements of each amplifier are mounted on a single movable plate to facilitate handling; and anodic intensity is reduced to 45 volts. Stabilization of the oscillographic generator is achieved by a tuning fork made of elinvar steel having a low thermoelastic coefficient. Telephonic connection between the recorder of the time of explosion and the shot point includes a commutator and an amplifier. Other features are indicated. The station can be operated on the ground, on an automobile, or on a boat. $-V$. S.

10329. Sloat, John. Geophysical history of Raisin City field, California [abstract] : Oil and Gas Jour., vol. 45, no. 47, p. 123, Tulsa, Okla., 1947.

The discovery history of Raisin City field is presented because it demonstrates the ability of seismographs to locate low relief structures in areas where closure is present only in certain zones, even when records are of mediocre quality. The seismic map which led to leasing is shown along with detail maps made several years later. Gravimeter maps and maps made from well data are also presented.

10330. Stekol'nikov, I. s. Oscillograph records at velocities approaching the velocity of light: Acad. Sci. U.R.S.S. Comptes Rendus [Doklady], vol. 54, no. 6, pp. 495-408, Moscow. 1946.

The principle of impulse feeding with over-voltage on the cathode and an electronic-optic tube systen were applied by the author in 1943 to the sealed oscillograph with a hot cathode, operated at a normal anode voltage of 6 to 8 kilovolts, to increase its velocity of recording beyond $50,000 \mathrm{~km}$./sec. and approach the velocity of oscillographs with a cold cathode. The theoretical grounds for such approach, the scheme of the lay-out for impulse feeding, and the recording procedure are discussed, and illustrations are given of the records obtained by photographing the screen of a tube of type 2066A. In the experimental tests, two photographs. taken by means of an optical system with an objective lens and a diaphragm, showed that the cathode intensity attained is sufficient for recording at a maximum velocity of $200,000 \mathrm{~km}$./ $\mathrm{sec}_{\text {, }}$ reduced to normal conditions of photography. $-\nabla$. s.

10331. U. S. Naval Technical Mission to Japan. Eaxthquake-resistant construction in Japan: Rept. X-12, 27 pp., San Francisco, Calif., Jan, 1010, (Library of Congress, OTS PB Rept. 48380.)

This report deals with the historical background of shockproof construction, the progress of seismological research, the development of 
design practices and construction methods, steps toward standardization of requirements for the erection of earthquake-resistant buildings, research on building vibration and on earthquake-resistant structures, and present status of shock-resistant design and construction in Japan. A bibliography is appended.-U. S. Dept. Commerce, Office T'ech. Serv., Bibliog. Sci. Ind. Repts., vol. 4, no. 2, p. 11s, Washington, D. C., 19;\%. condensed by V.S.

10332. Vesanen, Eijo. On Alaska earthquakes: Isostat. Inst. Internat. Assoc. Geod. Pub., no. 17, 21 pp., Helsinki, 1947 ; Ann. Acad. Sci. Fenn., Ser. A, III, Geol.-Geog., no. 14, Helsinki, 1947.

The author calculates the focal depths of some Alaskan earthquakes with the aid of $p P, p S$, and $P S c S$ phases, making use of the Helsinki and Upsala records and employing the travel-time tables of Gutenberg and Richter. The computed focal depths of the shocks, corresponding to the time differences $p P-P, p S-S$, and $p S c S-S c S$, agree well with one another; but the data on the deeper shocks are conflicting. The discrepancies apparently can be resolved by assuming that there exists, in addition to the normal $p P$, another corresponding wave reflected on the under surface of the earth's crust.

The records employed for the analysis are found to be characterized by certain distinctive features. They show greater values of $S-P$ than those given in the tables of arerage travel-times and also indicate the existence of regional variations in $S-P$, the values of which, computed as a function of focal depth, are greater than in the tables. Other observations and findings are given. For the uniform calculation of impulses in various records the author used a method based on his classification of seismograms by types.-V. S.

10333. Veshniakov, N. V. A master mechanical oscillator for tests and calibration of vertical seismographs [in Russian]: Seismol. Inst. Trudy, no. 119, pp. 97-101, Moscow, 1947.

An oscillating platform was built in 1932 at the Seismologic Institute of the Russian Academy of Sciences for the study of seismic recorders. The platform is driven by an electric motor with frequencies of vibrations adjustable between 0.2 and 70 hert\%. The amplitude of vibrations of the platform remains the same for all frequencies and can be made equal to $0.05 \pm 0.005$ millimeter. Readings of the amplitudes can be magnified 10,000 times. The oscillator has been in use for many years and found very satisfactory for the purpose. The paper gives a detailed description of the design of the oscillator. $-S . T . V$.

10334. Veshniakov, N. V., and Kirnos, D. P. A modification of Galitzin's scheme for galvanometric registration of the vibrations of the seismograph [in Russian] : Seismol. Inst. Trudy, no. 119, pp. 102-104, Moscow, 1947.

The most reliable and accurate seismograph is the pendulum type equipped with only optical registration of displacements and free from any mechanical attachments amplifying vibration. However, such an instrument has two important limitations: It does not give sufficient magnification, and makes impossible remote registration of displacements. The authors proposed a new scheme of galvanometric registration giving very accurate records and making a magnification up to 4,000 possible. The characteristics of this scheme are as follows: Period 
of vibrations of the pendulum 4 seconds and damping coefficient 0.3 ; period of vibrations of the galvanometer 0.2 second and damping coefficient 60 ; and coefficient of coupling 0.03 . The circuit of the galvanometer has only ohmic resistance. Experiments with a seismograph constructed according to these specifications gave very good results. $-S . T . V$.

10335. Waterman, J. C. Multiple-reflection evidence: Geophysics, vol. 13, no. 1, pp. 41-44, Tulsa, Okla., 1948.

A brief uote describes multiple seismic reflections observed in an area on the east side of the San Joaquin Valley, California. The local seismograms show the basement complex to be a good reflecting horizon at a depth of about 2,750 feet and this is confirmed by well data. Beyond the basement reflection they indicate four or five events which appear to recur at regular intervals and which may be, at least in part, multiple reflections between the basement and the strong local sedimentary reflecting horizon.- $-\mathrm{V}$.

10336. Waters, K. H. The geometry of steep dip reflection work with some implications of importance in interpretation [abstract]: Geophysics, vol. 12, no. 3, p. 502, Tulsa, Okla., 1947.

By the method of differential geometry some conditions are established whereby the reflecting point for a given subsurface structure and a given shot point may be found. This is illustrated by formalized structures which can be represented by an algebraic equation. An extension of the method, in which the algebraic analysis is replaced by graphic methods, leads to a procedure by which the reflecting point for a given shot point can be found whenevel a contour map of the subsurface horizon is given. The possibility of "homostratic" reflections (that is, more than one reflection from the same horizon) is shown.

10337. Weatherby, B. B. Effects of subsurface detonations in earth, part 2: U. S. Office Sci. Res. and Devel. Rept. 3036, 44 pp., New York, Dec. 1943. (Library of Congress, OTS PB Rept. 50855.)

A description is given of the new SG-3 detectol's of a moving-coil type which were developed for measuring horizontal and reitical components of particle velocities in earth waves. Ther are suitable for the waves genelated by subsurface detonations causing lirge displacements and high accelerations. Some 60 shots ranging in chalge from 2.5 pounds to 515 pounds of dynamite were recorded for tests, and a study was made of wave characteristics. Graphs and formulas show the resulting valiation of the period and the change of the first maximum of the velocity, the acceleration, and displacement occurring with an increase in the weight and the distance of the charge.

The findings indicate that accelerations and frequencies were much higher in the limestone than in loarb. when vertical detectors were buried at different depths, no significant variations in the wave form were observed. Moreover, when the depths of the shots were increased, the measured velocity and associated acceleration and displacement at the sulface l'elldillel Virtually constave. An no accerse in these values occurred in spite of an appreciable increase in path length, it follows that, within the range of 24 feet of depth for the 40-pound charges used, 
the deeper shots were more effective wave generators than the shallower shots. Tables, schematic drawings, graphs, and photographs of records are given with the discussion.-Author's abstract, condensed by V. S.

10338. Wilson, J. T., and Baykal, Orhan. Crustal structure of the North Atlantic basin as determined from Rayleigh-wave dispersion: Seismol. Soc. America Bull., vol. 38, no. 1, pp. 41-53, Berkeley, Calif., 1948.

Records of the earthquake of November 25, 1941, were used for a seismic determination of the crustal structure of the North Atlantic basin by the method of dispersion of surface waves of the Rayleigh type. The necessary arrival times and wave periods were measured on the seismograms from the stations at Weston, Fordham, St. Louis, Huancayo, Mount Wilson, and Berkeley. The techniques of the dispersion method are discussed, the dispersion data obtained are tabulated and plotted in curves, the theoretical dispersion curves are deduced for a homogeneous single-layer crustal structure overlying a homogeneous semi-infinite medium, and the observed and theoretical dispersion results are compared. It was found that the near-surface material under the Atlantic basin is characterized by a considerably higher velocity of wave propagation than the material at an equal depth under the American Continent. As a check, the effects of wave refraction on the computed relocities were calculated and were found generally negligible.-V. S.

\section{ELECTRICAL METHODS}

10339. Aquilina Carmelo. Considerazioni teoriche sulla "curva indicatrice" nei metodi di prospezione elettromagnetica ['Theoretical considerations on the use of indicatrix curve in prospecting by electromagnetic methods] : Riv. Geominer., vol, 8, no 1, pp. 17-30, Milan, 1947.

The author reviews J. J. Jakosky's conclusions on the use of: the indicatrix curve and develops a general theory for the interpretation of the field results obtained from the dip method survers using a vertical loop energized by a high-frequency alternating current. Equations of index curves for several practical cases are derived and the results are compared with the field measurements from Dundas Cuni region, Tasmania.-Author's English abstract, edited by S. T. V.

10340. Belluigi, Arnoldo. Fondamenti di una nuova prospezione geoelettrica [Fundamentals of a new geoelectric method of prospecting] : Facolta Ingegneria Cagliari Pub., no. 15, 16 pp., Cagliari, Italy, 1947.

The greatest obstacle to the extension of the geoelectric methods of prospecting is the screening effect of orerlying formations if these are conductors. The author presents a method of reducing this effect in the case of galvanic methods of prospecting by an appropriate modification of the measurements, and in the case of "inductive prospecting" by the use of a new type of inductor which eliminates the screening effect. Further it is shown that induced currents can be produced at different depths through the use of a new principle of exploration called by the author "the electromagnetic projector." The paper contains six maps of the magnetic fields generated in the different cases discussed above. $-S . T . V$. 
10341. Breusse, J. J. Applications de la géophysique aux recherches de mines métalliques [The application of geophysics to prospecting for metalliferous deposits] : Chronique Mines Coloniales, Bur. Etudes Géol. Minières Coloniales, vol. 16, no. 141, p. 72, Paris, 1948.

This is an address before the Chambre Syndicale des Mines Metalliques discussing geophysical prospecting for metals which the author considers a more difficult problem than that of prospecting for oil.

The author states that the method of spontaneous polarization gives reliable results in cases of electrically conductive bodies, but that this method cannot be applied to carbonates, galena, or blende. In general, good results are obtainable only in the case of an unbroken distribution of ores. The limiting depth of successful exploration by this method is about 50 meters. The method of the charged body is applicable in cases where an outcrop of the ore body can be reached. It then becomes possible to get a general idea about the shape and the dimensions of the ore body.

In the opinion of the author, the use of the resistivity method yields the best results, especially if it is applied in a detailed survey after preliminary investigation by the method of spontaneous polarization. The resistivity method can also be applied in the investigations of regions containing ores of low natural potentials.

Magnetic prospecting is recommended in searching for iron ores and for distinguishing between magnetic iron ores and pyrrhotite, when this method is combined with the method of spontaneous polarization.-S. T. $V$.

10342. Čechura, F. Geoelektricke zjišt'ování zlomů v kůře zemské odporovým měrenim [Determination of geologic faults by the resistivity method]: věstník Státního geologického ústavu Ceskoslovenské Republiky, vol. 22, pp. 271-276, Prague, 1947.

This study presents an application of geophysical methods to the solution of geologic problems, specifically an application of the resistivity method to the determination of faults in a geologic formation. Using the wenner electrode arrangement and varying the spacing a peculiar kink in the resistivity curves is obtained which makes possible the determination of the position and dip or the fault.-S. T. V.

10343. Iassen, L. Velocity of electromagnctic waves: Nature, vol. 159, pp. 611-612, London, May 3, 1947.

A description is given of the method rov measuring the velocity of electromagnetic waves on the basis of the resonance caused by a short guide wave closed on both ends. The velocity in vacuo was found to be of the order of $(200,793 \pm 9) \mathrm{km}$./sec.-Cent. Nat. Rech. sci., Bull. Anal., vol. 8, no. 9, pt. 1, p. 202R, Paris, 1047, transiated by V. S.

10344. Korzhev, A. A. Thyratron circuit-breaker [in Russian]: Prikiadisaia Geofizika, no. 2, pp. 52-56, Moscow, 1945.

In prospecting by the electrical resistivity method it becomes necessary to use currents of great intensity and direct current generators instead of storage batteries. To facilitate measurements and to assure greater accuracy the author proposes a special circuit with two thyratron current-breakers, two steadying resistances, and an automatic cut-out. The circuit was tried out successfully in field work. The 
article contains the wiring diagram and a description of the entire installation. $-S . T . V$.

10345. Muller, S. W. Permafrost or permanently frozen ground and related engineering problems, 231 pp., 87 figs., Ann Arbor, Mich., J. W. Edwards, Inc., 1947.

Research connected with construction work in permanently frozen ground is outlined on the basis of the writings of Sumgin, Tsytovich, Bykov, Tolstikhin, Lukashevich, and other investigators, and the results directly applicable in various engineering problems are presented. Among the techniques useful for the study of permafrost characteristics, brief consideration is given to measurements of electrical resistivity. This method appears to be most effective in areas where permafrost has an approximate thickness of 60 meters or less, and where its temperature is not lower than $-1.5^{\circ} \mathrm{C}$. For areas of greater thickness and lower temperatures the results have only qualitative significance. The electrical resistivity generally is found to depend on the frozen ground's composition, porosity, moisture content, concentration of dissolved salts, and temperature. As the conductivity is electrolytic rather than metallic, the lower the temperature the greater the amount of electrolyte passing into the solid state, and the higher the ground's specific resistivity. - V. S.

10346. Nagata, Takesi. Measurement of earth-current in the vicinity of Sikano fault: Imp. Acad. Japan Proc., vol. 20, no. 2, pp. 81-85, Tokyo, 1944 (?)

The variation of the earth's electrical field in the vicinity of the Sikano fault in the prefecture of Tottori, Japan, was observed for 3 weeks after the earthquake of September 10, 1943, which produced this fault. Observations were made along two traverses, one parallel to the fault line and the other at an angle of $73^{\circ}$ to this line, with the use of an electrode in the form of a spiral lead tube placed in the ground at a depth of 1.5 meters.

The results showed that the anisotropy of the earth current was exceedingly large, the electric conductivity in the $\mathrm{N} .86 .5^{\circ} \mathrm{W}$. direction having been almost 14 times that in the $\mathrm{N}$. $3.5^{\circ} \mathrm{E}$. direction, and that anomalous changes in the earth's electric field sometimes appeared even in advance of the occurrence of a group of fairly intense earthquakes. The variation of the earth's electric field had no definite relation to the variation of the geomagnetic field observed simultaneously at Simoda on the Izu Peninsula. These and other findings are taken to indicate that there was a local disturbance in the electric field in the vicinity of the new fault, and some possible causes are discussed.V. S.

10347. Petsch, B. O. A geophysical study of the Milbank granite area: South Dakota Geol. Survey, Rept. Inv. 60, 18 pp., Vermillion, S. Dak., Univ. S. Dak., April 1948.

To aid expansion of operations by granite quarries in the Milbank area, South Dakota, an electrical resistivity survey was made in $\mathbf{1 0 4 7}$ for determining the local depth to the granite bedrock. Geologically the Milbank granite appears to be an extensive subsurface island surrounded and overlain by marine rocks which, in turn, are covered by glacial drift. 
The electrical soundings were carried out with a Heiland resistance gradiometer at 145 stations over an area of 3 square miles. The dryness of the ground prevented readable potentials in the southwestern highland section underlain with gravels.

The results of the survey are interpreted quantitatively by an application of the Wetzel-McMurry standard curves to three layers and of the formulas and curves of I. Roman and G. Tagg to two layers. Findings, embodied in a contour map of the granite subsurface relief plotted with reference to sea level, indicate the existence of two granitic ridges and of areas of granite bedrock sometimes at depths of 100 feet under the ground. $-V$. S.

10348. Potapenko, G. On the penetration of alternating electrical currents into the ground [abstract]: Geophysies, vol. 13, no. 2, p. 301, Tulsa, Okla., 1948.

The theory of penetration of alternating electric current into the cround is relatively simple if limited to the case of two horizontal beds, provided the spread between the current-carrying electrodes is much larger than the depth to the boundary plane between the beds. In this simple case the penetration depends mainly upon the frequency $\nu$ of current and upon the ratio of the resistivity $\rho$ of the lower bed to the resistivity $\rho$ o of the upper bed.

Using the data available, a diagram has been constructed which indicates for each $\nu$ and each $\left(\rho-\rho^{\prime}\right) /\left(\rho+\rho_{0}\right)$ the two critical depth values $D_{m}$ and $D_{n}$, with $\left(D_{m}<D_{n}\right)$, defined as follows. When the depth $h$ to the boundary plane is smaller than $D_{m}$, the skin effect is negligible, the lower bed can be easily detected, and $h$ can be accurately determined. When $D_{m}<h<D_{n}$, the lower bed can be detected but $h$ cannot at present be determined accurately due to shortcomings of the theory. Finally, when $h<D_{n}$, the skin effect is so large that the lower bed cannot be detected.

Therefore, $D_{n}$ may be taken as a measure of the depth of penetration, that is, the maximum depth attainable in resistivity prospecting. $D_{m}$, on the other hand, must be used at present in place of $D_{n}$ when quantitative interpretation is needed. In the case of many horizontal layers, one of which may be chosen as a markel bed, the depth of penetration may be estimated by considering the layer's above the marker as a single layer of an equivalent resistivity $\rho^{\prime}$. The value of $\rho^{\prime}$ may be approximately calculaterl by using a formula suggested by Hummel fol the case of electric sounding.

10349. Ramachandra Rao, M. B. Geophysical survey report on the Sowanahalli copper ore block, Nanjangud Taluk, Mysole district: Mysore Geol. Dept. Records, vol. 43, pp. 31-46, Bangalore, India, 1946.

Electrical prospecting by the author in 1943 covered some 50 acres of glound in the Mysore lilstrict, India, where occirrence of manchite had suggested the possible presence of copper ores in the region. Measulements of self-potential and of electric resistivity were made along 20 lines totaling 21,000 feet and involving 1,620 determinations. The survey failed to yield any indications of copper ores in the area. This is attributed to the fact that the ore bodies in the area are completely oxidized and, being of malachite and cuprite, are electrically nonconductive. Furthermore the ground is covered by a thick cap of moist clayey soil, which produces a screening effect.-S. T.V. 
10350. Semenov, A. S. Combined profiling applied to conducting veins [in Russian] : Razvedka Nedr, vol. 13, no. 6, pp. 45-49, Moscow, 1947.

- A comparison is made between the exploratory advantages of symmetrical electrode arrangements parallel and perpendicular to the strike of a conducting subsurface body, investigated by V. A. Shpak, and those of asymmetrical arrangements perpendicular to the strike, tested by the author. For optimum results a new system of "combined profiling," consisting in the use of converging asymmetrical arrangements, is advanced on the basis of experiments with rectangular metal plates suspended in water.

The results of the experiments showed that when two converging asymmetrical electrode configurations are oriented perpendicular to a thin vertical conducting layer, they give mutually inverted profile curves, so that the maximum of one curve corresponds to the minimum of the other, the curves' intersection represents the location of the layer, and their divergence and other characteristics indicate the extent and thickness of the layer. The test curves, obtained from experimental valiations in the immersion depth, size, and inclination angle of the plates and in the spacing of the electrodes, are presented and are analyzed with reference to the underlying anomalies. $-V$. S.

\section{RADIOACTIVE METHODS}

10351. Hess, V. F. Surplus gamma-radiation from granite: Phys. Rev., vol. 72, no. 9-10, pp. 609-614, Lancaster, Pa., 1947.

Ionization produced by gamma rays from granite samples has been found to be approximately twice that calculated from their uranium, thorium, and potassium contents. Neither production of photons in transmutations induced by alpha rays in the granite, nor spontaneous fission of uranium and thorium by cosmic rays or neutrons could account for the effect. Experiments with dunite containing negligible amounts of uranium, thorium, and potassium showed complete absence of radiation. It is concluded that a new penetrating radiation is given off by granite.-L. J. J., British Abstracts, A.1-9, p. 38, London, Feb. 1948.

10352. Landsverk, 0. G. A survey meter for the measurement of alpha, beta, and gamma rays, fast and slow neutrons: U. S. Atom. Energy Comm., MDDC-396, 16 pp., Washington, D. C., May 1946. (Library of Congress, OTS PB Rept. 52743.)

A new quartz-fiber type electrometer, called the " $L$ and $R$ Plurad," has been developed for radioactivity surveys. It can be used for measuring alpha, beta, and gamma rays and is suitable for both fast and slow neutrons. A description is given, illustrated by photographs and diagrams.-U.S. Dept. Commerce, Office Tech. Serv., Bibliog. Sci. Ind. Repts., vol. 4, no. 3, p. 221, Washington, D. C., 1947, revised by V. S.

10853. Luco Muro, F. P. de. Anomalías radioactivas del aire telúrico sobre yacimientos de asfaltitas [Anomalies in radioactivity of the atmosphere over asphaltic deposits] : Bol. Inform. Petrol., vol. 24, no. 277, pp. 161-163, Buenos Aires, 1947.

Exploring asphaltic deposits in Argentina, especially in the province of Mendoza and to the north of the city of Neuquen, the author found a relatively high radon content in the atmosphere over such deposits. An 
increase of the radon content was observed also in samples taken over faults in the subsoil. Consequently anomalies in the radon content are indicative of asphaltic deposits in the region and of certain features of its geologic structure. The measuring apparatus was of the Ambronn type; samples of the air were taken through a pipe driven into the ground to avoid interference from the humidity of the upper soil.S. T. V.

10354. Montgomery, C. G., and Montgomery, D. D. Time lags in Geiger-Mueller counter discharges: Rev. Sci. Instruments, vol. 18, no. 6, pp. 411-414, Lancaster, Pa., 1947.

The probability of the occurrence of a time lag in a counter discharge is expressed in terms of the probability of capture of an electron by an oxygen molecule. The capture probability is shown to be independent of the number of electrons produced and to correspond to a value for the capture cross section in agreement with direct determinations.Authors' abstract.

10355. Nichkevich, O. N. Radioactivity of the connate waters of the Borislav oil fields [in Ukrainian] : Acad. Sci. Ukrainian S. S: R. Repts., no. 1-2, pp. 9-15, Moscow, 1945.

Samples of water were taken from several oil wells producing from seven different oil horizons in the Borislav oil fields and tested for content of radioactive substances. The determination of radium content was made by the vacuum method with a Wulff bifilar electrometer. The sensitivity of the installation used was $1 \times 10^{-11} \mathrm{gm}$. of radium. The determination of the thorium $X$ content was carried out by the Baranov method with the sensitivity of the apparatus equal to $1 \times 10^{-5} \mathrm{gm}$. of thorium. Bromine content was determined by the Lange method.

Every sample tested showed the presence of radium, thorium, and bromime. The greatest content of radium was $7.81 \times 10^{-10} \mathrm{gm}$. per liter, of thorium $24.31 \times 10^{-5} \mathrm{gm}$. per liter, and of bromine $0.916 \mathrm{gm}$. per liter.S. $T \cdot V$.

10356. Nogami, H. H., and Hulley, P. M. The absorption factor in counting alpha rays from thick mineral sources: Am. Geophys, Union Trans., vol. 29, no. 3, pp. 335-340, Washington, D. C., 1948.

The total measured alpha emission from a thick layer of powdered sample of each of a number of minel'als and rocks of known uranium and thorium content has been found to agree well with the emission nredicted for the samples on the basis of a source absorption proportional to the square root of the atomic weight of the elements comprising the source. Thlts, the measurement of combined uranium and thorium in most minerals and rocks may be made by the simple count of alpha rays above a thick layer of the sample, and the application

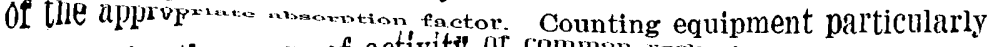
suitable for the range of activity of common "escm sa described which will count all of the alphas emitted above the plane of the source hal'ing a residual range greater than a specified amount, thus requiring no calibratịn.-Authorṣ' abstract. 
10357. Solomon, A. K., and Estes, H. D. The measurement of radioactivity in solution: Rev. Scl. Instruments, vol. 19, no. 1, pp. 47-50, Lancaster, Pa., 1948.

The conditions for measuring radioactivity in solution have been examined, and recommendations are given for optimum counting effciency. The relative sensitivity of a dip counter has been found to compare favorably with other methods of counting, provided the beta radiation being measured has an energy of about $1 \mathrm{mev}$ or higher.-Authors' abstract.

10358. Trudu, Renato. I contatori Geiger e Müller ed il lore impiego nella indagine geofisica [Geiger-Müller counters and their use in geophysical exploration] : Riv. Geominer, vol. 7, no. 2, pp. 15-24, Milan, 1947.

This article explains the basic principles of the operation of GeigerMüller counters, describes their characteristics, and gives detailed information concerning structural elements of these instruments, including a high-voltage generator for energizing the counter. Various methods of amplification and selection of appropriate resistances are discussed. A detailed description is given of a portable counter, adapted for field work. Also an installation is discussed for remote reading of GeigerMüller counters, important in well logging. A chapter is devoted to data on the radioactive properties of different minerals. $-S$. T. $\boldsymbol{\nabla}$.

10359. Winston, W. B. Uranium: California Jour. Mines and Geol., vol. 44, no. 1, pp. 73-92, San Francisco, Calif., 1948.

This report on properties of uranium, identification of uranium minerals and their occurence also contains information on prospecting for uranium ores. All uranium ores are irregularly distributed in relatively small deposits, which makes prospecting an important factor even after commercial development has begun. In prospecting for and delineating ore bodies all the usual methods may be employed, but particularly important for the prospector for uranium ores are the Geiger-Müller counters. Certain types of instruments have been adapted for field use. The instrument is capable of detecting not only a pitchblende or shoot in a shear zone, but also a mildly radioactive "host rock" at a considerable distance from the ore body. An electroscope yields surprisingly accurate results but gives no indication whether the ore specimen contains uranium, thorium, or both.-S. T. V.

\section{GEOTHERMAL METHODS}

10360. Andreae, Charles. Hundert Jahre Schweizerischer Tunnelbau [A hundred years of Swiss tunnel building], 46 pp., Naturf. Gesell. Zürich, Switzerland, 1948.

A short history of the tunnel building in Switzerland containing a discussion of geologic questions related to this branch of engineering is presented. Of interest to geophysicists is the chapter on geothermal observations which were made during the construction of long tunnels such as the Simplon, where the temperature in the tunnel was more than $10^{\circ} \mathrm{C}$. higher than the expected value based on preliminary compu- 
tations. Theoretical investigations made by different authors on the heat flow through the rocks and the resulting thermal gradients in the valleys and below the mountain ridges are cited.-S. T. V.

10361. Coster, H. P. Terrestrial heat flow in Persia: Royal Astron. Soc. Monthly Notices, Geophys. Suppl., vol. 5, no. 5, pp. 131-145, London, 1947.

Measurements are described which permit the determination of the terrestrial heat flow in 18 boreholes in southwest Persia. The variations of heat flow that are found to exist can be explained to a great extent by the geologic structure. The influence of topographic irregularities, climatic changes, recent tectonic movements, and denudation upon the heat flow is discussed. If we assume that the climate became warmer in the last 10,000 years, this may have reduced the terrestrial heat flow by at most $0.31 \times 10^{-6} \mathrm{cal} . / \mathrm{cm}^{2}$ sec. The other agencies discussed have only a small influence upon the observed beat flow. The mean heat flow in 18 bore holes is $0.87 \times 10^{-6} \mathrm{cal} . / \mathrm{cm}^{2}$ sec. This is a low value, but it agrees rather well with the recently determined values: of $0.98 \times 10^{-6}$ in Great Britain and $1.16 \times 10^{-8}$ in South Africa.Author's abstract.

10362. Jahn, A. Badania nad strukturą i temperaturą gleb w Grenlandiĩ zachodniej [Research on the structure and temperature of soils in western Greenland] : Acad. Polonaise Sci. et Let. Bull. Internat., Sér. Sci. Math., 1940-46, pp. 50-59, Cracow, Poland, 1948.

As a member of the 1937 Polish expedition to western Greenland, the author examined geomorphologically the tundra region in the foreground of the Greenland inland ice near the fiord Arfersiorfik, paying special attention to structural soil markings characteristic of polar areas. The investigation included systematic measurements of temperature near the surface in sandy soils with vegetation and in silt fields of the tundra craters, made with soil thermometers and a remote recording thermograph at depths to 40 centimeters.

It was found that the large oscillations of temperature observed on the surface diminish rapidly. in the deeper layers; that variations in the speed of thawing with locality are due to a variable heat convection in soils depending on their mineral composition, porosity, dampness, and vegetation; and that a lag exists during the year in the process of thawing because its speed diminishes in summer with the inclease in thickness of the layer subject to thawing. $-\nabla$. $s$.

\section{GEOCHEMICAL METHODS}

10303. Fansett, G. R. Field tests for the common metals: Arizona Univ. Bull., vol. 19, no. 1, 56 pp., Tucson, Ariz., 1948.

This pamphlet has been compiled as a text to be used in the Arizona Bureau of Mines' extension lectures on "Field tests for metals." Many of the people attending these programs, especially those most interested, have had very little, if any, technical training in mineralogy, chemistry, and allied sciences. For that reason this pamphlet has been written in as simple and nontechnical language as the subject permits. Yet the directions given are full enough so that anyone should be able to understand how to do the work. 
The method of procedure suggested for beginners is tirst to practice each specific test for each metal on a mineral that is positively known to contain that metal, or to practice the tests on a piece of that metal. This practice should be continued until the beginner becomes thoroughly familiar with the various tests for that metal as well as those for other metals. These tests can then be applied to ores of unknown metallic contents if it is desired to determine whether a certain metal is present.-Preface.

10364. Hawkes, H. E. Annotated bibliography of papers on geochemical prospecting for ores: U. S. Geol. Survey Circ. 28,6 pp., Washington, D. C., Aug. 1948.

This bibliography is a compilation of references dealing with methods of prospecting for ore deposits by chemical studies of soil, vegetation, and natural water. A total of 48 papers are listed, of which 20 are Russian, 14 Scandinavian, and 10 American. Short annotations are added to indicate the general content of the papers, and references are given where abstracts have been published in one or more of the standard American abstract series. The Russian papers listed in the bibliography deal principally with soil sampling and analysis which has been a standard prospecting technique with Soviet exploration parties since .1935. A few Russian papers describe vegetation and water studies. Most of the Scandinavian work has been on plant sampling and analysis, although recently some research has been directed toward the relation of soils to buried mineral deposits. Most of the American papers are general discussions of the results of the Scandinavian work.

The bibliographic list includes no references published later than January 1, 1948. Subsequent publications will be included in the Geochemical Prospecting section of the Geophysical Abstracts series of the U. S. Geological Survey.-Abstract prepared by the author for this report.

10365. Miholič, Stanko. Ore deposits and geologic age: Econ. Geology, vol. 42, no. 8, pp. 713-720, Lancaster, Pa., 1947.

The content of heavy metals in mineral waters differs according to the age of faults with which the occurrence of the mineral water is connected. As available data are scarce, this regularity has been investigated for two regions in detail and found in agreement with the proposed hypothesis. The occurrence of ore deposits shows a similar, although not so clear, regularity. The reasons for this regularity are to be looked for first in the more advanced erosion of the older strata thus exposing deeper parts of the faults, and second in the decrease of the geothermal gradient with time owing to the decrease of radioactive matter in the earth's crust.-Author's abstract.

10366. Rosenquist, A. M., and Vogt, T. Geokjemisk og geobotanisk malmleting5, Bestemmelse av kobber i vannprøver, Analysemetoden [Geochemical and geobotanical ore prospecting-5, Determination of copper in natural waters, the analytic method ] : Kon. Norske Vidensk. Selsk. Forh. 1942, vol. 15, no. 22, pp. 83-86, Trondheim, Norway, 1943.

A description is given of the method of Hahn and Leimbach for the determination of very small quantities of copper. The copper acts catalyti- 
cally on the reduction of $\mathrm{Fe}$ (III) with $\mathrm{Na}_{2} \mathrm{~S}_{2} \mathrm{O}_{3}$, rhodanide being used as indicator. The standard solutions employed are listed, and the data of a numerical example are tabulated and plotted in a curve for adjustment. This method was used on natural waters in the Røros district in the summer of 1941 as a technique for chemical ore prospecting.Authors' abstract.

10367. Subbota, M. I. Problems of field procedure in oil exploration by the bacteriological method [in Russian] : Razvedka Nedr, vol. 13, no. 3, pp. 20-24, Moscow, 1947.

To determine the effects of the seasons of the year on the efficacy of the bacteriological method of oil exploration, a test was made in the area of the Mashtaginsk oil deposit near Baku, U. S. S. R. Each month, from July 1945 through May 1946, soil samples of 100 to 150 grams were collected from a depth of $\mathbf{1 . 5}$ meters at intervals of 100 meters over two parallel traverses. In all, about 700 samples were analyzed on an average of 1 to 3 months after sampling for the presence chiefly of methane-oxidizing and propane-oxidizing bacteria.

The results showed that propane-oxidizing bacteria were absent at all seasons of the year and that the number of methane-oxidizing bacteria declined sharply through August to November when the soil humidity decreased, though the temperature and methane content in the ground changed little. During the winter the number of methane-oxidizing bacteria remained small, apparently because of low temperature. It is concluded that in the warm and dry climate of the Apsheron Peninsula (Apsheronskiy Poluostrov) soil samples taken from shallow depths may give unrepresentative bacteriological results during the seasons destructive to bacteria. $-\nabla$. $S$.

10368. Vogt, T., and Braadlie, O. Geokjemisk og geobotanisk malmleting-4, Plantevekst og jordbunn ved Rørosmalmene [Geochemical and geobotanical ore prospecting-4, Vegetation and soil at the ore deposits of Røros] : Kon. Norske Vidensk. Selsk. Forh. 1942, vol. 15, no. 7, pp. 25-28, Trondheim, Norway, 1943.

Some analyses of ore-poisoned soil from $\mathbf{R} \phi$ ros are presented in a table. The soil samples are taken chiefly.near the roots of different plant species growing seattered on the polsoned soil and also from the ground with normal vegetation in the immediate neighborhood. The weathering ore is composed of pyrrhotite, chalcopyrite, some sphalerite, and other minerals. The decisive poisonous agent in the soil probably was copper, possibly also $\mathrm{FeSO}_{4}$. The plant species, arranged according to the copper content in the soil, are tabulated.-Authors' abstract.

10369. Vogt, T., and Rosenquist, A. M. · Geokjemisk og geobotanisk malmleting6, Bestemmelse av kobber i vannprøver fra Rørosfeltet [Geochemical and geobotanical ore prospecting-6, Determination of copper in natural

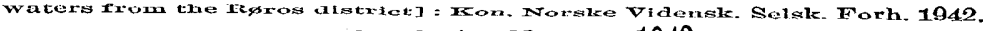
vol. 15, no. 23, pp. 87-90, Trondheim, Norway, 1943.

As an experiment we have tried a method of geochemical ore prospect. ing consisting in the determination of small quantities of copper in natural waters from brooklets and other aqueous sources by the procedure described in communication 5 of this series. The results, which 
are tabulated, can be differentiated into the following groups: Samples excessively colored by humus substances and unsuitable for analysis, samples free from copper within limits of error, samples with little copper derived from decaying plant remains and from soil, samples with copper derived from hidden copper ore, and samples with copper collected from copper mines and pits.-Authors' abstract, condensed by V.S. (For communication 5 of this series see Geophys. abstract 10366.).

\section{DRILL-HOLE METHODS}

10370. Abdurashinov, S. A. Refractive index of connate waters from the oil fields of Kala in the Caucasus [in Russian] : Acad. Sci. Azerbaydzhan S. S. R., vol. 2, no. 9, pp. 367-368, Baku, U. S. S. R., 1946.

Thirty-six samples of water were taken from different horizons of the oil fields of Kala and refractive indices of these were determined with the aid of the Abbe refractometer. The water was kept at $20^{\circ} \mathrm{C}$. during the measurements, and the results show that the refractive index of samples taken from a depth of 712 meters is 1.3650, that of the samples from 1,080 meters is 1.3570 , and that of the samples from 2,105 meters is 1.3375. Thus the refractive index varies amost linearly with depth.

This property is important in identification of horizons in oil wells. For the measurement of the refractive index only a few drops of water are needed.-S. T. $V$.

10371. Agricultural and Mechanical College of Texas. Well logging methods conference : Texas Agr. Mech. Coll. Bull. 93, 171 pp., College Station, Tex., 1946.

This symposium consists of 12 lectures delivered at the Well Logging Methods Conference held by the Department of Petroleum Engineers, A. \& M. College of Texas, March 11-15, 1946. The lectures covered geochemical logging, electrical logging, radioactivity logging, temperature logging, caliper logging, mechanical logging, spontaneous potential dipmeter surveys, and electric pilot applications. In an introductory talk H. Guyod, in charge of the conference, pointed out that each method permits the solution of only a limited number of problems but that an adequate combination of them frequently can supply all desired data. He presented a tabulation of logging methods according to type, use, and the property investigated, and showed statistical curves on the cost of logging and the progress and cost of drilling. A comprehensive bibliography is given in an appendix.-V. S. (See also Geophys. Abstracts 126 , no. 8744 .)

10372. Al'pin, L. M. Method of expanding electrodes [in Russian] : Prikladnaia Geofizika, no. 2, pp. 29-40, Moscow, 1945.

Electrical well logging and the interpretation of the results are discussed for a case in which potential electrodes MN are both fixed symmetrically near the middle point, and the third electrode $\mathrm{A}$ is placed at a great distance and subsequently moved to infinity. This makes one reference ratio equal to unity. By this change in the position of the electrodes the Hummel's curve, with the ratio two, can be transformed into the Schlumberger curve, characterized by the ratio unity.

Analyzing the above case, the author compares the computed theoretical curves of apparent resistivity with the field measurements. 
Discrepancies between these two sets of curves are caused by the fact that the measured value of the potential difference is a function of the position of both electrodes, whereas in the limiting case the value of this difference is the function of one. Corrections are computed for the regions where these discrepancies become important, and this makes the comparison of the curves easier and facilitates the interpretation of the results of the well logging.-S. T. V.

10373. Arkhangel'skii, A. A. An approximate determination of the capacity of a gas-producing formation [in Russian]: Akad. Nauk SSSR., Instit. mekhan. Inzhen. Sborn., vol. 4, no. 1, pp. 188-196, Moscow, 1947.

The problem discussed by the author can be stated as follows: A circular, horizontal, homogeneous layer has a borehole in its center through which gas escapes to the surface. The radial flow of the gas from the periphery of the formation towards the foot of the borehole continues until the pressure at all points of the horizon becomes equal, which fact determines the limit of its gas-producing capacity. The flow of gas through the formation is not a steady process, but it is possible to assume the entire process as a sequence of discrete short periods of steady gas flow. The results of the computations are presented in the form of graphs giving the variation of the gas output with time, and pressure in the formation, as a function of the distance from the hole as well as a function of time.-S. T. $V$.

10374. Bays, C. A., and others. Electrical well logging in Illinois basin [abstract] : Am. Assoc. Petroleum Geologists Bull., vol. 32, no. 2, pp. 303-304, Tulsa, Okla., 1948.

Electrical logging has been used widely in the exploration and develment of the Illinois basin oil fields of Illinois, Indiana, and Kentucky. Standard logging techniques have been evolved during the decade of activity in the basin. The relations of electrical values to formation fluids, lithology, porosity, permeability, drilling fluids, and hole diameter are discussed.

Electrical $\operatorname{logs}$ have furnished valuable records of the wells drilled. They have formed the basis for much of the stratigraphic and structural work in the territory. Recognition of commercial saturation in wells and predictions of reservoirs have been successful in some cases by integration of electrical log data with core and production information. The electrical log has been a valuable tool in guiding completions. The available electrical-log information on the wells or tho minos basin promises additional future value in further exploration and secondaryrecovery operations.

10375. Dakhnov, V. N. Electrical well logging, interpretation of electric logs [in Russian], 496 pp., Moscow, 1941.

This book, designed for the use of geophysicists, geologists, petroleum engineers, and well-logging operators, gives the most comprehensive survey of electrical logging at present available. It aims to cover all practical aspects of such logging in the light of underlying theory and industrial practices. Particular attention is given to the effects of porosity, interstitial water, salinity, and saturation on the resitivity of reselvoirs; the relation between apparent resistivity and true resistivity in low 
resistivity and high-resistivity formations; the departure-resistivity curves for invaded and noninvaded formations, and true resistivity determinations, primarily by curve matching; the relation of observed drill-hole potentials to concentration potentials and streaming potentlals, and the drill-hole potentials in coal beds; and composite logs comprising the curves of self-potential, of resistivity, and sometimes of temperature and drilling rate. Numerous examples of surveys, tracings of $\operatorname{logs}$, and accessory information are included.-V. S. (A review appeared in Geophysics, vol. 13, no. 2, pp. 281-283, Tulsa, Okla., 1948.)

10376. David, H. Discoveries-Industry ends greatest wildcatting year : Oil and Gas Jour., vol. 45, no. 38, p. 148, Tulsa, Okla., 1947.

In 1946 a total of. 4,518 exploratory wells were drilled in the United States, constituting an increase of 6.2 percent over 1945 . They resulted in the discovery of approximately 491 new oil reservoirs, a number of new pay formations in existing fields, and 144 extensions of the older fields. This activity represented an increase of 15.9 percent over the previous year in the number of successful wildcats drilled and added nearly 150 million barrels of oil to the national reserves. Other statistics on exploratory wells in 1946 are given, and the wildcat drilling and its results in the leading states during the past 5 years are summarized in diagrams. $-\nabla . S$.

10377. Doll, H. G. The spontaneous potential dipmeter: Texas Agr. Mech. Coll. Bull. 93, pp. 142-145, College Station, Tex., 1946.

Determination of formational dip can be made from the data of a single well by making logs with the spontaneous potential dipmeter. Measurements are taken using three independent electrodes, disposed $120^{\circ}$ apart in the well's circular cross section of known diameter. At the same time the inclination and direction of the well and the orientation of the electrodes are determined by a photoclinometer equipped with a compass, which is placed axially in the dipmeter assembly above the electrodes.

On the three spontaneous-potential curves, traced $120^{\circ}$ apart by logging operations, the changes registered in passing from a permeable bed to a non-permeable bed are recorded at different depths depending upon the dip of the boundary plane. Accordingly, the registrations together with photoclinometer data give a measure of this dip. The procedure of using the dipmeter is described briefly. The dipmeter has been applied extensively in the southern oil regions of the United States, and its use in the mid-continent areas is increasing.- $V . S$.

10378. Dyk, Robert. Note on shooting in a well to determine velocity [abstract] : Geophysics, vol. 13, no. 2, p. 302, Tulsa, Okla., 1948.

An example of a velocity survey is given where explosive charges were placed in the well being surveyed, and the energy received by surface geophones was recorded. The field procedure is described and the advantages of this method over the conventional technique are discussed.

Gilchrist, Lachlan, and Robinson, B. $\dot{W}$. The use of cores to determine the subsurface magnetic dip, magnetic declination, and total force of the earth's magnetic field and to determine the attitude of drill holes [abstract]. See Geophysical abstract 10253. 
10379. Guyod, Hubert. Temperature logging: Texas Agr. Mech. Coll. Bull. 93, pp. 132-141, College Station, Tex., 1946.

The principles of temperature well logging are explained very briefly and are illustrated by charts. Several factors provide indications of local geology in cable-tool wells where thermal balance is least disturbed. Isogeotherms, horizontal in cases of uniform horizontal layers deposited on a horizontal substratum, become warped in localities where igneous rocks intrude sediments. Various materials, such as shale, sand, and salt, have different geothermal gradients, and their different hardnesses produce variations of the hole diameter which affect mud: temperatures. Thus curves of temperature measurements or gradient measurements in terms of depth can serve as exploratory logs. An electric bridge circuit is generally used for recording the temperature when a continuous graph is desired.- $V$. $S$.

10380. Komarov, S. G. The influence of galvanic corrosion on the self-potential curve [in Russian]. Prikladnaia Geofizika, no. 2, pp. 87-91, Moscow, 1945.

In electrical logging of boreholes difficulties can be encountered owing to contact electromotive forces caused by the presence of different metals in the same fluid. These phenomena of galvanic action are especially troublesome in cases of high resistivity of the formations $(\rho>100 \mathrm{ohm}$ meters). The following measures are proposed by the author to over: come the above-mentioned difficulties: avoid the use of brass or copper parts in the borehole, use only steel; cover the electrode assembly with a layer of insulating rubber or use measuring equipment embedded in a compound of asbestos and cement. In the experience of the author galvanic corrosion is always present when the self-potential curve resembles a resistivity curve. Absence of galvanic corrosion can be safely assumed when the same self-potential curve is obtained with different arrangements of electrodes.-S. T. $\boldsymbol{V}$.

10381. Lyle, H. N. Electric logging, identification of horizons [in English and: Spanish]: Petroleo Interamericano, vol. 5, no. 11, pp. 62-65, Tulsa, Okla., 1948.

One of the principal objectives of electrical logging is the identifcation of geologic horizons by colrelation. Several problems of oil-well exploration which can be solved by such application are discussed. In: coring, the identification of horizons within close 11 mits is aided by electric logs useful for establishing markers facilitating the selection of coring points. Planning the location of a new well makes the identificntion of horizons essential so as to judge the well's structural and stratigraphic relations to otwer weus.

A suitable interpretation of horizons in electric logs aids also in the delineation of faults which sometimes cause oil accumulation and sometimes prevent it. Oil felds are often associated with normal faults. or with slip faults characterized by a fault prane aspoins toward the downthrown side, which furnishes a clue for correlation. In exploration the identification of horizons by the drilling and logging of a number of suitably disposed shallow holes of small diameter may aid in locating: faults in the investigated area.- $-\nabla$. $S$. 
10382. Nichols, P. B. Mechanical well logging: Texas Agr. Mech. Coll. Bull. 93, pp. 105-188, College Station, Tex., 1946.

In petroleum exploration the mechanical logging of drill holes can aid in detecting oil-bearing strata because changes in the rate of penetration of the bit indicate degrees of hardness and porosity of rocks and thus help to identify the formations known to be typically associated with oil. The author describes four types of mechanical rate-of-penetration recording instruments, the underlying principles of construction, the operational procedures, and the application of drilling-time records. Attention is also given to a combined use of mechanical and electrical logs. The text is illustrated by examples of d drilling time curves, geolographs, and corresponding electrical logs. A bibliography is appended.V. S.

10383. Petroleo Interamericano. Mechanics of electric well logging [in English and Spanish]: Vol. 5, no. 9, pp. 61-78, Tulsa, Okla., 1948.

Self-potential $\operatorname{logs}$ and electrical-resistivity logs are discussed with reference to the underlying physical phenomena, the typical general patterns of geologic formations, and the factors causing deviations of $\log$ curves from such patterns. The self-potential curve is more particularly examined with relation to processes of electro-osmosis and electro-filtration in wells, the reversal of the self-potential sign, and range of values. The resistivity curves are considered in the light of the influence of temperature, invasion, colloids, and the salinity of drilling fluid. It is found that electrical resistivity depends not on the mineral characteristics of rocks but primarily on their water content and their physical characteristics. Saline waters have low resistivity, whereas fresh waters, sulfur waters, oil, and gas have high resistivity.V.S.

10384. Pirson, S. J. Electric logging; electric log interpretations: Oil and Gas Jour., vol. 46, no. 31, pp. 84-90, 113-115, Tulsa, Okla., 1947.

A complete interpretation of the electrical $\log$ of an oil well requires knowledge of the lithology of the formations traversed and of the porosity, permeability, and saturation of the reservoir. The determination of these characteristics by various methods from the data of the logging curves and from accessory information is examined. With regard to the lithologic picture attention is given to the empirical interpretation of selfpotential data and of resistivity data. For the quantitative determination of reservoir porosity, the saturation formula of Archie and similar relationships are considered in the light of the restrictions under which selfpotential deflections measured from the shale base line can be taken to indicate reservoir porosity.

For the quantitative determination of effective reservoir permeability, a study is made of the possibilities of measuring differential effects produced in self-potential and resistivity curves by an application of increments in hydrostatic pressure on the well. To aid in the quantitative determination of reservoir saturations, a formula is deduced for calculating the original connate-water saturation from data on the total water saturation obtained from core analysis, the reservoir porosity determined either by core analysis or by the self-potential curve, the original salinity and resistivity of the connate water, and the true formation resistivity. $-V . S$. 
10385. Polubarinova-Kochina, P. J. Concerning unsteady motions in the processes of filtration [in Russian] : Prikladnaia Matemat. Mekhan., vol. 9, no. 1, pp. 79-90, Moscow, 1945.

The study of oil filtration through porous media may be based on the problem in which a certain formation filled with oil is surrounded by water along a closed contour line. In this region one or several oil holes allows oil to flow out of the formation. The determination of the time when the surrounding water contour reaches the bore-hole, setting limits to the productivity of the oil well, is the problem discussed by the author. Solutions are given on the basis of certain simplifying assumptions for cases most often encountered under practical conditions. $-S . T . V$.

10386. Taylor, G. L., and Reno, D. H. Magnetic properties of "granite" wash and unweathered "granite": Geophysics, vol. 13, no. 2, pp. 163-181, Tulsa, Okla., 1948.

Routine measurements of the magnetic properties of various geological formations show that "granite" wash, although having an appearance in well samples very similar to that of unweathered "granite," has very different magnetic properties. Magnetic logs of wells located in southwestern Oklahoma, the Texas Panhandle, and eastern New Mexico show a large increase in the magnetic susceptibility when unweathered granite is encountered. Samples of granite and granite wash collected from the Wichita Mountains in Oklahoma show a marked decrease in magnetic susceptibility during the formation of granite wash from unweathered granite. It is concluded that magnetic logs made by testing well samples will be of assistance in differentiating granite wash from the underlying unweathered granite. Tests of samples of unweathered granite upon exposure to weather show a measurable to marked decay of susceptibility and remanent magnetism in the relatively short time of a few years.Authors' abstract.

\section{UNCLASSIFIED GEOPHYSICAL SUBJEĊTS}

10387. Argall, G. O. Society of Exploration Geophysicists holds first mining symposium in Denver. Mines Mag., vol. 38, no. 5, pp. 23-24, Denver, Colo., 1948.

At the 18th annual meeting of the Society of Ixploration Geophysicists on April 26-29, 1948, in Denver, Colo., one day was devoted to a symposium on the application of geophysical methods to the search for ores. The papers presented covered uses of magnetic, electrical, seismic, and geochemical methods and dealt with subjects of theory, instruments, fleld techniques, and related geology and with particular applications in the Fredericktown lead district in Missouri and the Iron Springs district in Utah. The general consensus of views appeared to be that the use of geophysics in mining can be further improved and expanded.- $-\nabla$. $S$.

10388. Berman, Isadore. Geophysics as a profession: Nat. Roster Sci. Spec. Personnel, Vocat. Booklet 5, 16 pp., Washington, D. C., 1947.

This booklet on geophysics aims to furnish a brief description of the field and an account of the various kinds of work geophysicists do, how they are trained, and where and how they are employed. It is 
intended for those thinking about becoming geophysicists and those individuals-teachers, counselors, vocational guidance personnel, and others-who are called upon to give advice about choice of a profession. The booklet was prepared by the staff of the National Roster with the valuable assistance of Dr. Waldo $\mathrm{E}$. Smith, Executive Secretary of the American Geophysical Union.-Foreword.

10389. Boletin del Instituto Sudamericano del Petróleo. La exploración del petróleo en el Brasil [Exploration for oil in Brazil]: Vol. 2, no. 5, pp. 647-657, Montevideo, Uruguay, 1947.

The search for oil in Brazil started in the year 1919 in the form almost exclusively of exploratory drilling, usually in the vicinity of bituminous deposits. Most of the drilling was done by the Federal Government of Brazil, which spent over 17 million United States dollars on these investigations. Private companies participated in these drilling operations with some geophysical exploration preceding them. More important geophysical work was done during the year 1935 in the region of Lobato, where the probability of oil-bearing formations was established near Monte Recôncavo, using gravimetric and magnetic methods of exploration. In 1939 the Conselho Nacional do Petróleo was created, and it is now in charge of oil exploration for the Government. Under contract with this organization some seismic exploration was done by the United Geophysical Co. of Texas in the states of Alagoas and Bahia. In the last few years the search for oil has been concentrated in the state of Bahia, the only region where prospecting for oil is good. Here six oil wells were drilled and logged by the Schlumberger method.-S. T. $V$.

10390. Bullard, E. C. The figure of the earth : Roy. Astron. Soc. Monthly Notices, Geophys. Suppl., vol. 5, no. 6, pp. 186-192, London, 1948.

A purely numerical method has been devised for the treatment of Darwin and de Sitter's theory of the figure of a rotating earth in hydrostatic equilibrium. This has been applied to the density. distribution suggested by Bullen. De Sitter's numerical constants $\lambda_{1}$ and $k_{1}$ are found to have the values: $\lambda_{1}=0.00016 \pm 0.00018$, and $k_{1}=68 \times 10^{-8}$. The ellipticity, on the assumption of hydrostatic equilibrium, is found to be: $\epsilon^{-1}=297.338 \pm 0.050$. A A thor's abstract.

10391. Chemical Engineering and Mining Review. Activities of Commonwealth Bureau of Mineral Resources: Vol. 39, no. 11, pp. 416-417, Melbourne, Australia, 1947.

A brief account is given of the activities of the Australian Bureau of Mineral Resources, Geology and Geophysics, established in Melbourne in 1946 (see Geophys. Abstracts 128, no. 9072). Private exploration for gas in the Lake Frome-Broken Hill region was assisted by a gravity survey of an area of 300 square miles in the Lake Frome embayment section. Private exploration in the Roma district of Queensland is also to be aided by a geophysical survey of a part of this area. In preparation for oil and gas exploration by geologic and geophysical methods in the Kimberley basin of Western Australia, parts of this area were mapped with the aid of aerophotography.

The search for coal was furthered by geophysical surveys of the Collie coal field in Western Australia and a part of the Leigh Creek 
coal field in South Australia, wherein the gravitational method proved the most successful. Geophysical surveys will be made at the Blair Athol and Callide coal fields in Queensland. The work of the Bureau has also included a geophysical survey at the Cobar gold and copper field in New South Wales and radioactivity tests in connection with search for uranium and thorium. Plans for further investigations are indicated. $-\boldsymbol{V} . \boldsymbol{S}$.

10392. Geyer, R. A. Annotated bibilography of marine geophysical and geological surveys: Geol. Soc. America Bull., vol. 59, no. 7, pp. 671-695, Baltimore, Md., 1948.

This bibliography lists approximately 300 publications on marine surveys by geophysical and geological methods which appeared during 1910-45. The geophysical methods employed for exploration were primarily adaptations of seismic, gravity, and magnetic methods used on land. More recent techniques, applied particularly in the decade preceding the second world war, included echo sounding, radioacoustic ranging, and explosive core sampling. In the case of each type of survey the entries are grouped for the most part under the headings of "data," "instruments and methods," "theoretical aspects," and sometimes "interpretations." Some references, especially in the sections on submarine topography and geology, are omitted in order to keep the bibliography within limits. $-\nabla$. S.

10393. Hammer, Sigmund. Geophysical applications of the "Law of Propagation of Errors" [abstract]: Geophysics, vol. 12, no. 3, p. 496, Tulsa, Okla., 1947.

The "Law of Propagation of Errors" in the theory of errors is discussed briefly. Its broad field of usefulness in planning and conducting geophysical prospecting operations is illustrated by applying it to selected typical problems. The problems include the relative importance of errors in the various factors which enter seismic velocity and depth determinations, the reliability of gravimetel calibrations, and the weighting of data. The paper emphasizes physical principles.

10394. Hedberg, H. D., Sass, L. C., and Funkhouser, H. J'. Oil fields of greater Onciana avea central Anzoategui, Venezuela: Am. Assoc. Petroleum Ge0logists Bull., vol. 31, no. 12, pp. 20so-2169, Tulsa, Okla., 1947.

This geological study of the important Oficiana oil region in eastern venezuela includes references to exploration by geophysical methods. Two ...en is characterized by sparse folding, normal faults chiefly re-

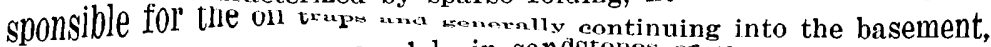

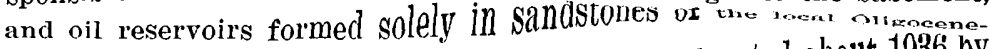
Miocene formation. The first producing well was located abollt 1936 by combined torsion-balance and seismic-lefraction surveys. Since then seismic l'efraction, reflection, magnetic. gravimetric: electrical, and geochemical work has been done with varied success.

As yet by far the most useful method is a combination of seismic re. flection surveying and structure drilling by portable rigs to depths of 3,000 feet accompanied by electrical logging. Gravity and magnetic results were at variance with known sedimentary structures, and the 
geochemical and surface electric results are not yet evaluated.- $\nabla$. S. (A review appeared in Geophysics, vol. 13, no. 2, pp. 284-285, Tulsa, Okla., 1948.)

10395. International Union of Geodesy and Geophysics. Report for the year ending 30th June 1947 : Internat. Council Sci. Unions, Rept. Exec. Com., July 1947, pp. 7-12, Cambridge, England. 1948.

This report includes a summary of the proceedings of the Extraordinary Assembly of the Union held in Cambridge in August 1946, a list of the international bodies forming the Union, and a brief account of some of the Union's activities and publications during the year ending June 30, 1947.- V. S.

10396. Mine \& Quarry Engineering. State geophysical surveys: Vol. 14, no. 1, p. 1, London, 1948.

The establishment of geophysical departments in the dominion and colonial geological surveys of the British Empire is advocated on grounds that these departments are an aid to exploration for ores. The simplified conception of earlier days that metalliferous lodes typically associated with earth movements ought to be found chiefly in mountainous regions has been disproved in the Andes of South America. Therefore it becomes essential to devote equal attention to the plains where movements might have taken place in more remote times and where exploration is handicapped by heavier sediments.

In such regions geophysical methods have proved useful for oil search. Their application to ores is more costly, however, because metalliferous lodes are connected with smaller deformations and are thus marked by less pronounced anomalies which are more difficult to find and to interpret. Accordingly, geophysical surveys for ores must be more detailed and can be profitable only when organized on a large scale, usually exceeding the means of small mining companies. As an aid to such companies the establishment of state geophysical surveys is advocated to bring exploration for ore up to the level of efficiency attained in oil search.- $V$. S.

10397. National Research Council of Canada, Committee on Geodesy and Geophysics. Annual report [1947] : Canadian Geophys. Bull., vol. 1, no. 4, 35 pp., Ottawa, Ontario, 1948.

The report for 1947 outlines the history, organization, and activities of the committee and the scientific work undertaken and proposed. The research problems, initiated as financially supported projects or defined and clarified by discussion, included subjects classifiable under the headings of rock properties, geophysical theory, methods of exploration, instruments, geological interpretation, technical aids, and new observatories, and the more specialized subjects of microseisms, rockbursts, aurora, geologic age, snow and ice, and others. The committee is listed by sections, members, and publications, and abstracts of Canadian contributions to the pending 8th General Assembly of the International Union of Geodesy and Geophysics are given.- V. S.

National Roster of Scientific and Specialized Personnel. Geophysics as a profession. See Geophys: abstract. 10387. 
10398. Richardson, L. A. Geophysical activities at Kyoto Imperial University [Japan], 5 pp., March 1946. (Library of Congress, OTS PB Rept. 19729.)

Geophysical investigations in Japan, conducted at Kyoto Imperial University, are reported, and brief remarks are included on the work of the Geological and Mineral Institute and of the Laboratory of Applied Geology. The Geophysical Institute of Kyoto University is chiefly concerned with problems of the internal structure of the earth, elasticity of the earth's crust, gravitation and its constants, earth tides, and seismic research. It does not conduct seismic surveys, except for experimental purposes, but is the chief center for the design and construction of seismic instruments. This equipment has been used for oil and ore exploration, coal field investigations, and foundation studies. The Geological and Mining Institute made gravity surveys in Manchuria and Korea, a torsion balance survey in Sumatra, and analyses of radon content in spring waters and of soil air in various places. The Laboratory of Applied Geology conducted mainly electrical resistivity surveys.-V.S.

10399. Shakhnazarov (Chahnazaroff), D. A. Geofísica mineral ciencia de hoy [Mining geophysics, the science of today] : Industria Minera, vol. 7, no. 81, pp. 15-17, Buenos Aires, 1948.

Applied geophysics is a young branch of physical science. It does not claim to be infallible, but its potency in the exploration for minerals increases from year to year. The introduction of geophysical prospecting methods gives to the mining engineer a useful tool in his search for mineral treasures. In Argentina geophysical exploration for oil was introduced about 20 years ago by the Yacimientos Petroliferos Fiscales, but geophysical exploration for metals still is in its initial stage. The author quotes industrial and state organizations which are instrumental in this field in Argentina and concludes by stressing the great importance of applied geophysics to the national economy.S. T. V.

1.0400. Slotnick. M. M. The education of an exploration geophysicist: Am. Inst. Min. Met. Eng. Trans., vol. 164, 1945, pp. 337-341, New Ioric, 1010.

Education in exploration geophysics must give the student sufficient general training and discipline in the scientific approach to enable him intew gentiy to find and nssimilate the knowledge required by any particular problem, In this sense, broadness of scientinic preparation is even more essential than intensive schooling in any special field.

For such a foundation, the indispensable subjects are physics, mathemntics, and geology, in the order named. Undergraduate courses should include the theory of heat, sound, light, electricity, and mecianaies in physics; differential and integral calculus, descriptive geometry, and three-dimensional analytical geometry in mathematics; and general and structural seology, and geological field nractice. Graduate work of one or two years can profitably cover advanced theory in mathematici, physics, and geology, and practical problems in geophysics. Exxclusively geological curricula have the disadvantage of making the graduates dependent in their work on physicists and mathematicians.- V. S. 
10401. Straley, H. W., III. Geophysicists discuss airborne instruments and employment of untrained observers: Mining and Metallurgy, vol. 29, no. 495, p. 180, New York, 1948.

At the annual meeting of the American Institute of Mining and Metallurgical Engineers in New York in February 1948, the sessions on geophysics were devoted mainly to discussions of the advantages and limitations of aeromagnetic surveys and of the advisability of an increased use of geophysical instruments by untraining personnel. Among the indicated draw-backs of aeromagnetic surveys were the unsuitable- 。 ness of the airborne magnetometer for small-scale exploration, the obliteration of minor anomalies of the magnetic field because of the height from which measurements are made, the inadequacy of position fixing by means of aerial photographs in forested areas, and the difficulty of precise determination of the height of the instrument over any particular locality. These criticisms were countered by arguments that the difficulties were minor in actual practice and that helicopters largely overcame them. In the question of broadening the use of geophysical instruments, attention was given to the Scandinavian practice of employing trappers and woodsmen for field observations and trained geophysicists for the interpretation of data. $-V$. S.

10402. Tripp, R. M. “Is it an anomaly?" Geophysics, vol. 13, no. 3, pp. 443-451, Tulsa, Okla., 1948.

A method is proposed and described whereby it is possible to examine statistically the data from a geophysical survey to determine the relative probability of their occurring as a result of pure chance. When the probability is less than 0.01 , a technique is outlined for further "reducing" the data in an objective manner and testing anomalous areas for significance. The method is particularly applicable to highly variable data which result from random background fluctuations found in some of the modern prospecting techniques.-Author's abstract.

10403. World Oil. Geophysical activity increased as year begins: Vol. 127, no. 11, p. 158, Houston, Tex., 1948.

Statistical data are given on geophysical activity in 20 oil-producing states in the United States during 1946 and 1947, based on reports of the Interstate Oil Compact Commission. It is found that 491 geophysical crews and 38 core-drilling crews were engaged in the search for oilbearing and gas-bearing structures at the end of 1947, as compared with an approximate total of 418 crews at the end of 1946 . When classified according to oil provinces, the number of geophysical crews was 80 in southern Louisiana, 61 in western Texas, 56 in southwestern Texas, 49 in southeastern Texas, 44 in Oklahoma, 29 in Mississippi, and 25 in northern Louisiana. When differentiated by geophysical methods, the total included 388 seismic crews, 96 gravity crews, and 7 magnetic crews active at the close of 1947 , as compared with 251 seismic crews, 95 gravity crews, and 21 magnetc crews at the close of 1946.- V. S. 


\section{RELATED GEOLOGICAL SUBJECTS}

10404. Blyth, F. G. H. A geology for engineers, $2 d$ ed., 329 pp. London, Edward Arnold \& Co., 1947.

The book covers the course in geology for civil engineering students at the Imperial College of Science and Technology, London. Applications of geology to engineering problems are discussed in the closing chapters which contain analyses of many cases of interest to the geophysicist. These cases deal with the geology of water supply, reservoirs, dam sites, and tunnels. The book includes two appendixes, one written by A. W. S. Kempton dealing with soil mechanics, the other written by J. McG. Bruckshaw on geophysical prospecting and engineering problems. The last appendix contains a summary of geophysical methods of exploration and examples of their application.-S. T. V. (For the paper by Bruckshaw see Geophys. Abstracts 120, no. 7822.)

10405. Deegan, C. J. Canada in midst of greatest exploration play in Dominion's history: Oil and Gas Jour., vol. 46, no. 52, p. 150, Tulsa, Okla., 1948.

The belt of possible oil-bearing territory in Canada lies between the Rocky Mountains and the pre-Cambrian shield, being 800 miles wide at the United States border and $\mathbf{1 5 0}$ miles wide at Fort Norman. There is about 650,000 square miles of sediments $1,000-13,000$ feet thick, largely marine. The area has a number of oil and gas fields and the Athabaska tar sands. Fort Norman produces from a Devonian reef, and 900 miles to the south at Leduc and Woodbend there is further Devonian reef production. Much of the area will require wells less than 5,000 to 7,000 feet in depth. The area of the present play, bounded in the north by climatic and general development conditions, covers about 100,000,000 acres in Alberta and 40,000,000 acres in Saskatchewan.-G. D. H., Inst. Petrol. Jour., vol. 34, no. 296, pp. 215A-216A, London, 1948.

10406. Fedosov, A. E. Preaictions of settling of structures caused by the thawing of the permafrost (in Russian): Inst. Merzlotovedeniia Trudy, vol. 4, pp. 93-124, Moscow, 1944.

The freezing and thawing of the ground is a fairly complex process varying with the kind of soil, its nhysical state, and mineral composition. The author distinguishes two main solls, suna axa clas. Sand. when freezing, shows a uniform transformation of its mass into a more porous composition on account of an increase in volume of its interstitial water. This process is reversible; that is, when sand thaws it retains its moisture in the pores and its volume unixomis aecreases about 10 percent. Clay behaves quite differently. Clayey soil is never as homogeneous us sand. A certain degree of separation takes place between the frozen clay and Water, twe nattior freesing into ice cakes imbedded in the solid substance. On thawing, clayey soll produces water which often migrates into the adjoining portions of the ground under the pressllle of the supporitu structure, thus increasing its settling. The author presents his method of deverwains the expected settling of the foundation under a structure on the basis of graphs obtailled Irow bixpersacent on samples of the soil. The method is not applicable when the ground contains volds, party filled with air. Instructions for taking ground samples and for testing them for compressibility are appended to the article. The necessary graphs are to be constructed on the basis of these tests.-S. T. $\nabla$. 
10407. Flint, R. F. Glacial geology and the Pleistocene epoch, 589 pp., 6 maps, 88 figs., New York, John Wiley \& Sons, 1947.

This book deals with the Pleistocene epoch from the viewpoint of glacial geology and describes the last ice age. The first ten chapters are devoted to the definition and explanation of glacial processes and terms, the eleventh chapter deals with glacial stratigraphy and its relation to Pleistocene stratigraphy, and the last twelve chapters give a description and chronology of glacial events over the world with major emphasis on North America. A 40-page bibliography on glaciation is appended.-V. S. (A review appeared in Pacific Discovery, vol. 1, no. 2, pp. 31-32, Berkeley, Calif., 1948.)

10408. Haalck, H. Zur Kuhn-Rittmannschen Theorie über die Beschaffenheit des Erdinnern [Remarks about the hypothesis of Kuhn and Rittmann concerning the properties of the earth's core]: Zeitschr. Geophysik, vol. 17, no. 1-2, pp. 32-42, Braunschweig, 1943.

In the opinion of the author, the new hypothesis advanced by Kuhn and Rittmann concerning the properties of the earth's core gives a better explanation of the geophysical process caused by the cooling of the earth than the now generally accepted theory of an iron substance forming the core of the earth. The discontinuity of the earth's structure at a depth of 2,900 kilometers established by seismic observations is less satisfactorily explained by this new hypothesis. Also uncouvincing is the assumption of much greater dimensions of the earth's core. In the opinion of the author the old theory gives a more probable explanation of this point. It must be admitted however that the Kuhn-Rittmann hypothesis represents a physical possibility.-Author's abstract, condensed and translated by S. T. V. (For the hypothesis of Kuhn and Rittman see Geophys. abstract 10410.)

10409. Heck, E. T. New York subsurface geology: Am. Assoc. Petroleum Geologists Bull., vol. 32, no. 8, pp. 1449-1456, Tulsa, Okla., 1948.

This paper summarizes the data available on the Trenton and subTrenton formations as shown in wells in New York State. Approximately a score of wells have been reported to have reached the basement complex, and nearly all have been near the Great Lakes or the Adirondack pre-Cambrian area. The relationship of the rocks east and west is shown by means of a cross section. Contour maps show the approximate sub-sea elevation of the top of the Trenton and the top of the preCambrian.-Author's abstract.

10410. Kuhn, Werner. Zur Diskussion über die Homogenität des Erdinnern [Concerning the question of homogeneity of the earth's interior]: Experientia, vol. 2, no. 1, pp. 391-397, Basel, Switzerland, 1946.

According to considerations presented some years ago by the author and A. Rittmann, the chemical composition of the interior of the earth must be rather homogeneous. The well-known discontinuity which occurs at 2,900 kilometers with respect to the propagation of seismic waves should not be attributed to a discontinuity of the material composition, but to a continuous decrease of the viscosity. As is well known from the theory of elasticity, transverse waves cannot be propagated at all through a medium that is not viscous enough, whereas the longitudinal waves show a decrease of their velocity. 
A further consideration shows that a mixture of 99 atomic percent hydrogen and 1 atomic percent of iron is most probably supercritical at a temperature of $5,000^{\circ}$ absolute. It can be shown that the hydrogen present in a mixture of 90 percent hydrogen and 10 percent iron would be completely absorbed by the iron at this temperature and at a total pressure of $2 \times 10^{6}$ atmospheres.

The main argument for dismissing the assumption of an iron core is the fact that the present state must be the result of an asymptotic process which in its final phase was progressing under conditions similar to the present conditions of temperature, pressure, and viscosity. These latter conditions prevent the process of sedimentation, which would be indispensable.-Author's abstract, condensed by S. T. V.

10411. Magnitskii, V. A. Concerning the possible deformation of deep layers of the earth's crust and of the subcortical region [in Russian]: Soc. Naturalistes Moscou Bull., Sér. Géol., vol. 23, no. 2, pp. 3-22, Moscow, 1948.

The best interpretation of the available geologic evidence obtained from gravimetric and geodetic studies can be made by advancing a hypothesis of displacement of masses continuously taking place in the earth's interior during its geologic evolution. Parallel processes of metamorphic character, as, for instance, changes of density, are also admitted in this theory, but only as a result of the new positions of the displaced masses. Seismological evidence confirms this hypothesis by establishing the presence of a thinner cortex underneath the oceans and a decrease of the velocity of seismic waves in the lowest layer of the crust.

Experiments with rocks and other materials exposed to very high pressure show a great plasticity, observable also in the earth's crust where great tectonic changes took place. This can be considered as an indirect confirmation of the hypothesis. The author considers less probable the assumption of initial conglomerations of masses having different densities causing their consequent displacement.-S. T. V.

10412. Meng, H. M. The bearing of regional tectonics on ore-deposition: Nat. Tsing Hua Univ. Sci. Repts., vol. 1, no. 2, pp. 125-140, 3 maps, Feking, China, 1947.

A study is made of regional and local structural features of the geology of southern and central China in their relation to ore deposits. The evidence shows that such deposits are usually located in areas of great crustal stress characterized by arcuate structures and thrust zones. Ore formation may also be favored by folding, as exemplifled by the rauchang and Malaga tin deposits of Kochiu and the tungsten deposits of Kiangsi. Falllts or fissures have been found to determine ore deposition in some cases, such as in the Hsianghualing, Lauchang, LohsueYinming, and Pingtoushan areas.

other relationships are observed between structures and deposits, and different processes of ore deposition are studied. It is considerea that these geologic clues can be used as guides in exploration for ores. In the case of deposits formed by the ascension of mineral solutions special promise is found in a study of the tectonic channel ways of such move. ment.- $\boldsymbol{\nabla} . \mathrm{S}$. 
10413. Rankama, Kalervo. New evidence of the origin of pre-Cambrian carbon : Geol. Soc. America Bull., vol. 59, no. 5, pp. 389-416, 6 pls., 4 figs., Baltimore, Md., 1948.

An investigation was carried out concerning the origin of carbon in the following pre-Cambrian materials from Finland: graphite, carbonbearing schists, carbonaceous accumulations in phyllites including the suggested fossil Corycium enigmaticum Sederholm, and shungite from Karelo-Finnish S. S. R. Geological and petrological descriptions of the materials investigated are given, and $\mathrm{CuO}, \mathrm{V}_{2} \mathrm{O}_{5}$, and $\mathrm{MoO}_{3}$ contents of the samples and the isotope ratios $\mathrm{C}^{12} / \mathrm{C}^{13}$ in carbon extracted from same are presented. Geological evidence and trace-element determinations make probable the division of carbon in these samples into organic and inorganic groups. The mass spectrometric $\mathrm{C}^{12} / \mathrm{C}^{13}$ determinations furnish definite proof of this and also final proof of the organic nature of the Corycium which thus is a real fossil of the Late Archean time, the oldest ever recorded with definite certainty.-Author's abstract.

10414. Rubinstein, L. I. Concerning the process of ground freezing [in Russian] : Acad. Sci. U. R. S. S. Bull. [Izv.], Sér. Géog. et Géophys., vol. 11, no. 6, pp. 389-406, Moscow, 1947.

The discussion of the problem of ground freezing is based upon the assumption that the water content of the ground is a combination of several aqueous solutions having different freezing temperatures. This assumption deviates from that of Stefan and is introduced by the author as the result of the observation made by $\mathbf{N}$. E. Korovin that the temperature of the ground during the freezing process does not vary monotonically but shows several pronounced minima. The assumption that the water contained in the ground is a combination of different aqueous solutions of mineral salts is conflrmed. The author discusses the modification of Stefan's problem, preserving the initial and the boundary conditions, and confirms the observations of N. I. Korovin. (See also Geophys. Abstracts 133, no. 10151.) 一S. T'. V.

10415. Shakhnazarov, D. A. Petroleuni problem of Siberia: Am. Assoc. Petroleum Geologists Bull., vol. 32, no. 2, pp. 153-197, Tulsa, Okla., 1948.

The development of exploration for oil in Siberia is outlined, general local geology is discussed by regions and epochs, possible oil-bearing areas are examined, and the stratigraphy of the most promising districts is described in detail. It is found that surface indications of oil in Siberia are relatively few, which may be due in part to the permanently frozen ground of large sections of the country. However, exploratory work has revealed favorable lithology and structure of sedimentary formations in some vast areas, such as the general region of the Aldan massive, the Tungusian basin, the Khatanga depression, the Kuznetsk and Minusinsk basins, and the Lake Baikal area.- $\boldsymbol{D}$. S.

10416. Whitten, C. A. Horizontal earth movement, vicinity of San Francisco, California : Am. Geophys. Union Trans., yol. 29, no. 3, pp. 318-323, Washington, D. C., 1948.

Earth movements in California, caused by seismic activity in the earth's crust, have been measured by precise surveys at different intervals of time since the 1906 earthquake. Surveys made in 1947 give 
positive evidence of a slow continuous movement of the area west of the San Andreas fault, relative to the area east of the fault. The outer coastal area is moving northwestward at an annual rate of about 5 centimeters per year and has a total displacement of 3 meters since 1880, the date of the first precise surveys.-Author's abstract.

10417. World Oil. Wildcatting success shows gain for 1947: Vol. 127, no. 11, p. 142, Houston, Tex., 1948.

In 1947 about 14.7 percent of the oil wells completed in the United States were wildcats, of which $\mathbf{1 1 . 5}$ percent were successful, whereas in 1946 about 9.8 percent of the wildcats completed were successful. A tabulation by States and districts gives the total number of new wells and of strict wildcats drilled in 1947 and in the period 1937-46, together with the numbers and percentages of wildcats which were successful.G. D. H.. Inst. Petrol. Jour., vol. 34, no. 296, p. 214A, London, 1948.

10418. Yuster, S. T. Homogeneous permeability determination: Pennsylvania State Coll., Mineral Ind. Exper. Sta. Tech. Paper 129, 6 pp., State College, Pa., 1948.

In determinations of the permeability of geologic formations, commonly made with the use of pressured air, it is assumed that the permeability to any other fluid (whether liquid or gas) is the same as to air, that the flow takes place in the viscous range, and that no reaction occurs between the flowing fluid and the porous medium. Recent investigations by the author, Grunberg, Nissan, Calhoun, Bates, Cruver, Johnson, Beeson, and others have shown that these assumptions are not justified.

The investigations are reviewed in the light of previous work, and the conclusion is reached that the permeablity determined for a porous medium depends primarily upon the fluid used for measuring it. This dependence is particularly marked when a reaction takes place between the fluid and the medium but holds true even without such reaction. Therefore the routine air permeability determinations currently made are erroneous and may lead to false predictions of reservoir behavior. Ways to improve these determinations are discussed briefly.- - . S.

\section{TECHNICAL AIns TO EXPLORATION}

10419. Brailsford, F. Magnetic materials, 156 pp., 86 diagrs., London, Methuen \& Co., 1948.

Considerable advance has been made in the field of magnetic materials during the past 30 years. The resulting body of knowledge is reviewed for the benefit or students, research workers, and persons making use of magnetic instruments and materials. The subjects covered include ferromagnetism, single crystals, factors affecting magnetic properties, sinicon-iron alloys, nickel-iron alloys, and permanent magnets. Exposition deals $Y^{\text {ith }}$ problems of theory, manufacture, and applications. A bibliography is appended. $-V . S$.

10420. Brundall, Laurence. Photogeology applied to search for new petroleum reserves [in English and Spanish]: Petroleo Interamericano, vol. 6, no. 1, pp. 44-48, Tulsa, Okla., 1948.

Photogeology is defined as the technique of surface geologic evaluation accomplished by interpretation of aerial photographs, and the conditions 
of its successful use, the applications of its methods in aerial photography and photogrammetry, and the techniques of geologic interpretation of photographs are discussed. It is found that the trimetrogon system, generally comprising aerial photographs of an average scale of $1: 40,000$ and suitable for the preparation of small-scale base maps, can be used for petroleum photogeologic evaluation only in areas containing well-exposed massive sediments which have dips greater than $5^{\circ}$. In most other areas a scale of at least $1: 20,000$ is preferable, and in some particularly difficult areas a scale of $1: 10,000$ may be necessary.

For geologic interpretation the photographs obtained are studied stereoscopically to trace outcropping key beds, identify faults, and otherwise map the locality surveyed, mainly by plotting the attitude of exposed sediments. When the preliminary photogeologic evaluation has been completed, a field check is made of promising anomalies, the photographs are reexamined in the light of the additional informaiton, and the final map is prepared. A photogrammetric reconstruction of relief on the photographs may be necessary for more detailed evaluation.-V.S.

10421. Burmeister, F. Über die Verwendung von Photozellen bei Messungen der Schwingungsdauer von Magneten [The use of photoelectric cells in measuring periods of vibrations of magnets] : Zeitschr. Geophysik, vol. 18, no. 3-4, Braunschweig, 1944.

Visual or acoustic methods employed for determining the periods of vibrations of magnets can be replaced by automatic registration of vibrations using a photoelectric cell and a chronograph. Such a set up was successfully tried at the Fïrstenfeldbruck Magnetic Observatory, Germany. The old and the new methods were compared and the accuracy of the latter was found to be ten times greater. The experiments performed as well as the instruments used are described.-Author's abstract, translated by S. T. $V$.

10422. Hersey, J. B., and Moore, H. B. Progress report on scattering layer observations in the Atlantic Ocean, with discussion: Am. Geophys. Union Trans., vol. 29, no. 3, pp. 341-354, Washington, D. C., 1948.

Observations with a fathometer have shown the wide occurrence of a layer of scatterers of supersonic sound in the daytime in the Atlantic Ocean and the Gulf of Mexico at a depth of 150-250 fathoms. Other subsidiary layers are also recorded. The main layer exhibits diurnal migration in depth whose similarity to the behavior of plankton suggests planktonic control. The behavior of the layer under various conditions, alternative hypotheses on the nature of the scatterers, and preliminary experiments to test the theory of planktonic control are discussed.-Authors' abstract.

10423. Lang, A. H. Air photographs in relation to prospecting: The Precambrian, vol. 21, no. 4, pp. 4-7, Winnipeg, Manitoba, 1948.

The Geological Survey of Canada recently began a collection of air photographs selected for their particular suitability in illustrating geologic features. The collection now numbers about 250 prints, supplemented with descriptive text and references, and is listed in an interimcatalog pamphlet giving serial numbers, notes, references, and information on the purchase of prints. It is believed that these photographs may be helpful to teachers of geology, practical geologists, and pros- 
pectors. To aid their utilization, the present paper outlines the advances of Canadian aerial photography and explains briefly the classification of the collection and its possible applications in reconnaissance mapping and exploration. Reproductions of photographs illustrate the text.-Author's preface, amplified by V. S.

10424. Peay, L. W. Development of a portable vacuum-tube voltmeter for field use [abstract] : Geophysics, vol. 12, no. 3, p. 498, Tulsa, Okla., 1947.

This paper covers the development of a battery-operated vacuum-tube voltmeter designed for field application, the primary considerations being light weight, long battery life, high input impedance, and reliable and accurate measurements under extreme conditions.

10425. Rich, J. L. Reconnaissance mapping from oblique aerial photographs without ground control: Photogram. Eng., vol. 13, no. 4, pp. 600-609, Menasha, Wis., 1947.

A rough or mountainous terrain can be mapped for geologic reconnaissance from oblique photographs without ground control if it is possible to locate on them starting points with essentially the same elevation. The first step requires determining on each of two partly overlapping oblique photographs a point outside the overlap area situated at about the same level as a point inside that area and the direction between these points. The second step consists in making a transparent template corresponding to each of the photographs and showing the selected points with the direction between them, the trace of the picture plane; and the projected position of the camera; these templates are further superposed in exact coincidence. The third step is to cut in by intersection, using any of the standard methods for oblique photographs, as many points inside the area of overlap as may be desired. The underlying principles of oblique perspective are outlined, and an example of mapping is discussed, $-\nabla$. $S$.

10426. Stearn, J. L., and Braaten, N. F. A method or simuitaneous solution of a system of observation and condition equations: Am. Geophys. Union Trans., vol. 29, n0. 2, pp. 157-162, washington, D. C., 1948.

The purpose of this naner is to deduce a new' method fol obtaining a solution to a system of observation equations which is constrained by a number of conditions.' A most general case in least-squares theory is first formulated, followed by an actual problem in geodesy. The results of this paner lead to the conclusion that the method is very well adapted to adjustment problems in area triangulation inasmuch as it is both efficient and flexible.-Authors' abstract.

sass. stmobell. T. D. The multiplex compilation of geologic maps: Photogram. Eng., v0l. 13, 110. \$, pp, 889 -

The transfer of geologic features from aerial photos to a base IIIAY by means of the multiplex aeroprojector is accoimplished by means of the folloWing stepi i $\{x\rangle$ eeolose is first manped on contact prints or enlargements; (2) it is further compiled on a SCl OI low-shripk contact veints. with some simplification; (3) the low-shrink prints are photographed on film negatives the exact size of the original aerial negative; (4) diapositives are made in the reduction printer from the last-named film 
negatives; (5) a base map copy is prepared at the required scale; (6) geology is plotted thereon in pencil from the models set up in the multiplex; and (7) the resulting geologic map is inspected, edited, completed, and inked. In the case of some of the steps alternative procedures are indicated.-Author's summary, condensed by $V$. $\mathrm{S}$.

10428. Stulken, E. J. Preparing reports on geophysical prospecting [abstract] : Geophysics, vol. 12, no. 3, p. 503, Tulsa, Okla., 1947.

The readers' needs for complete, concise, clear, restrictive accounts of geophysical prospects should determine the content of reports. From the viewpoint of the interests of geologists, executives, and reviewers, one serviceable order of topics is : introduction, discussion of data, results; maps, and supplement on field operations. Usual contents of these and lesser headings are set forth as an aid to report writing. Pleasing form and style are attainable through adherence to carefully developed standards as well as through a functional approach to sentence structure. Special reports on operations, projects, or interpretation problems comprise valuable records of hard-won findings which, used as references, effectively shorten prospect reports.

10429. Thyssen, Stephan von. Versuche mit einer neuartigen Schneidenentlastung [Experiments with a new knife-edge suspension provided with a pressure relieving device]: Zeitschr. Geophysik, vol. 17, no. 1-2, pp. 53-59, Braunschweig, 1943.

The limits of sensitivity of such important measuring instruments as the chemical balance, the gravimeter, and the pendulum are determined by the friction and the microscopic deformations of their knife edges, especially noticeable at higher loading. The author describes a device which serves to decrease the pressure on the knife edges and consists of a symmetrically formed magnetic field. Experiments were performed on a balance and a pendulum.-Author's abstract, translated by S. T. V.

10430. Waters, K. H. An improved method of land surveying for use in brushcovered areas: Geophysics, vol. 13, no. 2, pp. 259-268, Tulsa, Okla., 1948.

The problem of surveying for seismic parties working with the refraction technique in brush-covered areas has been solved by placing the required points rapidly by means of an odograph and surveying them by an adaptation of the horizontal-stadia method, using truck-mounted towers to elevate the instruments above the brush. Some considerations affecting the accuracy of the method are discussed, and the mechanical details of the truck-mounted towers are given.-Author's abstract.

10431. World Petroleum. British oil companies find widening use for airplanes: Vol. 19, no. 6, pp. 48-51, New York, 1948.

British oil companies use airplanes increasingly for photogeologic and aeromagnetic exploration, communication with field parties, transportation of personnel and materials, servicing of equipment, and moving of machinery including complete drilling rigs. The Anglo-Iranian Oil Co. has employed De Haviland Rapides and Doves in Iran for communication and photogeology and is now using an adapted British Freighter for the latter work. In Papua, New Guinea, this company made use of a Douglas-Dolphin amphibian plane for photogeologic mapping. 
The Royal Dutch Shell Co. has recently purchased a supermarine Sea Otter amphibian flying boat built by Vickers-Armstrong for servicing survey parties in the Venezuela swamps. In Ecuador this company used a Grumman Goose amphibian plane for transporting seismic and other field parties prior to the building of air strips in the jungle of the Oriente region east of the Andes. Other applications of airplanes in Peru, Colombia, India, and Burma are discussed, and the use of the Decca Navigator is explained.- $V$. S.

\section{PATENTS}

[The figure in parentheses indicates the classification of the entry; see table of contents]

10432. (1) Werkwijze en toestel voor het meten van de relatieve zwaartekracht door middel van een astatische slinger [Method and apparatus for measuring relative force of gravity by means of an astatic pendulum]. Elektrisk Malmletning, Stockholm : Dutch patent 53,375, issued Nov. 16, 1942.

A pendulum, mounted within a mobile frame, is subjected periodically to the action of equal but opposite gravity moments, while at the same time the frame is moved at regular intervals to symmetrically deflected positions on opposite sides of the vertical. Registration is effected preferably by automatic means, such as photographic recording, and is calculated to occur at a constant phase difference with reference to the movement of the frame. A driving mechanism coupled with a timing device is connected with the frame to move it to deflected positions. [Free translation from Dutch.] Claims allowed, 5 .

10433. (2) Improved means for the detection and measurement of magnetic fields. Donald Orr, London, and A. J. Hughes, Chigwell Row, Essex, England : British patent 592,241. issued Sept. 11, 1947.

This invention relates to improved means for the detection and measurement of magnetic fields, comprising a first coil, a second coil disposed with its convolutions at right angles to the convolutions of said first coil, a thin sheet of high permeability ferromagnetic material mutually disposed in both coils, means for supplying alternating current to one of the coils, and phase sensitive means for measuring the current induced in the othel coil by a magnetic field component parallel wtih the axis or said other coil. Claims allowed, 9.

10434. (2) Adjustable flux valve. M. C. Depp, Hempstead, and C. F. Fragola, East Hempstead, N. Y., assignors to sperry Gyroscope Co., Inc., a corporation of New York: U. S. patent 2,432,514, issued Dec. 10, 1947,

In a flux valve for supplying a potential output dependent in magnimae upon the airection of an external magnetic field relative thereto, an inductor comprising a pdill OI lulerally opursi, enongatea core, members of permeable magnetic material so relatively arranged that a first thereof extends axially beyond a second at one end while the second extends aXially Deyomg the arst at the other end. means for causing exciting fluxes to circulate through said inductor whereny asymmetricus ar: leakage occurs at the ends thereof, and a pickup winding having convolutions extending about both core members. Claims allowed, 9. 
10435. (2) Magnetic compass. E. W. Hart, San Diego, Calif.: U. S. patent 2,437,692, issued Mar. 16, 1948.

In a magnetic compass, a pair of substantially identical inner magnetic needles, a pair of substantially identical outer magnetic needles, said needles being substantially parallel and having their like poles oriented in the same direction and all of their poles lying substantially on the same circle, and having pole strengths and being positioned laterally substantially in accordance with the formula

$$
\frac{m_{1}}{m_{2}}=-\frac{\cos 3 p_{2}}{\cos 3 p_{1}}=-\frac{\cos 5 p_{2}}{\cos 5 p_{1}}
$$

wherein $m_{1}$ and $m_{2}$ represent the pole strengths of the inner and outer needles respectively, and $p_{1}$ and $p_{2}$ represent the pole angles of the inner and outer needles respectively, and means to support said needles in the foregoing relationship. Claims allowed, 4.

10436. (2) Precision magnetometer. L. I. Mendelsohn, Lynn, Mass., assignor to General Electric Co., a corporation of New York: U. S. patent 2,438,372, issued Mar. 23, 1948.

A magnetometer comprising a pivoted shaft having thereon a pointer and an armature polarized at right angles to the shaft, a scale with which said pointer cooperates, a stop for said shaft, a spring for rotatively biasing the shaft with its pointer downscale against said stop such position being referred to as the pointer stop position, said spring being adjusted such that if the stop were removed the spring would rotate the shaft and pointer further in a downscale direction through an angle of the order of 80 degrees from the pointer stop position, said instrument being adapted to be placed in a unidirectional magnetic field to be measured with its shaft at right angles to such field and with the polarized armature, in the pointer stop position thereof, partially opposing such field and with its polarized axis at an angle of the order of $50 \mathrm{de}$ grees to the direction of such field and with such field producing upscale torque on said armature. Claims allowed, 2.

10437. (2) Magnetic field detector. D. H. Cunningham, Haddonfield, and Herbert Belar, Palmyra, N. J., assignors to Radio Corp. of America, a corporation of Delaware: U. S. patent 2,438,964, issued Apr. 6, 1948.

A magnetic field detector including three similar cores of high permeability magnetic material fixedly disposed normal to each other in said field, a first winding on each of said cores, three separate similar sources of alternating current of substantially sine wave form, means for applying said current to each of said first windings from a different one of said sources, a second winding on each of said cores, a plurality of filter networks for deriving currents of a selected even harmonic of said applied currents, means connecting a separate one of said filter networks to each of said second windings, the amplitude of said selected even harmonic currents being a function of the strength of said field on the axes of each of said cores, three separate square-law detectors, means for applying the output currents from each of said filters to a different one of said detectors, means for indicating separately the output currents of each of said detectors, each of said output currents being proportional respectively to the square of the field intensity on the axis of 
different ones of said cores, means serially connecting said detectors for combining algebraically said detector output currents, and means for indicating said combined currents in terms of the algebraic sum of the squares of the field intensities on the axes of said cores. Claims allowed, 1.

10438. (2) Magnetic gradiometer. C. H. Fay, Houston, Tex., assignor to Shell Development Co., San Francisco, Calif., a corporation of Delaware: U. S. patent 2,440,503, issued Apr. 27, 1948.

A system for measuring the gradient of a magnetic field, comprising first and second coils spaced from each other, means pivoting said coils for independent oscillation in said field, light source means, first and second photo-electric elements, optical means carried by said pivoted coils for varying the illumination of said photo-electric elements whereby the output current of said elements is varied proportionally to the oscillation of said pivotal coils, amplifier means energized by the outputs of said photo-electric elements, controlled rectifier means in circuit with said amplifier means for rectifying a portion of the output current of said amplifier means, Helmholtz coil means mounted coaxially with the pivoted coils in planes parallel and adjacent thereto, said Helmholtz coil means being energized by the direct current output of said rectifier means for neutralizing the magnetic field in which the pivoted coils oscillate, means in circuit with the amplifier means and said piroted coils for passing through said pivoted coils the non-rectified portion of the output current of the amplifier means, and indicating means in circuit with said amplifier means for comparing the strength of the magnetic fields produced at the location of each of said pivoted coils as a resultant of said magnetic field and the neutralizing field of the Helmholtz coil means. Claims allowed, 4.

10439. (2) Electron discharge compass system. H. E. Hartig, Robbinsdale, Minn., assignor to Minneapolis-Honeywell Regulator Co., Minneapolis, Minn., a corporation of Delaware: U. S. patent 2,441,269, issued May 11, 1948.

In a compass : a cathode ray tube including an electron gun directing a beam or electrons along a normal axis from which it is subject to deflection in response to the earth's magnetic field. means energizable to modulate the intensity of said beam, and a pluraity of target plates mounted for variable impingement, according as said beam is deflected, to transmit variable target currents; a source of alternating voltage of a selecter xxequency: means energizing said modulating means from said source to give to said target currents arewnetns components having lixed phase relationships to said source; a controlled device; and means, including means combining said target currents, for energizing sald contronea cteviee with niternating voltage which reverses in phase with reversal in the relationship between sula conponenes or saia target currents. Claims allowed, 8.

10440. (2) Stabilized gyrocompass, w. B. Bolster, Baldwin, N. Y., assignor to The Sperry Corp., a corporation of Delaware: U. S. patent $2,441, \bar{\nabla}, 6$, issued May 18, 1948.

In a gyrocompass, a gimbal ring pivoted about a normally horizontal axis fixed relative to the ship, a gyroscopic element pivotally mounted on 
the ring about a second horizontal axis normal to said first axis, motor means connected to said gimbal ring for stabilizing it about said first named axis, a universally mounted gyro-vertical having its two horizontal axes respectively parallel to said other axes, pick-off means between said gyro-vertical and said gimbal, control connections between said pick-off and said motor means for controlling said motor means to stabilize said gimbal from said.gyro-vertical, said gyro-vertical having a gravitationally controlled erecting means and means for rendering said erection means inoperative during turns of the ship of sufficient magnitude and rate to otherwise disturb the gyro-vertical. Claims allowed, 6 .

10441. (2) Magnetometer. J. H. Rubenstein, Buffalo, N'. Y. : U. S'. patent 2,442,732, issued June 1, 1948.

In a magnetometer, a pair of longitudinally spaced antenna members having high permeability and concentrating an external magnetic field in the space therebetween; means in said space and responsive to changes in the flux of the concentrated field therein, means measuring changes in the response of said flux responsive means, means for varying the number of lines of force in said concentrated field in said space independently of said external field, comprising means for supporting said antenna members for movement toward and from each other, and means for adjustably moving said antenna members toward and from each other in equidistant relation to said flux responsive means to provide a sensitivity adjustment for the magnetometer, comprising a screw having its ends reversely threaded with respect to each other, an internally threaded member screwed on each end of said screw and operatively connected with a corresponding one of said antenna members, and means for turning said screw. Claims allowed, 1.

10442. (2) Method and apparatus for sorting magnetic materials according to their residual magnetism. K. L. Scott, Western Springs, Ill, assignor to Western Electric Co., Inc., New York, N. Y., a corporation of New York : U. S. patent 2,444,751, issued July 6, 1948.

A method of sorting ferromagnetic bars in accordance with their magnetic characteristics comprising magnetically suspending a bar to be tested in a magnetic field to magnetically saturate said bar, removing said field to permit said bar to drop by the force of gravity through a coil thereby to cause an electromotive force to be generated in said coil, and utilizing said generated electromotive force to operate a separating device to classify said bar-in accordance with the amount of residual magnetism therein. Claims allowed, 7.

10443. (3) Connécting means for explosive cartridges. W. F. Smith, Wilmington, Del., assignor to Hercules Powder Co., Wilmington, Del., a corporation of Delaware: U. S. patent, 2,429,089, issued Oct. 14, 1947.

An explosive device adapted for attachment to a similar explosive device comprising a cartridge; a sleeve of substantially the same length as the cartridge and coextensive therewith; andlocking means carried by the cartridge and the sleeve, one of said locking means being in the form of a thread and the other of said locking means. being in the form of two sets of lug elements for locking engagement with said thread, one set of lug elements being positioned in the central portion of the device 
and slightly toward one end away from the center and the other end away from said center, whereby when the cartridge and sleeve of the device are halfway unthreaded for attachment of a similar device one set of lug elements remains in locking engagement with said thread and the other set of lug elements is adapted to engage the thread of said similar device. Claims allowed, 3.

10444. (3) Thermionic valve amplifier. P. K. Chatterjea and C. T. Scully, London, England, assignors, by mesne assignments, to International Standard Electric Corp., New York, N. Y., a corporation of Delaware: U. S. patent 2,431,307, issued Nov. 25, 1947.

A thermionic valve amplifier including a first stage and a second stage, an indirectly heated thermistor having a heater and a resistance element, means for connecting the resistance element thereof between the control grid and cathode of said second stage, said means being capable of passing direct current, a source of $D$. C. voltage included in said connecting means, and means for connecting the heating coil of said thermistor in series with the anode circuit of the first stage, whereby currents of substantially zero frequency may be amplified. Claims allowed, 9.

10445. (3) Electric explosion initiator. D. D. Huyett, Wilmington, Del., assignor to Atlas Powder Co., Wilmington, Del., a corporation of Delaware: U. S. patent 2,431,871, issued Dec. 2, 1947.

The method of making leg wire and shell assemblies for electric explosion initiators which comprises charging an explosive composition into an organic thermoplastic shell, inserting through the open end of said shell an insulated leg wire previously provided with an ignition element, swaging a section of the wall of the shell which lies about the leg wire to form a cup-shaped end closure embracing said leg wire and introducing a mutual solvent into said end closure for both the insulating material of the leg wire and the thelmoplastic material of the shell, the solvent softening and tending to dissolve the inner contacting surfaces of said shell to form an adhesive layer, which on evaporation of the solvent dries to seal said shell. Claims allowed 5.

10446. (3) Seismograph recording apparatus. W. M. Palmer, Oakmont, Pa., assignor to Gulf Research \& Development Co., Pittsburgh, Pa., a corporation of Delaware: U. S. patent 2,440,970, issued May 4, 1948.

In a system for recording on a longitudinally moving record receiving band the seismic impulses from a seismic source received at a plurality of distant seismic receiving stations by means of a plulality of adjacent recording elements disposed to make contiguous records of seismic events received via electrical transmission channels from their respective seismic receiving stations, the improvement which comprises means for independently longitudinally moving each of the recording elements by a follower bearing on a moving cam surface, said cam surface being in the form of a cone moved along an element thereof, each of said followers being guided to move in a line at right angles to the axis of said cone and at a lateral distance from said cone element which is proportional to the respective distance of the associated receiving station from the seismic source, and means for moving said cam at a speed proportional to the speed of the record receiving band. Claims allowed, 2. 
10447. (3) Acoustic structure. Hugo Benioff, Pasadena, Calif., assignor, by mesne assignments, to Submarine Signal Co., Boston, Mass., a corporation of Delaware: U. S. patent 2,444,911, issued July 13, 1948.

An acoustic housing for a receiving unit forming a substantially closed container adapted to permit the transmission of acoustic vibrations therethrough comprising an outer shell and an inner shell substantially coextensive therewith and spaced therefrom, and a viscous material filling the space between the shells, the combined thickness of the elements making up said housing being small compared to the wave length of the acoustic wave for which the structure is desired to be used. Claims allowed, 2.

10448. (3) Apparatus for measuring short time intervals. H. J. Kurtz, Terrace Park, Ohio: U. S. patent 2,444,935, issued July 13, 1948.

An apparatus for measuring the time interval required for an impulse wave to travel a measured distance in a selected medium comprising similar initial and final wave impulse sensitive units, each unit including a wave responsive pick-up, an amplifying system and a thyratron system including a thyratron provided with input and output circuits, the input circuit being coupled to said pick-up through the amplifying system, a control system having a circuit coupled to both units, said control system being provided with an electronic tube adapted to maintain a constant plate current regardless of change in plate voltage, said tube including plate and grid circuits, said plate circuit being coupled through a biasing resistance to the plate circuit of the thyratron of the initial unit whereby to start a uniform flow of current in the plate circuit of the electronic tube of the control system with energization of the initial pick-up and the consequent firing of the thyratron by effecting a change in plate potential and said grid circuit of the electronic device of the control system being coupled through a second biasing resistance to the plate circuit of the thyratron of the final unit whereby to stop the uniform flow of current in the grid circuit of the electronic device with energization of the final pick-up, and metering means connected with the control system for determining the quantity and rate of flow in the plate circuit of said electronic tube during said interval. Claims allowed 2.

10449. (4) Method for determining the subterranean extension of geologic bodies. F. W. Lee, Owings Mills, Md. : U. S. patent 2,440,693, issued May 4, 1948.

The method of determining geologic extension at a deeply-buried region remote in depth from a pair of current electrodes inserted into a surface region of the earth, when one portion of said deeply-buried region is accessible by way of a drill hole or the like, which consists in spacing said current electrodes from each other in one azimuthal direction by a distance approximately three times the depth to said remotely-buried region, establishing a flow of direct current through the earth between said current electrodes to create a plurality of spaced equipotential shells in the earth, making a potential contact with the earth in said bore hole at the approximate depth of said remotely-buried region to tap the potential of the shell crossing the bore hole thereat, making another potential contact with the earth, at the surface region and spaced away from the drill hole by a distance approximately equal to one half the depth of said remotely-buried region, to tap the potential of a shell 
spaced away from the drill hole and from said current electrodes, and measuring the difference in potential between said potential contacts; then rotating said configuration of current electrodes and potential contacts to each of a plurality of other azimuthal directions about said bore-hole contact as a zenithal center and repeating the said measurement in each of said azimuthal positions of rotation; so that comparing the resistivities indicated by said measurements for the respective azimuthal directions of orientation of the configuration can determine those directions which by maxima and minima resistivities indicate the presence of geologic extensions and bodies in those portions of the earth spaced away from the bore hole in proximity to said remotely-buried region. Claims allowed, 2.

10450. (5) Geiger counter improvement. A. F. Reid, New York, N. Y., assignor to the United States of America as represented by the United States Atomic Energy Commission : U. S. patent 2,442,314, issued May 25, 1948.

A Geiger counter including a quenching gas comprising an alkyl monohalide of two to six carbon atoms. Claims allowed, 7.

10451. (5) Circuits for the control of radiation detectors. Gerhard Herzog, Houston, Tex., assignor to The Texas Co., New York, N. Y., a corporation of Delaware: U. S. patent 2,443,857, issued June 22, 1948.

A circuit for the operation and control of radiation detectors of the counter type which comprises a detector of said type, means for applying a direct current operating voltage across the electrodes of the detector, quenching means associated with said detector, means for amplifying pulses formed in said detector, a high vacuum electronic tube having a control grid and connected in parallel with the detector to control the voltage applied thereto, an integrating circuit comprising a condenser and a resistance, means supplying to said integrating circuit negative amplified pulses for said amplifying means, whereby a negative voltage is derived which is a function of the rate of pulse formation, and means for impressing such negative voltage to the control grid of said control tube to vary the flow of current therethrough as an inverse function of the rate of pulse formation in the detector and to thereby control the operating voltage applied to said detector. Claims allowed, 3.

10452. (5) Radiation detector. F. P. Hochgesang, Woodbury, N. J., assignor to Socony-Yacuum on Co., Inc., a corporation of NeW York: U. s. patent 2,445,305, issued July 13, 1948 .

An apparatus for recording a wave length band spectrum or penetratws maiation, such as gamma or $X$-rays, having a plurality of wave lengths that comprises an combination a multiple detector, said detector having a housing, an ionizable llle(llum sn snid housing, a plurality of spaced concentrically disposed electrodes in said hoilsing urrans the interior thereof into a plurality of ionization chambers, said electrodes being formed of a material having a selected radiation coefficient of absorption, electrode circuits for said ionization chambers, a source of potential in each electrode circuit, means for amplifying the ionization current produced in each ionization circuit, a multiple recorder, and means for transmitting the amplified currents to the recorder for actuation of the same. Claims allowed, 16. 
10453. (6) Heat detection device. John Evans, Kingston, N. J., assignor to Radio Corp. of America, a corporation of Delaware: U. S. patent 2,437,085, issued Mar. 2, 1948.

A heat detection device including in combination a radio frequency generator including a quarter wave concentric line, one end of said line including a capacitive element, said element having a heat absorption surface whereby the capacity of said element varies as a function of the heat to be detected, means effectively connected to said quarter wave line for amplifying said radio frequency changes, detection means connected to said amplifier for converting said amplified radio frequency currents into a current corresponding to the frequency changes produced by the capacity changes of said element, and means for indicating said converted currents whereby said heat is indicated. Claims allowed, 13.

10454. (7) Multicomponent-gas analyzer. R. B. Barnes, Stamford, Conn., assignor to American Cyanamid Co., New York, N. Y., a corporation of Maine: U. S. patent 2,431,019, issued Nov. 18, 1947.

A device for analyses of multicomponent gases, which comprises, in optical alignment, a source of infrared radiation, means for producing a beam therefrom, a gas analyzing chamber provided with inlet and exit windows transparent through a wide band of the infrared spectrum, mèans permitting a flow of gas to be analyzed through said chamber, a plurality of detector cells positioned to be traversed in series by said beam, means for filling the detector cells with different gases, and measuring means responsive to temperature changes in said detector cells due to infrared absorption by the gases therein, said gases having substantially no overlapping absorption bands in the wave lengths of the infrared beam traversing the chamber and striking the detector cells. Claims allowed, 9.

10455. (7) Determination of hydrocarbon concentration in soil samples. E. E. Roper, Tulsa, Okla., assignor to Stanolind Oil and Gas Co., Tulsa, Okla., a corporation of Delaware: U. S. patent 2,437,045, issued Mar. 2, 1948.

A method for determining an index of the concentration of hydrocarbons sorbed on a soil sample, comprising subjecting each of a plurality of de-aerated, substantially similar portions of said soil sample to an artificial atmosphere, each of said atmospheres initially containing a difierent known concentration of hydrocarbons, maintaining each of said atmospheres in contact with the corresponding portion of said soil sample for a substantial period of time sufficient to establish substantial equilibrium between the partial pressures of the hydrocarbons in the artificial atmosphere and the hydrocarbons sorbed on the soil sample, then determining the concentration of hydrocarbons in each of said atmospheres, whereby said index may be determined. Claims allowed, 5 .

10456. (8) Improvements in or relating to apparatus for geophysical exploration. F. J. Cleveland, Well Surveys, Inc., Tulsa, Okla.: British patent 590,601, issued July 23, 1947.

This invention relates to apparatus for geophysical exploration and particularly to a method and device for measuring radiations from radioactive materials in subsurface strata as these radiations penetrate 
a drill hole or well bore. An improvement is devised, comprising the insertion in the circuit, just ahead of the amplifier, of a capacitator the capacity of which varies in a cyclic manner so as to convert the very weak direct electrical current or voltage resulting from the action of the phenomena upon the device responsive thereto into a pulsating or alternating current or voltage, whereby an alternating current or voltage amplifier may be used instead of a direct current or voltage amplifier to amplify the resulting current or voltage. Claims allowed, 16.

10457. (8) Fremgangsmaade till udforskning af bitumenlejer [Method of locating bituminous deposits]. Gesellschaft für Praktische Lagerstättenforschung G. m. b. H., Berlin: Danish patent 62,551, issued July 31, 1944.

In drill hole exploration the flushing liquids rising to the surface are subjected to continuous or intermittent physico-chemical analyses for determining their content of hydrocarbons as an index of bitumen. Claims allowed, 2.

10458. (8) Method for determining fluid conductance of earth layers. R. W. French, Jr., Ponca City, Okla., assignor to Continental Oil Co., Ponca City, Okla., a corporation of Delaware: U. S. patent $2,429,577$, issued Oct. 21, 1947.

In the production of hydrocarbons from a subsurface formation, a method for determining the path of both injected and produced gas in depth and areally, comprising use of at least two wells in a common pool respectively for gas injection and production, said input gas having been previously rendered radioactive by the addition of a radioactive component, followed by exploration in various boreholes in said common radioactive pool by a well logger to determine the formation level showing maximum radioactivity. Claims allowed, 4.

10459. (8) Oil detection in drilling muds. D. H. Larsen, Los Angeles, Calif., assignor to National Lead Co., Los Angeles, Calif., a corporation of New Jersey : U. S. patent 2,431,487, issued Nov. 25, 1947.

The method of detecting oil in drilling mud, comprising the steps of treating the mud with a mutual solvent for oil and water and subjecting the treated mud to analyses for oil. Claims allowed, 13.

10460. (8) Radiological measurement of the permeability of porous media. $\mathbf{x}$. $\mathbf{m}$. Brunner, El Cerrito, and E. S. Mardock, Berkeley, Calif., assignor's to Shell Development Co., San Francisco, Calif., a corporation of Delaware: $U$. S. patent 2,437,935, issued Mar. 16, 1948.

In a method for determining the permeability at high pressures of a porous body with regard to a fluid flowing therethrough under polyphase flow conditions, the steps of confining said body in a zone maintalned at a ${ }^{\text {nig }} \mathrm{g}^{\mathrm{n}}$ messume. simultaneously saturating said body with a plurality of fluid phases, at least one of Sald pllašs beins " nuid containing hydrogen atoms, causing a fluid flow through said body, measuring the rate of said fluid flow, measuring the pressure drop occurring during said flow between points in said body spaced from each other along the line of said flow, subjecting said body to neutron radiation, detecting 
the neutrons slowed down within said body by collision with hydrogen atoms, and determining the saturation of said body with regard to said hydrogen containing fluid from the amount of the detected slow neutrons. Claims allowed, 8.

10461. (8) Circuit for measuring voltage of an alternating source. R. G. Piety, Yonkers, N. Y., assignor to Phillips Petroleum Co., a corporation of Delaware: U. S. patent 2,438,518, issued Mar. 30, 1948.

In an electrical circuit for measuring the voltage of an alternating signal current having interference voltage components, comprising a source of such alternating signal current, means fed thereby for amplifying said signal current, means for producing a derived current therefrom, clipping means for suppressing the interference voltage peaks of said derived signal current, means connected thereto and tuned to the frequency of said signal current, means for rectifying the output of said tuned means, means for measuring the average value of said rectified current, means for applying said rectified current to said clipping means to control the clipping level thereof, a full wave rectifier fed by said clipping means, and means for applying a portion of said last rectified current to said clipping means so that its voltage is in opposition to the voltage applied to the clipping means from said first rectifier. Claims allowed, 6.

10462. (8) Apparatus for well logging. W. G. Green, Tulsa, Okla., assignor to Engineering Laboratories, Inc., Tulsa, Okla., a corporation of Oklahoma : U. S. patent, 2,441,065, issued May 4, 1948.

Apparatus for recording a physical characteristic of a bore hole, comprising an elongated recording element, means for lowering said element into said hole so that it extends longitudinally of said hole from the top to a predetermined depth within said bore hole and for withdrawing said element from said hole, means for developing a signal representative of said characteristic at a predetermined depth in said hole, means for recording said signal upon said element at a point therealong representative of the hole depth at which said signal is developed, means for translating said signal as said element is withdrawn from said hole, and means for recording the translated signal. Claims allowed, 6 .

10463. (9) Prospecting for petroleum deposits. M. S. Taggart, Jr., Houston, Tex., assignor, by mesne assignments, to Standard Oil Development Co., Elizabeth, N. J., a corporation of Delaware: U. S. patent $2,442,476$, issued June 1, 1948.

A method for surface prospecting for subterranean petroleum deposits which comprises collecting samples of soil at spaced points over an area to be explored, said samples being collected at uniform depth, mixing the same quantity of each sample with the same quantity of an electrolyte, forming a half cell by inserting a suitable electrode into said mixture, comparing the potential of each of the half cells so formed with the potential of a standard half cell and correlating the results with sample locations to establish a relationship useful in the detection of subterranean petroleum. Claims allowed, 6 . 
10464. (9) Support for submerged area surveying. J. C. Pollard and C. F. Sellers, Houston, Tex., assignors to R. H. Ray Co.: U. S. patent 2,444,669, issued July 6. 1948.

A support for a geophysical instrument for water covered areas comprising, a frame, spaced clamping means about said frame, a vertical support in each of said means, whereby the frame is vertically adjustable on the supports, a support assembly for each of said supports, each of said assemblies comprising a plurality of uprights having their bases engaging the submerged surface at spaced points and extending convergingly upwardly toward a point proximate one of said supports, and additional clamping means interconnecting the uprights and support at each assembly whereby the frame is suspended upon the assemblies. Claims allowed, 4.

10465. (11) Photoelectric drift indicator. Henry Konet, Paramus, N. J., assignor to Bendix Aviation Corp., Teterboro, N. J., a corporation of Delaware: U. S. patent 2,425,541, issued Aug. 12, 1947.

In a drift-indicating instrument, the combination of a photo-responsive A. C. circuit and a generated A. C. circuit, normally in synchronism when an aircraft carrying the instrument follows a path of travel corresponding to a set heading, means responsive to drift of an aircraft from said corresponding path of travel and cooperating with a photoresponsive portion of said photo-responsive circuit adapted to alter the phase of the current in said photo-responsive circuit, and a polyphase induction means adapted to indicate the amount of drift of said aircraft from said previously mentioned set heading, the last-named means being electrically connected to the photo-responsive circuit to operate the lastnamed means when the current phase of said photo-responsive circuit is changed from synchronism. Claims allowed, 16.

10466. (11) Speed indicator. Leo Mackta, United States Army, Brooklyn, N. Y.: U. S. patent 2,426,228, issued Aug, 26, 1947.

A speed indicator for aircraft comprising, in combination, a pair of radiators adapted to transmit sharply defined beams of electro-magnetic waves forming equal and opposite acute angles with a vertical axis of said aircraft, means for simultaneously energizing said radiators, means ineluding a single antenna for receiving only the reflected components of both of said beans concurrenty with said twansmission. and means responsive to the flequencies of the reflected components to indicate the speed of said aircraft. Claims allowed, 11.

10467. (11) Electrical guidance system for surface vessels. E. N. Dingley, Jr., United States Navy! U. S. patent 2,428,360, issued oct. $7,1947$.

An electrical guidance system comprising a source of alternating current. a submerged conductor extending along the desired course of vessels enelgized by sala source ror proancing an oscillnting magnetic field, a vessel provided with a steel hull, a vertical coll positioned in the fore and aft plane of said vessel adapted to have alternating magnetic field, a horizontal coil, identical with and bisecting the plane of said first mentioned coil, adapted to have alternating voltages induced therein by said oscillating magnetic field, means for mounting said coils on said vessel in front of the bow thereof, means for amplifying the volt- 
ages induced in each of said coils, means for indicating the voltages induced in said vertical coil and means responsive to the product of the in-phase components of said amplified voltages for indicating the position of said vessel with respect to said conductor. Claims allowed, 2.

10468. (11) Continuous angularly movable light beam recorder. R. S. Fox, West Hartford, Conn. : U. S. patent 2,432,303, issued Dec. 9, 1947.

A recording device comprising in combination, a supporting member over which passes an electrically sensitized record-receiving strip, advancing means for said strip, a freely rotating member contacting a surface of said strip, said rotating member having spaced narrow annular portions rendered conductive when illuminated, means to illuminate narrow sections along the length of said rotating member, a source of electric current, and a circuit including said source, the illuminated portion of said rotating member and the contacting portion of said strip, whereby a record is made of the successively illuminated portions of said rotating member. Claims allowed, 4.

10469. (11) Oscillator. Paul Weathers, Haddon Heights, N. J., assignor to H. K. Neuber, Philadelphia, Pa. : U. S. patent 2,436,129, issued Feb. 17, 1948.

A self-excited electronic-tube oscillator system having a tuned grid circuit, an anode circuit, and means to provide feed-back from the anode to the grid circuit, comprising a feed-back inductance coupled to both the grid circuit and to the anode circuit, and having a coupling connection from an intermediate point thereon, by means of which connection coupling to one of said circuits is effected, and means for: conveying feed-back current from the anode circuit through said inductance differentially to provide differential in-phase and counter-phase inductive feed-back of energy to said grid circuit to vary the amplitude of oscillations therein, as well as controlling the relative resonant frequencies of the circuits by reflected reactance. Claims allowed, 17.

10470. (11) Pulse echo distance measuring system. Irving Wolff, Merchantville, N. J., assignor to Radio Corp. of America, a corporation of Delaware: U. S. patent 2,438,836, issued Mar. 30, 1948.

A radio frequency pulse echo system including, in combination, a sweep voltage generator, a keyer synchronized with said generator, a transmitter connected to said keyer, means connected to said transmitter for radiating pulses of radio frequency energy, a cathode ray tube including means for deflecting said ray along a distance scale as a function of said sweep voltage, and means for deflecting said ray along an amplitude scale, means for amplifying said sweep voltages whereby shorter distances may be indicated on said distance scale, a radio receiver including means for amplifying the radio frequency components of said pulses and for detecting said pulses, means for applying timing currents derived from the transmitted radio frequency currents to said amplitude scale of said cathode ray tube to mark said shorter distances, and means including said recéiver for deflecting said ray on said amplitude scale in response to the radio frequency components of an echo pulse derived by reflection from objects within a predetermined distance and in response to the detected pulses derived by reflection from objects located beyond said predetermined distance. Claims allowed, 18. 
10471. (11) Radio direction finding system. A. G. Richardson, Boonton, N. J., F. O. Chesus and F. G. Thomas, Islip, N. Y., assigniors to Federal Telephone and Radio Corp., Newark, N. J., a corporation of Delaware: U. S. patent 2,438,946, issued Apr. 6, 1948.

In a radio direction finding system having a directional receiving antenna and a translator having a continuously rotating means for deriving from the received energy a voltage which varies with the angular position of said rotating means and with the direction of said received energy, the combination of means for producing sweep voltages, an oscillograph controlled by said sweep voltages and said derived voltage, a sweep oscillator, having an output voltage for controlling said sweep voltages producing means, a pulsing circuit for producing pulses at a predetermined angular position of said rotating means, and means for applying said pulses to said oscillator for synchronizing said output voltage with said derived voltage, whereby said oscillograph indicates the direction line of said received energy. Claims allowed, 5.

10472. (11) Airplane course indicating system. O. H. Dicke, Rochester, N. Y., assignor to General Railway Signal Co., Rochester, N. Y.: U. S'. patent 2,439,846, issued Apr. 20, 1948.

In an indicating system for airplanes, the combination with a plurality of fixed radio radiating apparatuses arranged along the ground to define a path over which an airplane is to fly, a display means supported within view of the pilot on such airplane, and radio responsive means including two mechanically moved scanning devices in series of which one comprises a radio reflector and the other comprises a radio detector for displaying visual images of said apparatuses on said display means by a plurality of lighted spots one fol each apparatus, said spots being so juxtaposed as are the lines of sight connecting such airplane and apparatuses. Claims allowed, 18. 


\section{N DEX}

[The flgure in parentheses indicates the classification of the entry: see table of contents]

\begin{tabular}{|c|c|c|c|c|c|}
\hline \multicolumn{2}{|c|}{ Class } & Abstract & \multicolumn{2}{|c|}{ Class } & Abstract \\
\hline Abdurashinov, S. A. & (8) & 10370 & Columbia Univer & & \\
\hline $\begin{array}{l}\text { Agricultural and Mechanical Col- } \\
\text { lege of Texas. }\end{array}$ & $(8)$ & 10371 & Instruments $\mathbf{L}$ & (2) & $\begin{array}{r}10244 \\
10245\end{array}$ \\
\hline Akademiia Nauk SSSR Vestnik... & (3) & 10279 & Cortright, W. D. & (3) & 10285 \\
\hline Alcock, E. D........... & (3) & .10281 & Coster, H. P.... & (6) & 10361 \\
\hline Al'pin, L. M........ & $(8)$ & 10372 & Cunningham, D. F & (2) & 10437 \\
\hline Andreae, Charles..... & (6) & 10360 & & & \\
\hline Aquilina, Carmelo.... & (4) & 10339 & Dakhnov, V. N. & $(8)$ & 10375 \\
\hline Argall, G. O.............. & (9) & 10387 & Daly, J. W.. & (3) & 10280 \\
\hline Arkhangel'skii, A. A.- & (8) & 10373 & David, H...... & (8) & 10376 \\
\hline Australien Journal of & (2) & 10237 & Deegan, C. J & $\begin{array}{r}(10) \\
(2)\end{array}$ & $\begin{array}{l}10405 \\
10434\end{array}$ \\
\hline allard, T. J & (2) & 10259 & , O. H....... & (11) & 10472 \\
\hline , R. B....... & (7) & 10454 & Dingley, E. N., Jr. & (11) & 10467 \\
\hline artels, J.......... & (2) & 10238 & Dix, C. H & (3) & 30287 \\
\hline Orhan & (3) & 10338 & Doll, H. G........ & (8) & 10377 \\
\hline ays, C. A & (8) & 10374 & Dreshach, C. H. & (3) & 10288 \\
\hline crbert......... & (2) & 10437 & Dyk, Robert...... & (8) & 1037 \\
\hline ephone Labor & (2) & 10239 & & & \\
\hline , Arnoldo..... & (4) & $10 \$ 40$ & & (2) & 10246 \\
\hline Benioff, Hugo ........ & (3) & 10447 & If, Felix... & (2) & 10247 \\
\hline Berkey, C. P & (3) & 10280 & Malmletning.... & (1) & 10432 \\
\hline Berman, Isadoro..... & (9) & 10388 & de los Monteros, & (1) & 10230 \\
\hline Berroth, Alfred...... & (1) & 10218 & (n) & (4) & 10343 \\
\hline & & 10219 & I. D ........ & (5) & 10357 \\
\hline C.... & (1) & 10220 & Evans, John & (6) & 10453 \\
\hline Blyth, F. G. H. & (10) & 10404 & Ewing, Maurice. & (3) & 10320 \\
\hline Boletin del Instituto Sudamericano & & & Fans & (2) & 10248 \\
\hline ......... & (9) & 10389 & G. $\mathbf{R}$. & (7) & 10363 \\
\hline obert............ & (1) & 10227 & $\mathrm{H} \ldots \ldots$ & (2) & 10438 \\
\hline W. B............ & (2) & 10440 & v, A. E... & (10) & 10406 \\
\hline are, R. A...... & (3) & 10281 & , J. A... & (2) & 10249 \\
\hline O & (7) & 10368 & F...... & (10) & 10407 \\
\hline N. F & (11) & 10426 & ovarrubias, Luis. & (3) & 10289 \\
\hline rit, F & (11) & 10419 & (........ & (11) & 10468 \\
\hline skikh, L. M. & (3) & 10282 & $\mathrm{~F}$ & (2) & 10434 \\
\hline J. J & $(4,2)$ & 10341 & $\mathrm{~W}$ & (8) & 10458 \\
\hline Brundall, Laurence........... & (11) & 10420 & gene... & (2) & 10250 \\
\hline r, E. M & (8) & 10460 & Funkhouser, H. J & (9) & 10394 \\
\hline , E. C. & (9) & 10390 & & & \\
\hline Bullen, K. E................... & (3) & 10283 & $P$ & (3) & 10290 \\
\hline Burgaud, R. P. M........... & (2) & 10240 & Gane, P. G....... & (3) & 10291 \\
\hline Burmeister, F........ & (2) & 10241 & Gesellschaft für Praktischo Lager- & & \\
\hline & (11) & 10421 & stättenforschung & (8) & 10457 \\
\hline Burns, W. W.... & (2) & 1.0242 & Geyer, R. A..... & (9) & 10392 \\
\hline & & & tonio .......... & (2) & 10251, \\
\hline L..... & (3) & 10284 & & & 10252 \\
\hline 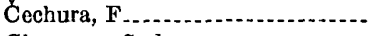 & (4) & 10342 & Gil & $(2,8)$ & 10253 \\
\hline n, Sydney. . . & (2) & 10243 & , G. G......... & (3) & 10292 \\
\hline Chatterjea, P. K. & (3) & 10444 & ean & (1) & 10221 \\
\hline Chemical Engineering and Min- & & & G. P........ & (3) & 10293 \\
\hline view & (9) & 10391 & C. H & (0) & 10213 \\
\hline Chesus, F. O & (11) & 10471 & W. G....................... & (8) & 10462 \\
\hline Cleveland, F. J & (8) & 10456 & Grenet, Gaston & (3) & 10294 \\
\hline
\end{tabular}




\begin{tabular}{|c|c|c|c|c|c|}
\hline & & Abstract & & lass & Abst \\
\hline Grindley, E. N & (2) & 10254 & Macht, H. G. & (2) & 10262 \\
\hline utenberg, Benc & (0) & 10214 & McKay, A. E. & (3) & 10318 \\
\hline & (3) & 10295 & Mackta, Leo.... & (11) & 10466 \\
\hline Guyod, Huber & (8) & 10379 & Madill, R. G......... & (2) & 10263 \\
\hline Azelishvili, I. & (3) & 10296 & Magnitskii, V. A & $(10)$ & 10411 \\
\hline Haalck, H. & (3) & 10297 & $\begin{array}{l}\text { Mardock, E. S................. } \\
\text { Martin, Jean. }\end{array}$ & $\begin{array}{l}(8) \\
(1)\end{array}$ & $\begin{array}{l}10460 \\
10227\end{array}$ \\
\hline & (10) & 10408 & Martin, Rodolfo..... & (0) & 10217 \\
\hline Haggerty, 1 & (3) & 10298 & ez Barrio, Doming & (3) & 10310 \\
\hline & (9) & 10393 & S. T............. & (3) & 10311 \\
\hline , E. J. & (3) & 10299 & n, W. J.... & (2) & 10264 \\
\hline$F_{-}$ & (3) & 10300 & tto & (3) & 10312 \\
\hline$\cdots$ & (3) & 10301 & n, L. I & (2) & 10436 \\
\hline$\cdots$ & (3) & 10302 & $4 \ldots . .$. & (10) & 10412 \\
\hline$\ldots$ & (2) & 10435 & nko..... & (7) & 10365 \\
\hline E. & (2) & 10439 & Uarry Engineer & (9) & 10396 \\
\hline $\mathbf{E}$ & (7) & 10364 & ddger.............. & (3) & 10313 \\
\hline $\mathbf{T}$ & (10) & 10409 & , M. S & (1) & 10228 \\
\hline H. D & (9) & 10394 & y, C. G... & (5) & 10354 \\
\hline & (2) & 10258 & , D. D & (5. & 10354 \\
\hline & (11) & 10422 & $3 . . . .$. & (11) & 10422 \\
\hline 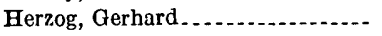 & (5) & 10451 & ............. & (3) & 10314 \\
\hline - & (5) & 10351 & arlo....... & (1) & 10229 \\
\hline 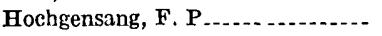 & (5) & 10452 & Muller, S. W & (4) & 10345 \\
\hline & (2) & 10260 & & & \\
\hline 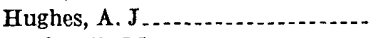 & (2) & 10433 & Fakesi. & (2) & .0265, \\
\hline & (5) & 1.0356 & & & 10266 \\
\hline .. & (3) & 10445 & M. A & $\begin{array}{r}(4,3) \\
(3)\end{array}$ & $\begin{array}{l}10346 \\
10315\end{array}$ \\
\hline--- & (2) & 10255 & National Research Cou & & \\
\hline & (9) & 10395 & $\begin{array}{l}\text { Canada, Associate Cor } \\
\text { on Geodesy and Geophy }\end{array}$ & & \\
\hline Ittne & (3) & 10303 & H. w & (2) & $\begin{array}{l}10397 \\
10267\end{array}$ \\
\hline 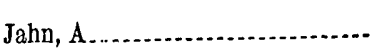 & (6) & 10362 & O.N. $\mathrm{N}$ & (5) & 10355 \\
\hline & (2) & 10256 & ... & $\begin{array}{l}\text { (8) } \\
(3)\end{array}$ & $\begin{array}{l}10382 \\
10316\end{array}$ \\
\hline 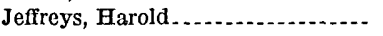 & (3) & 10304 & $\mathrm{Z}$ & (2) & 10268 \\
\hline & (2) & 10257 & Nogumi, H. H. & (5) & 10356 \\
\hline & (2) & 10258 & & & \\
\hline & (3) & 305 & ven & (3) & 10317 \\
\hline n. & (1) & 10222 & & (3) & \\
\hline & $(3$ & 10 & & (2) & 10433 \\
\hline -...- & (2) & 10259 & & (3) & 46. \\
\hline 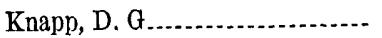 & (2) & 10260 & (1) & (3) & 10318 \\
\hline -- & (8) & 10380 & tanislaw..... & (2) & 10269 \\
\hline$\ldots$ & (11) & 65 & L $\ldots \ldots \ldots$ & (2) & 10270 \\
\hline & (4) & 10344 & 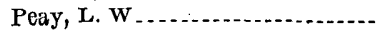 & (11) & 10424 \\
\hline & $\begin{array}{l}(10) \\
(0)\end{array}$ & 0 & americano.... & (8) & 10383: \\
\hline Kurtz, H. J... & (3) & $\begin{array}{l}10215 \\
10448\end{array}$ & orld_........... & (2) & 10271 \\
\hline & & & $\cdots$ & & \\
\hline & $\begin{array}{l}(1) \\
(2)\end{array}$ & ת & & (8) & 10384 \\
\hline & $\begin{array}{l}(2) \\
(5)\end{array}$ & 261 & & (9) & \\
\hline [.......... & (5) & $\begin{array}{l}10352 \\
10306\end{array}$ & a-Kochina, P. J. & (8) & 10385 \\
\hline & (II) & $1042 \mathrm{~J}$ & Prat & $\begin{array}{l}\text { (4) } \\
\text { (a) }\end{array}$ & $\begin{array}{l}10348 . \\
10310\end{array}$ \\
\hline H.......... & (8) & 10459 & Pres & (3) & 10320 \\
\hline . & (4) & 10449 & $0, J, M$ & (2) & 10272 \\
\hline & (0) & 10216 & fan & (2) & $102 \% 3$ \\
\hline 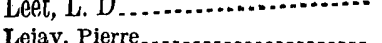 & (1) & 1022 & & & \\
\hline & & & $\mathrm{Re}$ & (1) & 10349 \\
\hline$J r_{\ldots}$ & (3) & 10308 & 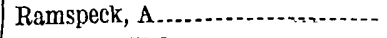 & (3) & 10321 \\
\hline ........ & (3) & 10309 & alervo & $(10)$ & 10413: \\
\hline vo, Luis.... & (1) & 26 & -- & (5: & 10450. \\
\hline P., de.... & (5) & & & (8) & 86 . \\
\hline Cyle, H. W & (8) & 10381 & Rey Pastor, Alfonso. & (3) & 10322, \\
\hline
\end{tabular}




\begin{tabular}{|c|c|c|c|c|c|}
\hline Clas & & Abstract & & ass & Abstract \\
\hline Rich, J. I... & (11) & 10425 & Straley, H. W., III. & ( $\theta)$ & 10401 \\
\hline Richardson, A. G... & (11) & 10471 & Strobell, J. D... & (11) & 427 \\
\hline Richardson, L. A..... & (9) & 10308 & Stulken, E. J... & (11) & 0428 \\
\hline ieber, Frank & (3) & 10323 & Subbota, M. I. & (7) & 0367 \\
\hline oberts, E. B....- & (2) & 274 & & & \\
\hline n, B. W & $(2,8)$ & 10253 & aggart, M. S. & (9) & 10463 \\
\hline oper, E. E........ & $(7)$ & 10455 & Taylor, G. L.. & (8) & 10386 \\
\hline osenquist, A. M.- & (7) & 10366 , & $\mathrm{A}_{-}$ & (11) & 10471 \\
\hline & (3) & $\begin{array}{l}10369 \\
10324\end{array}$ & (1) & (9) & $\begin{array}{l}10428 \\
10402\end{array}$ \\
\hline - n & (2) & 10441 & Trudu & (5) & 10358 \\
\hline n, L. I & (10) & 10414 & cal Mission to & & \\
\hline F..... & (3) & 10325 & & (3) & 10331 \\
\hline Guille & (1) & $\begin{array}{r}10230 \\
10231\end{array}$ & Vesanen, Eijo & (3) & 10332 \\
\hline$C_{\ldots} \ldots$ & (9) & 10394 & Veshniakov, N. & (3) & 10333, \\
\hline ews Lette & (2) & 10275 & & & 10334 \\
\hline 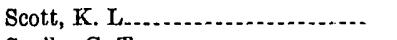 & (2) & 10442 & Vogt, $\mathrm{T}$ & (7) & 10366, \\
\hline cully, C. T..... & (3) & 10441 & & & 10368, \\
\hline $\begin{array}{l}\text { Seismological Society of America, } \\
\text { Eastern Section.......... }\end{array}$ & (3) & 10326 & Volet, Charles... & (1) & $\begin{array}{l}10369 \\
10234\end{array}$ \\
\hline$F$ & (9) & 10464 & & & \\
\hline A. S. & (4) & 10350 & Wat & (3) & 103 \\
\hline zarov, D. A & (9) & 10399 & Waters & (3) & 336 \\
\hline 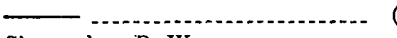 & (10) & 10415 & & (11) & 3430 \\
\hline R. $W_{-}$ & (3) & 10327 & & 1 & 10337 \\
\hline ov, L. K... & (3) & 0328 & & (11) & 10469 \\
\hline A & (2) & 10276 & & (10) & 10416 \\
\hline G.......... & (2) & 10277 & -. & (2) & 10256 \\
\hline (n.............. & (1) & 10232 & $\mathrm{~W}$ & (3) & 10338 \\
\hline (n) & (1) & 10233 & $\ldots$ & (5) & 10359 \\
\hline s, L........... & (2) & 10278 & $\mathrm{P}$ & (11) & 10470 \\
\hline hn.......... & (3) & 10329 & Woollar & $(1,2)$ & 10235 \\
\hline M. M.... & $(9)$ & 10400 & World & (9) & 10403 \\
\hline$F$ & (3) & 10443 & rld Petroleum & (10) & 10417 \\
\hline$\ldots . .$. & (3) & 10209 & rid Petroleum. & (Ii) & 0431 \\
\hline (n) & (5) & 10357 & Yuster, S. T............. & (10) & 10418 \\
\hline L............ & (11) & 26 & & & \\
\hline Btekol'nikov, I. S....... & (3) & 10330 & Zenor, H. M. . & (1) & 102 \\
\hline
\end{tabular}

